\title{
Experiments to Investigate the Effect of Flight Path on Direct Containment Heating (DCH) in the Surtsey Test Facility
}

The Limited Flight Path (LFP) Tests

Manuscript Completed: August 1991

Date Published: October 1991

Prepared by

M. D. Allen, M. Pilch, R. 'T. Nichols*, R. O. Griffith

Sandia National Laboratories

Albuquerque, NM 87185

\section{Prepared for}

Division of Systems Research

Office of Nuclear Regulatory Research U.S. Nuclear Regulatory Commission Washington, DC 20555

NRC FIN A1406

* Ktech Corp.

901 Pennsylvania N.E.

Albuquerque, NM 87110

\section{DISCLAIMER}

This report was prepared as an account of work sponsored by an agency of the United States
Government. Neither the United States Governmest employees, makes any warranty, express orernment nor any agency thereof, nor any of their bility for the accuracy, completeness, or usefuplied, or assumes any legal liability or responsiprocess disclosed, or represents that its usefulness of any information, apparatus, product, or ence herein to any specific commersial use would not infringe privately owned rights. Refermanufacturer, or otherwise does not process, or service by trade name, trademark. mendation, or favoring by the United necessarily constitute or imply its endorsement, recomand opinions of authors expressed states Government or any agency thereof. The views United States Government or

\section{MASTER}




\section{ABSTRACT}

The goal of the Limited Flight Path (LFP) test series was to investigate the effect of reactor subcompartment flight path length on direct cont-inment heating (DCH). The test series consisted of eight experiments with nominal flight paths of 1 , 2 , or $8 \mathrm{~m}$. A thermitically generated mixture of iron, chromium, and alumina simulated the corium melt of a severe reactor accident. After thermite ignition, superheated steam forcibly ejected the molten debris into a 1:10 linear scale model of a dry reactor cavity. The blowdown steam entrained the molten debris and dispersed it into the surtsey vessel.

The vessel pressure, gas temperature, debris temperature, hydrogen produced by steam/metal reactions, debris velocity, mass dispersed into the surtsey vessel, and debris particle size were measured for each experiment. The measured peak pressure for each experiment was normalized by the total amount of energy introduced into the surtsey vessel; the normalized pressures increased with lengthened flight path. The debris temperature at the cavity exit was about $2320 \mathrm{~K}$. Gas grab samples indicated that steam in the cavity reacted rapidly to form hydrogen, so the driving gas was a mixture of steam and hydrogen. In these experiments approximately $70 \%$ of the steam driving gas was converted to hydrogen. The total amount of hydrogen produced was a weak function of the total debris mass dispersed into the surtsey vessel, indicating that most of the steam/metal reactions occurred in the reactor cavity.

These experiments indicate that debris may be trapped in reactor subcompartments and thus will not efficiently transfer heat to gas in the upper dome of a containment building. The effect of deentrainment by reactor subcompartments may significantly reduce the peak containment load in a severe reactor accident. 


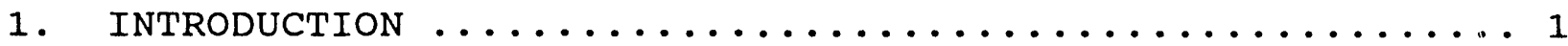

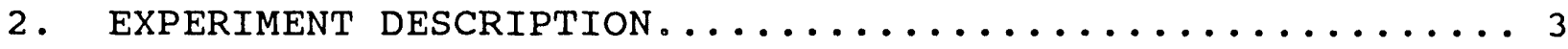

2.1 Measurements and Instrumentation $\ldots \ldots \ldots \ldots \ldots$

2.1.1 Pressure Measurements.............. 5

2.1.2 Temperature Measurements.............6 6

2.1 .3 Gas Composition................... 7

2.1 .4 Posttest Debris Recovery.............8 8

2.1 .5 Debris Velocity................. 8

2.2 Initial Conditions................... 9

2.2.1 Surtsey Atmosphere................ 9

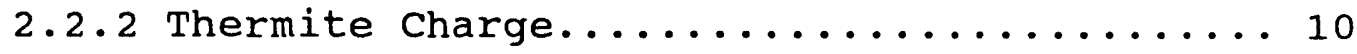

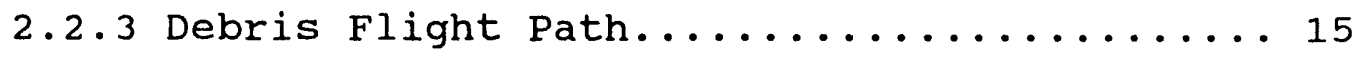

3. EXPERIMENT RESULTS....................... 22

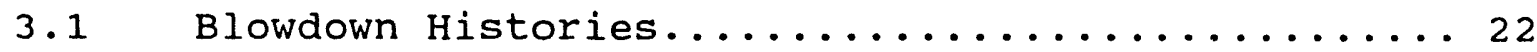

3.2 Pressure Measurements.................. 23

3.2 .1 Surtsey Vessel Pressure............. 24

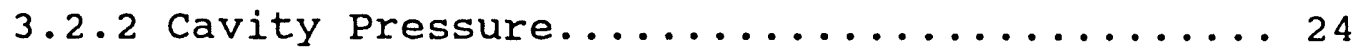

3.3 Gas Temperature Measurements.............. 25

3.4 Debris Temperature Measurements............ 25

3.5 Gas Composition Measurements............... 26

3.6 Debris Recovery Summary................. 28

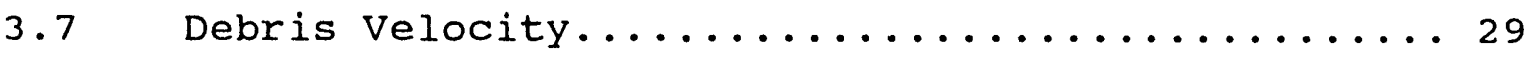

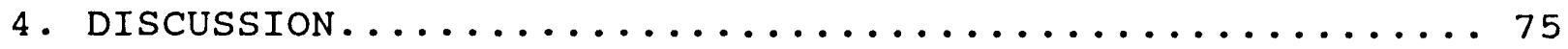

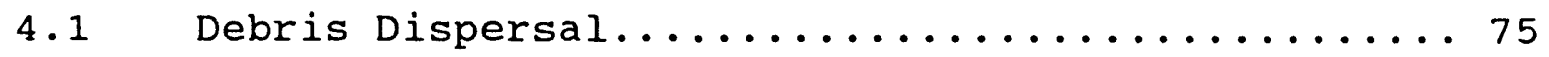

4.2 Pressure Increase................... $7 \epsilon$

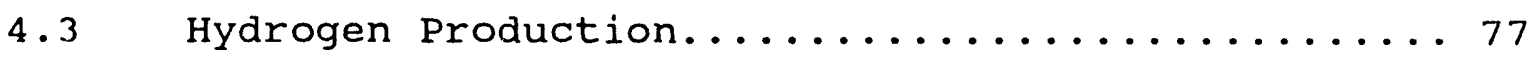

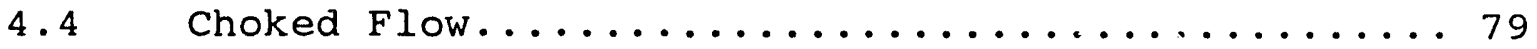

$4.5 \quad$ Particle size..................... 80

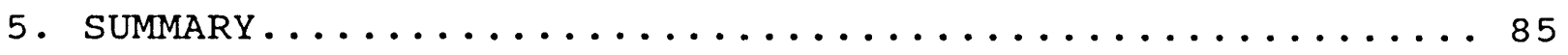

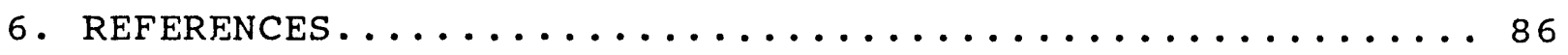




\section{LIST OF TABLES}

Table

Page

2-1. Initial Conditions for the LFP Experiments.........16

3-1. Hydrogen Concentrations Measured in the LFP

Experiments........................... 30

3-2. Gas Compositions in the Cavity Measured from Grab

Bottles Opened Between $0.5 \mathrm{~s}$ and $2.5 \mathrm{~s}$ in the LFP

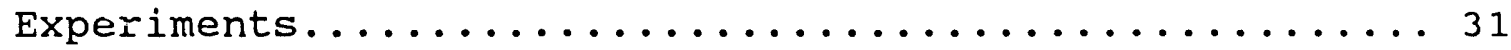

3-3. Summary of the Results of the LFP Experiments....... 32

3-4. Debris Recovery Summary of the LFP Experiments....... 33

3-5. Sieve Analysis of LFP-8A Debris from the Bottom Head

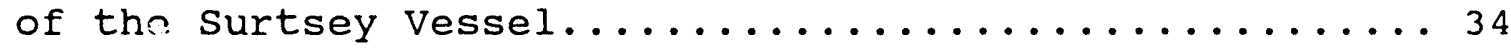




\section{IIST OF FIGURES}

Figure:

Page

2-1. Schematic of the Surtsey vessel showing the HPME delivery system and the concrete structure that

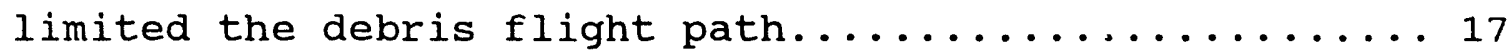

2-2. Experimental apparatus for steam-driven HPME into the

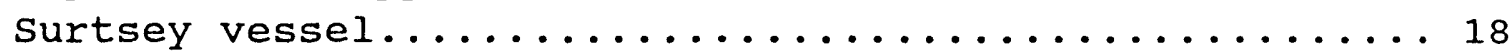

2-3. Side-view of the 1:10 linear scale model of the surry reactor cavity showing the melt delivery system and the transition piece that connects to the surtsey

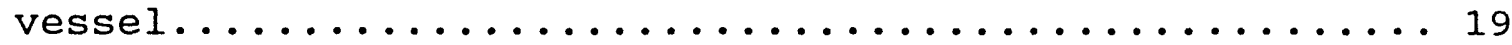

2-4. Exploded view of the 1:10 linear scale model of the

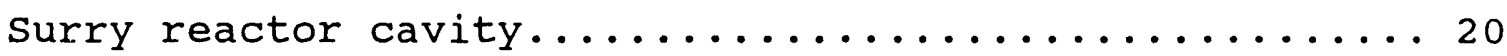

2-5. Pyrometer positions in the LFP experiments.........21

3-1. Blowdown history of the LFP-1A experiment..........35

3-2. Blowdown history of the LFP-1B experiment......... 36

3-3. Blowdown history of the LFP-2A experiment......... 37

3-4. Blowdown history of the LFP-2B experiment......... 38

3-5. Blowdown history of the LFP-2C experiment.......... 39

3-6. Blowdown history of the LFP-8A experiment..........40

3-7. Vessel pressure in the LFP-1A experiment..........41

3-8. Vessel pressure in the LFP-1B experiment..........42

3-9. Vessel pressure in the LFP-2A experiment..........43

3-10. Vessel pressure in the LFP-2B experiment..........44

3-11. Vessel pressure in the LFP-2C experiment..........45

3-12. Vessel pressure in the LFP-8A experiment..........46 


\section{LIST OF FIGURES (continued)}

Figure

Page

3-13. Cavity pressure versus vessel pressure in the LFP-1A

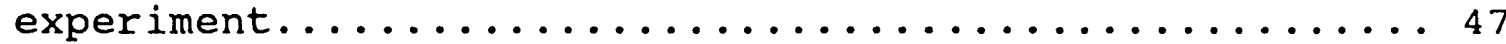

3-14. Cavity pressure versus vessel pressure in the LFP-1B

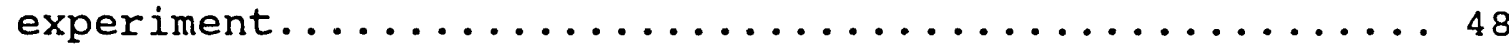

3-15. Cavity pressure versus vessel pressure in the LFP-2A experiment............................. 49

3-16. Cavity pressure versus vessel pressure in the LFP-2B

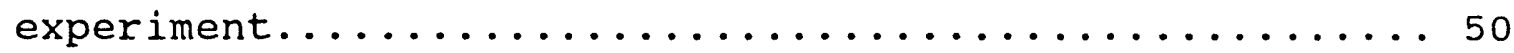

3-17. Cavity pressure versus vessel pressure in the LFP-2C

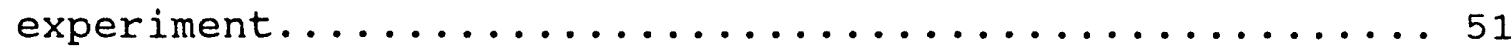

3-18. Cavity pressure versus vessel pressure in the LFP-8A

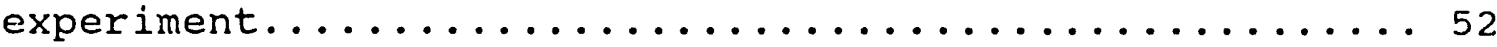

3-19. Gas temperatures measured with aspirated thermocouples

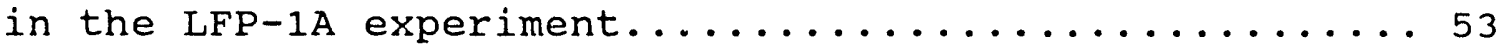

3-20. Gas temperatures measured with aspirated thermocouples

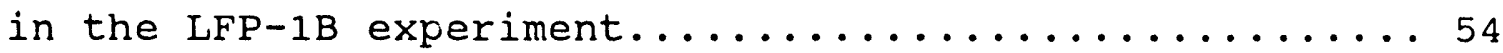

3-21. Gas temperatures measured with aspirated thermocouples

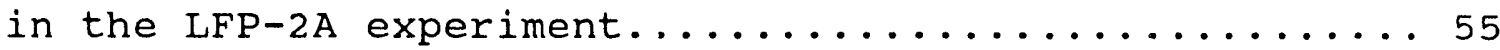

3-22. Gas temperatures measured with aspirated thermocouples

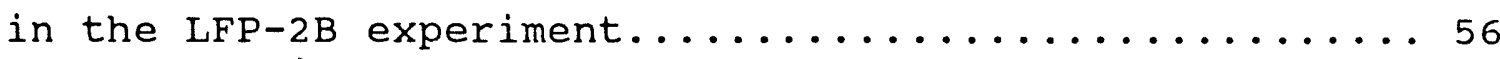

3-23. Gas temperatures measured with aspirated thermocouples

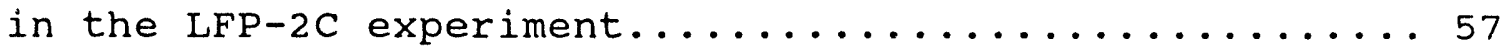

3-24. Gas temperatures measured with aspirated thermocouples

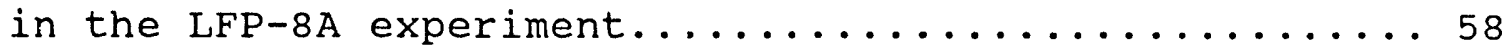

3-25. Debris temperature at the chute exit measured with an $11 \times 30$ optical pyrometer in the LFP-1A experiment..... 59 


\section{LIST OF FIGURES (continued)}

\section{Fiqure}

Page

3-26. Debris temperature at the chute exit measured with an $11 \times 20$ pyrometer in the LFP-1A experiment..........6.

3-27. Debris temperature at the chute exit measured with an $11 \times 30$ optical pyrometer in the LFP-1B experiment......61

3-28. Debris temperature at the chute exit measured with a two-color pyrometer in the LFP-1B experiment........62

3-29. Debris temperature at the chute exit measured with an $11 \times 20$ pyrometer in the LFP-1B experiment..........6 63

3-30. Debris temperature at the chute exit measured with an $11 \times 30$ optical pyrometer in the LFP-2B experiment.....664

3-31. Debris temperature at the chute exit measured with a two-color pyrometer in the LFP-2B experiment........6 65

3-32. Debris temperature at the chute exit measured with an $11 \times 20$ pyrometer in the LFP-2B experiment..........66

3-33. Debris temperature at the chute exit measured with an $11 \times 30$ optical pyrometer in the LFP-2C experiment..... 67

3-34. Debris temperature at the chute exit measured with a two-color pyrometer in the LFP-2C experiment........68

3-35. Debris temperature at the chute exit measured with an $11 \times 20$ pyrometer in the LFP-2C experiment..........69

3-36. Debris temperature at the chute exit measured with an $11 \times 30$ optical pyrometer in the LFP-8A experiment......70

3-37. Debris temperature at the chute exit measured with a two-color pyrometer in the LFP-8A experiment.......71

3-38. Debris temperature at the chute exit measured with an $11 \times 20$ pyrometer in the LFP-8A experiment.......... 72 


\section{LIST OF FIGURES (concluded)}

Figure

Page

3-39. Sieve diameter versus cumulative percentage greater than the stated size for the LFP-8A experiment.......73

3-40. Photograph of debris collected from the LFP-8A

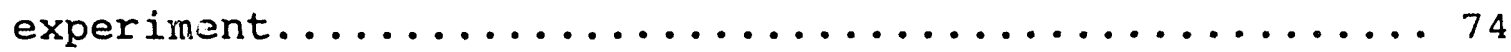

4-1. Percentage of debris mass dispersed from the cavity versus driving pressure for the LFP-1B, $2 \mathrm{~A}$ and $8 \mathrm{~A}$ experiments and the Tutu-Ginsberg correlation........ 81

4-2. Peak pressure increase in surtsey as a function of total available energy................... 82

4-3. Hydrogen production relative to mass of debris dispersed............................... 83

4-4. Blowdown history of the LFP-2C experiment..........84 


\section{INTRODUCTION}

Scaling analysis by Pilch and Allent has identified deentrainment of molten debris as having a significant effect on containment pressurization in a high-pressure melt ejection/direct containment heating (HPME/DCH) scenario. Other analyses have shown that a limited interaction length in the containment atmosphere, combined with debris trapping, may be a major mitigator of DCH [Tarbell et al. 1986]. Thus, it is important to understand the functional dependence of containment loads and hydrogen generation on the interaction time (flight path divided by debris velocity) of the debris in the vessel atmosphere.

The LFP tests were performed at approximately three week intervals. The first LFP experiment (LFP-1A) was performed in mid-July, and the final test in the series (LFP-8A) was conducted on October 18, 1990.

Results of these experiments suggest that the following may be true in a HPME reactor accident:

(1) Debris trapped in the subcompartments of a nuclear power plant (NPP) will not efficiently transfer heat to gas in the upper dome of the containment building.

(2) Blowdown steam reacts quickly with metallic debris in the cavity to form hydrogen, and the presence of hydrogen in the driving gas may affect debris entrainment.

(3) When a debris plume strikes a horizontal structure normal to its path, the debris will be deflected downward and will coalesce in a molten pool on the floor of a subcompartment.

1 Marty Pilch and Michael D. Allen, 1990, A Scaling Methodology for Direct Containment Heating with Application to the Design and specification of an Experiment Program for Resolving DCH Issues, unpublished, sandia National Laboratories, Albuquerque, NM. 
(4) A small fraction of the dispersed debris $(<5 \%)$ would be transported out of the first subcompartment.

(5) Larger ablated holes in the bottom head of the reactor pressure vessel (RPV) result in shorter blowdown times, higher cavity pressures, and higher debris velocities. 


\section{EXPERIMENT DESCRIPTION}

The experiments in the LFP test series were conducted with a generic structure that restricted the flight path of the debris ejected into the surtsey vessel (Figure 2-1). The structure used was a $5.08-\mathrm{cm}$-thick, $2.43 \times 2.43 \mathrm{~m}$ concrete slab. The body of the structure was constructed of reinforced concrete with a $30.5 \mathrm{~cm}$ overhang of $6.35 \mathrm{~mm}$ steel plate on each side. The underside of the structure was painted with an Ameron 90 coating, the paint commonly used in United states nuclear reactors. The Surtsey vessel (inside diameter $3.55 \mathrm{~m}$ ) has four $15.24 \mathrm{~cm}$ I-beams positioned at 90 intervals and mounted vertically on its wall. The restricting structure was welded to these I-beams at nominal distances of 1,2 , and $8 \mathrm{~m}$ from the chute exit. In this configuration the flight path of the debris was perpendicular to the underside of the structure.

While this structure was intended to be generic, in many ways the essential features are similar to the first subcompartment structures in the Surry Plant, i.e., the Residual Heat Removal (RHR) platform. In surry, molten debris from a HPME would be dispersed from the cavity and strike the ceiling of the RHR platform near the seal table. The debris might be trapped on the concrete ceiling; it might be deflected back to the floor of the RHR platform; or a small amount of aerosol might be entrained in gas flow through four large rectangular openings in the crane wall or openings in the sides of the pie-shaped RHR platform into the containment basement. Similarly, in the LFP tests the debris impacted the concrete slab, was deflected back to the lower head, and a small amount of aerosol was entrained in the gas flow around the annulus between the structure and the surtsey vessel wall.

The experimental setup used to produce the steam-driven HPME in the LFP experiments was the same as that used in the Technology Development and scoping (TDS) test series.2 The apparatus is

2 Michael D. Allen et al., 1991, Test Results on Direct containment Heating by High-Pressure Melt Ejection into the Surtsey Vessel: The TDS Test Series, to be published, SAND911208, Sandia National Laboratories, Albuquerque, NM. 
shown schematically in Figure 2-2. (Figures and tables are located at the end of each main section.) Figure 2-3 is a side view of the melt generator housing the refractory-insulated crucible that contained the high-temperature corium simulant reaction. Figure $2-3$ also shows the $1: 10$ scale surry cavity and the transition piece used to attach it to the surtsey vessel. Figure $2-4$ is an exploded view of tha 1:10 linear scale model of the surry reactor cavity. The melt generator and cavity were located outside of the surtsey vessel, as shown in Figure 2-1. This figure also shows the locations of the six levels of instrumentation ports and the relative locations of the 1,2 and $8 \mathrm{~m}$ levels in surtsey.

The melt generator housing the crucible was closed on the bottom with a steel plate. The plate was tapped and fitted with a fusible brass plug. In some experiments (LFP-1B, LFP-2A, LFP-2C and LFP-8A), a disk of $1.3 \mathrm{~cm}$-thick graphite with a round hole in the center was laid over the steel plate inside the crucible. The graphite disk was intended to limit ablation and thus maintain a specific exit hole diameter when the HPME transient melted the brass plug.

The LFP tests used an iron oxide/aluminum/chromium thermite mixture to simulate corium melt. The iron cxide and aluminum powders were baked at $525 \mathrm{~K}$ for four hours in order to drive off water. The aluminum was baked under vacuum to prevent oxidation of the aluminum. The iron oxide was held at $375 \mathrm{~K}$ and then allowed to cool just before mixing anci compaction, while the aluminum powder was cooled and sealed in 1 gallon paint cans. The chromium powder was not heat treated.

The appropriate amounts of each powder were placed in a mixer and mixed for five minutes. The thermite was added to the crucible about one-third $(17 \mathrm{~kg})$ at a time and compacted at 75 tons for two minutes after each addition. About $1 \mathrm{~kg}$ of thermite was kept for the ignitor. The crucible was weighed before and after the thermite was loaded, and the two weights were subtracted to verify the initial weight of the thermite charge.

In each experiment the $0.29 \mathrm{~m}^{3}$ accumulator tank was pressurized with superheated steam to $\simeq 4.2 \mathrm{MPa}$. The space between the rupture disks of the burst diaphragm was concurrently pressurized with argon to $\approx 2.1 \mathrm{MPa}$. The free volume in the crucible and in the $10-\mathrm{cm}$ diameter pipe above the crucible was 
purged with argon to an initial absolute pressure of $\approx 0.1 \mathrm{MPa}$. The crucible free volume was allowed to pressurize due to the heat from the aluminothermitic reaction. The crucibie vent was designed to open to relieve pressures over $1.4 \mathrm{MPa}$.

After the pressurization sequence, the thermite mixture was ignited remotely with a braided wire fuse placed on top of the compacted thermite. The resulting reaction front propagated downward, forming a mixture of molten iron, chromium, and alumina. A timing probe sensed the melt front approaching the brass plug at the bottom of the crucible and locked the crucible vent closed, causing the burst diaphragms to fail. This brought the superheated steam in contact with the molten thermite. Upon contacting and failing the plug in the bottom of the crucible, the molten thermite was expelled by the high-pressure steam into the cavity. The blowdown steam entrained molten debris and dispersed it into the surtsey vessel.

Zero time for HPME was set by the data acquisition system (DACS) as the time at which the melt failed the brass plug and entered the cavity. This event was signaled by a photodiode located at the exit hole. When the hot melt burst through the brass plug, the intense light emitted Erom the melt caused the photodiode to emit a signal that marked the initiation of the HPME.

\subsection{Measurements and Instrumentation}

The most important variables measured in the LFP experiments were (1) the increase in pressure in the surtsey vessel, (2) the number of moles of hydrogen generated by the reaction of metallic debris with steam driving gas, (3) gas temperatures at the vessel walls, and (4) mass of debris recovered from the Surtsey vessel. The instrumentation and techniques used to make these measurements are described in the sections below.

\subsubsection{Pressure Measurements}

Six pressure transducers, two each at levels 1,3 , and 5 (Figure 2-1), were used to measure the surtsey vessel pressure 
in the LFP experiments. These transducers were mounted in tapped holes in instrument penetration ports in the sides of the surtsey vessel, and had their sensing ends protected with steel turnings. Pressure transducers were also used to measure the gas pressure in the accumulator tank, between the rupture disks of the burst diaphragm, and in the crucible above the thermite. These devices were metal diaphragm, strain gaugetype pressure transducers (Model 141-1, Precise Sensor, Inc., Monrovia, CA).

All pressure transducers were factory calibrated by the manufacturer and had been recalibrated at regular intervals by the Sandia Calibrations Laboratory against standards traceable to the National Bureau of standards (NBS). In each of the LFP tests, if the pressure response curves from the pressure transducers were plotted on the same axes, all six curves would lie on top of each other, indicating excellent reproducibility.

The DACS recorded data from the pressure transducers at a rate of 50 data points per second beginning at thermite ignition and continuing to about $60 \mathrm{~s}$ after the HPME transient.

\subsubsection{Temperature Measurements}

Three aspirated thermocouple assemblies measured gas temperatures in the surtsey vessel following the HPME transient. An aspirated thermocouple assembly consisted of three bare, type-K thermocouples mounted in an anodized aluminum tube. These assemblies were installed through instrumentation ports at levels 1, 3, and 5 (Figure 2-1). Each tube had a remotely actuated, solenoid-operated valve that was opened immediately after the HMPE transient while the vessel was still at elevated pressure. Opening the solenoid valves caused hot gas in the vessel to flow through the tubes containing the thermocouples. This configuration allowed the tube surrounding the thermocouples to shield the instruments from the radiant heat flux.

The temperature of the driving gas in the steam accumulator tank was measured using two type-k thermorouples that extended through the accumulator shell and were secured in place using pressure-tight fittings. These measurements were important because the temperature and pressure in the accumulator tank 
were used to calculate the number of moles of steam driving gas.

Three pyrometers measured the temperature of the debris as it emerged from the cavity chute. Two optical pyrometers (a type $11 \times 20$ and a type $11 \times 30$, Ircon Inc., Niles, IL) were housed in a mild steel enclosure near the chute exit. A debris emissivity of 0.9 was assumed when converting the results (in $\mathrm{mV}$ ) from the optical pyrometers to temperature (in degrees $\mathrm{K}$ ). A two-color pyrometer (Modline R Series, Model Number R-35C10, Ircon Inc., stokie, IL) was also housed in the mild steel enclosure. All three pyrometers were focused at the cavity exit through fused silica windows. Figure $2-5$ shows the locations of these pyrometers.

The optical pyrometers had a response time of $1.5 \mathrm{~ms}$ to $95 \%$ of the full range, and they were capable of measuring temperatures between 1973 and $3073 \mathrm{~K}$ with a specified accuracy of $1 \%$ of the full-scale temperature. The two-color pyrometer (wavelengths 0.7 and $1.05 \mu \mathrm{m}$ ) had a temperature range of 1773 to $3773 \mathrm{~K}$ and a calibrated accuracy of $1 \%$ of the full-scale temperature. The response time of the two-color pyrometer was $0.1 \mathrm{~s}$ at the sensing head. In a transient event such as an HPME experiment, the accuracy of the pyrometer measurements was expected to be no better than $\pm 25 \mathrm{~K}$.

The DACS recorded data points from the thermocouples and the pyrometers at a rate of 1 per second prior to thermite ignition. slightly before the thermite was ignited, the DACS was switched to its fast data acquisition mode which recorded data points at 1400 per second.

\subsubsection{Gas Composition}

The Surtsey vessel was inerted with argon (>99 mol. $\%$ Ar) in the LFP test series to prevent metal/oxygen reactions and to preserve the hydrogen produced by metal/steam reactions. Nine pre-evacuated gas grab samples were drawn from the vessel: a background sample at level 4 (Figure 2-1) just prior to ignition of the thermite; three 10-s gas grab samples at levels 2,4 , and 6 (Figure 2-1) were taken at 2 minutes after the HPME; three 10-s gas grab samples at levels 2, 4, and 6 (Figure 2-1) were taken approximately 30 minutes after the HPME; one 
2-s gas grab sample taken at the lower head of the vessel $2 \mathrm{~s}$ after the HPME; and one 10-s gas grab sample taken at the lower head of the vessel at 2 minutes after the HPME. In addition, two gas grab samples were taken from the cavity during the HPME: one gas grab sample bottle attached to the cavity was opened at the beginning of the HPME and remained open for $2 \mathrm{~s}$, and one gas grab sample bottle attached to the cavity was opened at $0.5 \mathrm{~s}$ after the HPME and remained open for $2 \mathrm{~s}$.

For the 10-s gas grab samples, the pressure in the sample bottles became positive with respect to ambient pressure and almost equal to the pressure in the vessel; thus, any leakage would have been out of the bottle. Had leakage into the bottle occurred, high nitrogen concentrations would have appeared in the gas sample. The gas samples were analyzed using gas mass spectroscopy by Battelle, Pacific Northwest Laboratories in Richland, WA. Results of the analyses from the TDS test series and premixed blind samples have demonstrated excellent accuracy, reliability, and reproducibility. 3

\subsubsection{Posttest Debris Recovery}

After each experiment debris was manually recovered so that the cotal mass dispersed into the surtsey vessel and the fraction at specific locations could be determined. The following measurements were made: (1) mass of the molten debris dispersed into the surtsey vessel, (2) fraction trapped on the underside of the structure, (3) fraction on the lower head, (4) fraction that escaped around the annulus to the upper dome, (5) fraction retained in the cavity, and (6) posttest sieve analysis of debris recovered from the lower head of surtsey to determine the sieve mass median particle diameter.

\subsubsection{Debris Velocity}

In LFP-8A, breakwires were placed across the surtsey vessel at the chute exit, at five levels in the vessel, and at the

3 Allen, The TDS Test series 1991. 
concrete structure to measure the debris velocity from the chute exit to the concrete structure. When the debris front severed a breakwire, the DACS recorded a timing signal. In experiments with 1 or $2 \mathrm{~m}$ flight paths, breakwire measurements of debris velocity were unsuccessful. High-temperature, low-momentum aerosol was ejected from the cavity just after the beginning of the HPME and tended to sever the breakwires located low in the vessel at random times prior to steam blowthrough. Thus, for experiments in which the restricting structure was located at 1 or $2 \mathrm{~m}$ from the chute exit, the breakwire data was unreliable. In the experiment with an $8 \mathrm{~m}$ flight path, LFP-8A, the hreakwire data was also unreliable near the chute exit but was uniform among breakwires higher in the vessel. The measured debris velocities were consistent with data from other instrumentation, e.g., pyrometers and calorimeters.

\subsection{Initial conditions}

The experiments in the LFP test series were naned according to the following rationale: Each experiment begins with LFP, which is an abbreviation for limited flight path; the LFP designation is followed by $a$ dash and then a number and letter. The number indicates the nominal flight path in that experiment and the letter simply distinguishes experiments with the same flight path length from each other. For example, LFP-2A, LFP-2B, and LFP-2C were all conducted with a nominal flight path of $2 \mathrm{~m}$, but with different exit hole diameters.

In general, the LFP tests were performed with the following initial conditions: (1) the melt simulant was $50 \mathrm{~kg}$ of iron oxide/aluminum/chromium powder; (2) the driving gas was $\approx 250$ moles of superheated steam $(\approx 570 \mathrm{~K})$ at pressures between 2.5 and $3.5 \mathrm{MPa}$; (3) the initial pressure in the surtsey vessel was $\simeq 0.16 \mathrm{MPa}$ of relatively pure argon (> $99.0 \mathrm{~mol} . \% \mathrm{Ar}$ ); and (4) the cavity was a 1:10 linear scale model of the surry reactor cavity. Table 2-1 lists the exact initial conditions of the LFP experiments. 


\subsection{1 surtsey Atmosphere}

In each of the LFP experiments, the surtsey vessel was purged with argon in order to perform the tests in an atmosphere that was almost oxygen free (i.e., usually <0.08 mol.o $\mathrm{O}_{2}$ ). This virtually eliminated metal/oxygen reactions in the surtsey atmosphere and preserved hydrogen produced by steam/metal reactions so that hydrogen concentrations could be measured.

\subsubsection{Thermite Charge}

The first experiment in the LFP test series (LFP-1A) was a scoping test conducted with an initial thermite charge of $80 \mathrm{~kg}$ and a nominal exit hole diameter of $6 \mathrm{~cm}$. The initial conditions for the LFP-1A test were similar to those used in the TDS -6 and TDS 7 experiments, except that the TDS tests were performed with an open geometry in the surtsey vessel.4 Thus when making comparisons to understand the effects of LFP on pressure increase and hydrogen production, the results of LFP-1A should be compared to the results of TDS- 6 and TDS-7.

The other experiments in the LFP test series were performed with an initial thermite charge of $50 \mathrm{~kg}$. The thermite charge was compacted to approximately 57\% of its theoretical density.

All of the surtsey DCH tests, that is, $\mathrm{DCH}-1$ and $\mathrm{DCH}-2$ [Tarbel] et al. 1987, 1988], $\mathrm{DCH}-3$ and $\mathrm{DCH}-4,5$ the TDS test series, 6 and the LFP test series, were performed with iron oxide from the same 55-gallon drum. Quantitative analysis using powder

4 Allen, The TDS Test Series 1991.

5 Michael D. Allen et al., 1991, Experimental Results of Direct Containment Heating by High-Pressure Melt Ejection into the surtsey Vessel: The $\mathrm{DCH}-3$ and $\mathrm{DCH}-4$ Tests, to be published, NUREG/CR-5620, SAND90-21.38, Sandia National Laboratories, Albuquerque, NM.

6 Allen, The TDS Test Series 1991. 
$x$-ray diffraction was performed on a heat-treated iron oxide sample from this drum. This analysis showed that the iron oxide was composed of 62 wt. $\frac{\circ}{6} \mathrm{Fe}_{3} \mathrm{O}_{4}, 35 \mathrm{wt} . \% \mathrm{FeO}$, and 3 wt. $\%$ $\mathrm{Fe}_{2} \mathrm{O}_{3}$. Thus, the iron oxide used in the surtsey DCH experiments was not pure magnetite $\left(\mathrm{Fe}_{3} \mathrm{O}_{4}\right)--$ as was assumed in early DCH experiments such as the High Pressure Melt streaming (HIPS) test series [Tarbell et al. 1984], and the DCH-1 through $\mathrm{DCH}-4$ experiments. (See previous references to $\mathrm{DCH}-1$ and $\mathrm{DCH}-2$, and $\mathrm{DCH}-3$ and $\mathrm{DCH}-4$ on this page.) There was some free aluminum in the molten products of the reaction and, therefore, the molten mixture better simulated the potential of corium to convert steam to hydrogen.

In the surtsey DCH tests, the thermite was prepared by assuming the iron oxide was all $\mathrm{Fe}_{3} \mathrm{O}_{4}$ and reacted according to the stoichiometric chemical reaction

$$
3 \mathrm{Fe}_{3} \mathrm{O}_{4}+8 \mathrm{Al}+\mathrm{xCr} \rightarrow 4 \mathrm{Al}_{2} \mathrm{O}_{3}+9 \mathrm{Fe}+\mathrm{xCr}
$$

where $x$ is the number of moles of chromium in the reaction. Chromium was added to the iron oxide/aluminum thermite (1) to cool the melt to temperatures more prototypic of corium (chromium is inert in the thermite reaction and therefore dilutes the reactants), and (2) to make the oxidation potential of the melt more prototypic of corium (molten chromium reacts with $\mathrm{H}_{2} \mathrm{O}$ according to the reaction: $2 \mathrm{Cr}+3 \mathrm{H}_{2} \mathrm{O} \rightarrow \mathrm{Cr}_{2} \mathrm{O}_{3}+3 \mathrm{H}_{2}$ ). The mass of chromium added to the thermite was $18 \mathrm{wt} . \%$ of the metal products (iron plus chromium). This value was selected because stainless steel is generally about $18 \mathrm{wt} . \%$ chromjum and this amount will also allow the thermite reaction to propagate. The molecular weights of the constituents in the reaction above are:

$$
\begin{aligned}
\mathrm{MW}_{\mathrm{Fe}} & =55.847 \mathrm{~g} / \mathrm{mole} \\
\mathrm{MW}_{\mathrm{Cr}} & =51.996 \mathrm{~g} / \mathrm{mole} \\
\mathrm{MW}_{\mathrm{Al}} & =26.9815 \mathrm{~g} / \mathrm{mole} \\
\mathrm{MWO}_{\mathrm{O}} & =15.9994 \mathrm{~g} / \mathrm{mole} \\
\mathrm{MW}_{\mathrm{Fe}_{3} \mathrm{O}} & =231.517 \mathrm{~g} / \mathrm{mole}
\end{aligned}
$$


The value of $x$ is

$$
\begin{gathered}
\frac{{ }^{x M W}{ }_{C r}}{{ }^{9 M W_{F e}}+{ }^{x M W}}=0.18 \\
\mathrm{xMW}_{\mathrm{Cr}}-0.18 \times \mathrm{MW}_{\mathrm{Cr}}=1.62 \mathrm{MW} \mathrm{Fe}
\end{gathered}
$$$$
x=\frac{1.62 \mathrm{MW}_{\mathrm{Fe}}}{0.82 \mathrm{MW}_{\mathrm{Cr}}}
$$$$
\mathrm{x}=2.122 \text { moles of } \mathrm{Cr} \text { per } 9 \text { moles of } \mathrm{FE}
$$

The recipe for the reactants (assuming pure $\mathrm{Fe}_{3} \mathrm{O}_{4}$ ) was calculated from

$$
\frac{{ }^{3 \mathrm{MW}_{\mathrm{Fe}} \mathrm{O}_{4}}}{\mathrm{Y}}+\frac{{ }^{8 \mathrm{MW}} \mathrm{Al}}{\mathrm{Y}}+\frac{2.122 \mathrm{MW} \mathrm{Cr}}{\mathrm{Y}}=1
$$

The equation above gives $y=1020.735$. Thus the fractions of each constituent in the initial charge of a stoichiometric mixture are given by:

$$
\begin{aligned}
& \mathrm{f}_{\mathrm{Fe}_{3} \mathrm{O}_{4}}=\frac{{ }_{\mathrm{MW}} \mathrm{Fe}_{3} \mathrm{O}_{4}}{1020.735}=0.6804 \\
& f_{A I}=\frac{{ }^{8 M W_{A l}}}{1020.735}=0.2115 \\
& \mathrm{f}_{\mathrm{Cr}}=\frac{2.122 \mathrm{MW} \mathrm{Cr}}{1020.735}=0.1081
\end{aligned}
$$

In the LFP test series, the mass of the initial thermite charge was $50 \mathrm{~kg}$. Thus, 


$$
\begin{aligned}
\mathrm{f}_{\mathrm{Fe}_{3} \mathrm{O}_{4}}(50 \mathrm{~kg}) & =34.020 \mathrm{~kg} \\
\mathrm{f}_{\mathrm{Al}}(50 \mathrm{~kg}) & =10.575 \mathrm{~kg} \\
\mathrm{f}_{\mathrm{Cr}}(50 \mathrm{~kg}) & =\frac{5.405 \mathrm{~kg}}{50.00 \mathrm{~kg}} \\
\text { Total Mass } & =50.00
\end{aligned}
$$

This was the composition of the thermite used in the LFP experiments. However, the mass of iron oxide was not pure $\mathrm{Fe}_{3} \mathrm{O}_{4}$. As previously mentioned, the iron oxide was 62 wt. $\%$ $\mathrm{Fe}_{3} \mathrm{O}_{4}, 35$ wt. $\% \mathrm{FeO}$, and 3 wt. $8 \mathrm{Fe}_{2} \mathrm{O}_{3}$. Thus, the mass of each iron oxide form in the initial thermite charge was

$$
\begin{aligned}
& \mathrm{M}_{3} \mathrm{Fe}_{4}=(0.62)(34,020 \mathrm{~g})=21,092.4 \mathrm{~g} \\
& { }_{\mathrm{FeO}}^{\mathrm{M}}=(0.35)(34,020 \mathrm{~g})=11,907.0 \mathrm{~g} \\
& \mathrm{Fe}_{2} \mathrm{O}_{3}=(0.03)(34,020 \mathrm{~g})=1,020.6 \mathrm{~g}
\end{aligned}
$$

The number of moles of each iron oxide constituent was

$$
\begin{aligned}
& 91.11 \text { moles of } \mathrm{Fe}_{3} \mathrm{O}_{4} \\
& 165.73 \text { moles of } \mathrm{FeO} \\
& 6.39 \text { moles of } \mathrm{Fe}_{2} \mathrm{O}_{3}
\end{aligned}
$$

There were 263.23 moles of iron oxide in the initial thermite charge. The mole percentage of each constituent was

$$
\begin{aligned}
& 34.61 \mathrm{~mol} . \% \mathrm{Fe}_{3} \mathrm{O}_{4} \\
& 62.96 \mathrm{~mol} . \% \mathrm{FeO} \\
& 2.43 \mathrm{~mol} . \% \mathrm{Fe}_{2} \mathrm{O}_{3}
\end{aligned}
$$

The number of moles of aluminum was

$$
\frac{10,575 \mathrm{~g}}{26.9815 \mathrm{~g} / \mathrm{mole}}=391.94 \text { moles } \mathrm{Al}
$$


The number of moles of chromium was

$$
\frac{5405 \mathrm{~g}}{51.996 \mathrm{~g} / \mathrm{mole}}=103.95 \mathrm{moles} \mathrm{Cr}
$$

The actual chemical reaction in the LFP tests was

$$
\begin{aligned}
& 91.11 \text { moles } \mathrm{Fe}_{3} \mathrm{O}_{4}+165.73 \text { moles } \mathrm{FeO}+6.39 \text { moles } \mathrm{Fe}_{2} \mathrm{O}_{3} \\
& +391.94 \text { moles } \mathrm{Al}+103.95 \text { moles } \mathrm{Cr} \rightarrow \\
& \quad 183.11 \text { moles } \mathrm{Al}_{2} \mathrm{O}_{3}+451.84 \text { moles } \mathrm{Fe}+25.72 \text { moles } \mathrm{Al} \\
& +103.95 \text { moles } \mathrm{Cr} .
\end{aligned}
$$

The free metal in the products of the reaction was

$$
\begin{aligned}
& \text { Aluminum - } 25.72 \text { moles } \\
& \text { Chromium - } 103.95 \text { moles } \\
& \text { Iron - } 451.84 \text { moles }
\end{aligned}
$$

In the LFP experiments, there was free aluminum metal to react with the steam driving gas in addition to the chromium metal. The free aluminum metal calculated above (25.72 moles) was an upper bound on the aluminum metal in the thermite reaction. The mass of aluminum added to the initial thermite charge had some oxide in it. Also the calculation does not include reactions with impurities (such as $\mathrm{SiO}_{2}$ ) in the bed of reactants.

Steam oxidizes the metal products according to the following reaction:

$$
2 \mathrm{M}+3 \mathrm{H}_{2} \mathrm{O} \rightarrow \mathrm{M}_{2} \mathrm{O}_{3}+\mathrm{H}_{2}
$$

Thus, for 2 moles of metal, 3 moles of steam can be reduced to form 3 moles of hydrogen. In the LFP tests, there were $\simeq 250$ moles of steam. If just the aluminum $(25.72$ moles) and chromium ( 103.95 moles) are considered, there were 129.67 moles of metal, which could have reacted with steam to form 194.51 moles of hydrogen. The LFP experiments appeared to be neither steam-starved nor metal-starved. 
The primary initial condition varied in the LFP test series was the debris flight path. The first line of Table 2-1 lists the nominal flight path for each experiment. The actual flight path given in Table 2-1 was measured from the top of the chute exit to the underside of the structure that restricted the flight path of the debris.

In the LFP experiments conducted with a nominal flight path of $2 \mathrm{~m}$, the exit hole diameter was systematically varied. The nominal exit hole diameter for each of the LFP tests is listed in the third row of Table 2-1. The actual hole diameter was determined by using a planimeter to measure the area of a tracing of the ablated hole. The experiments performed with a hole diameter of $3.5 \mathrm{~cm}$ had a graphite plate with a $3.5 \mathrm{~cm}$ hole in the bottom of the crucible. The graphite plate did not ablate and thus the actual hole size was identical to the nominal size. 


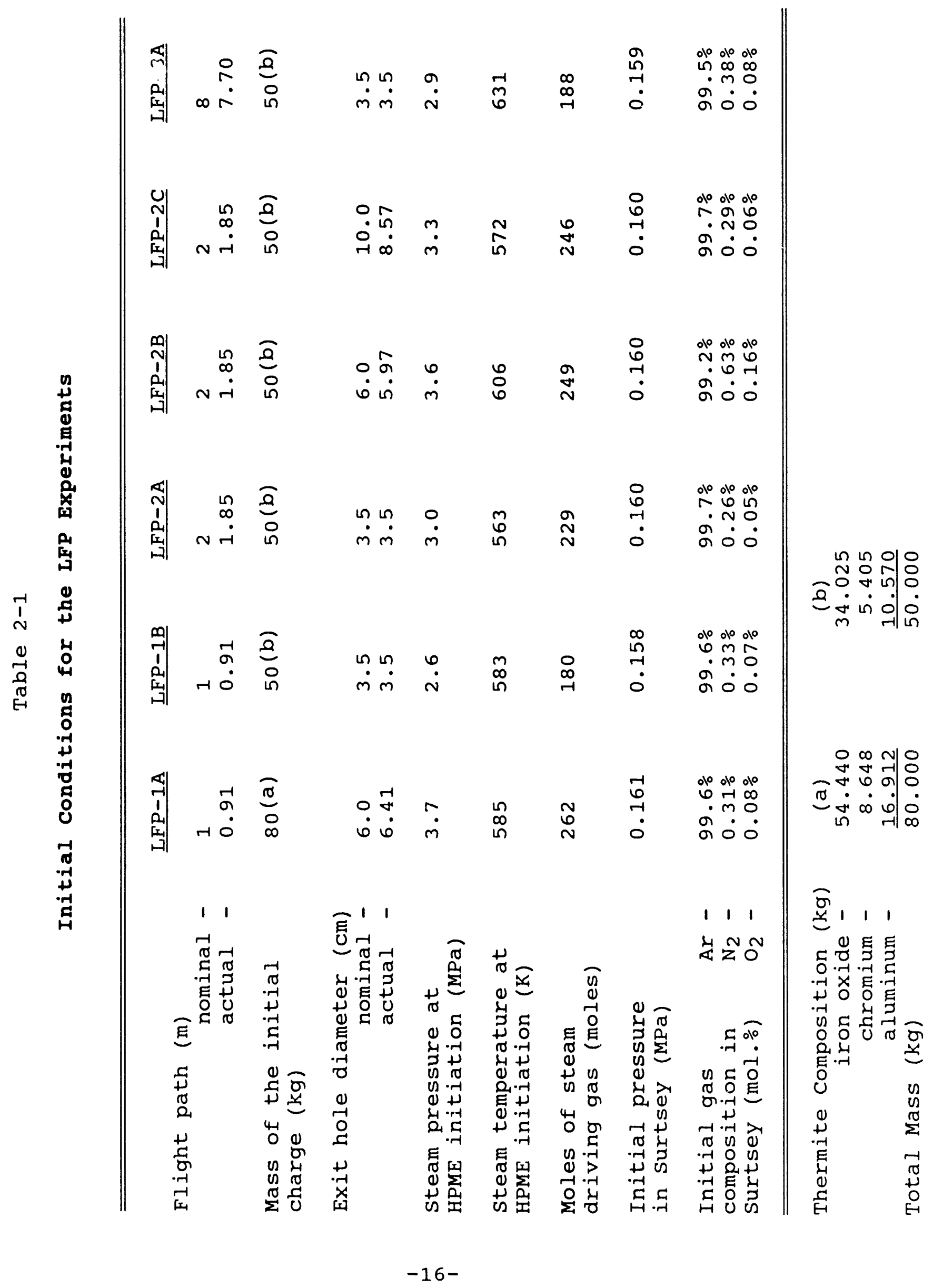




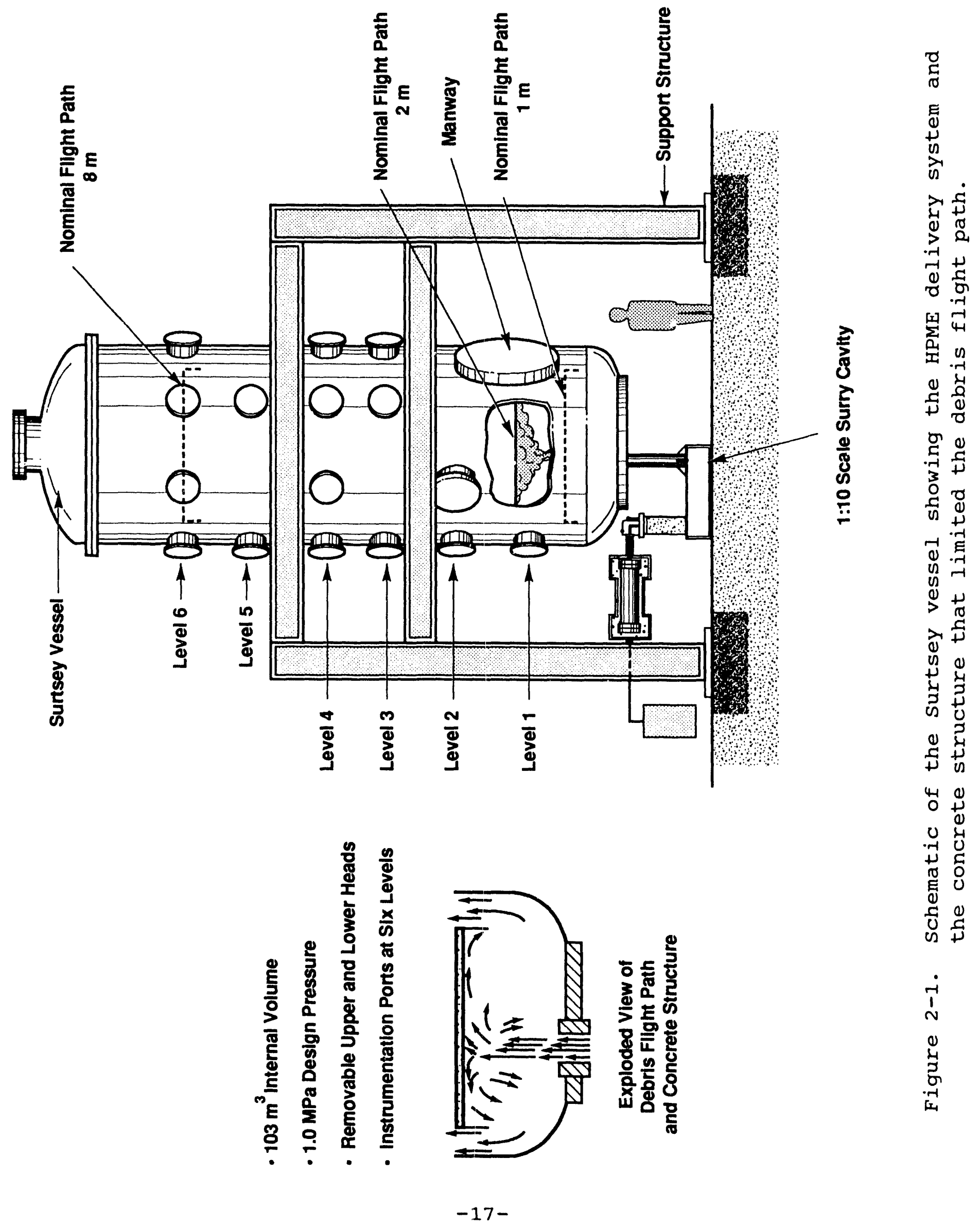




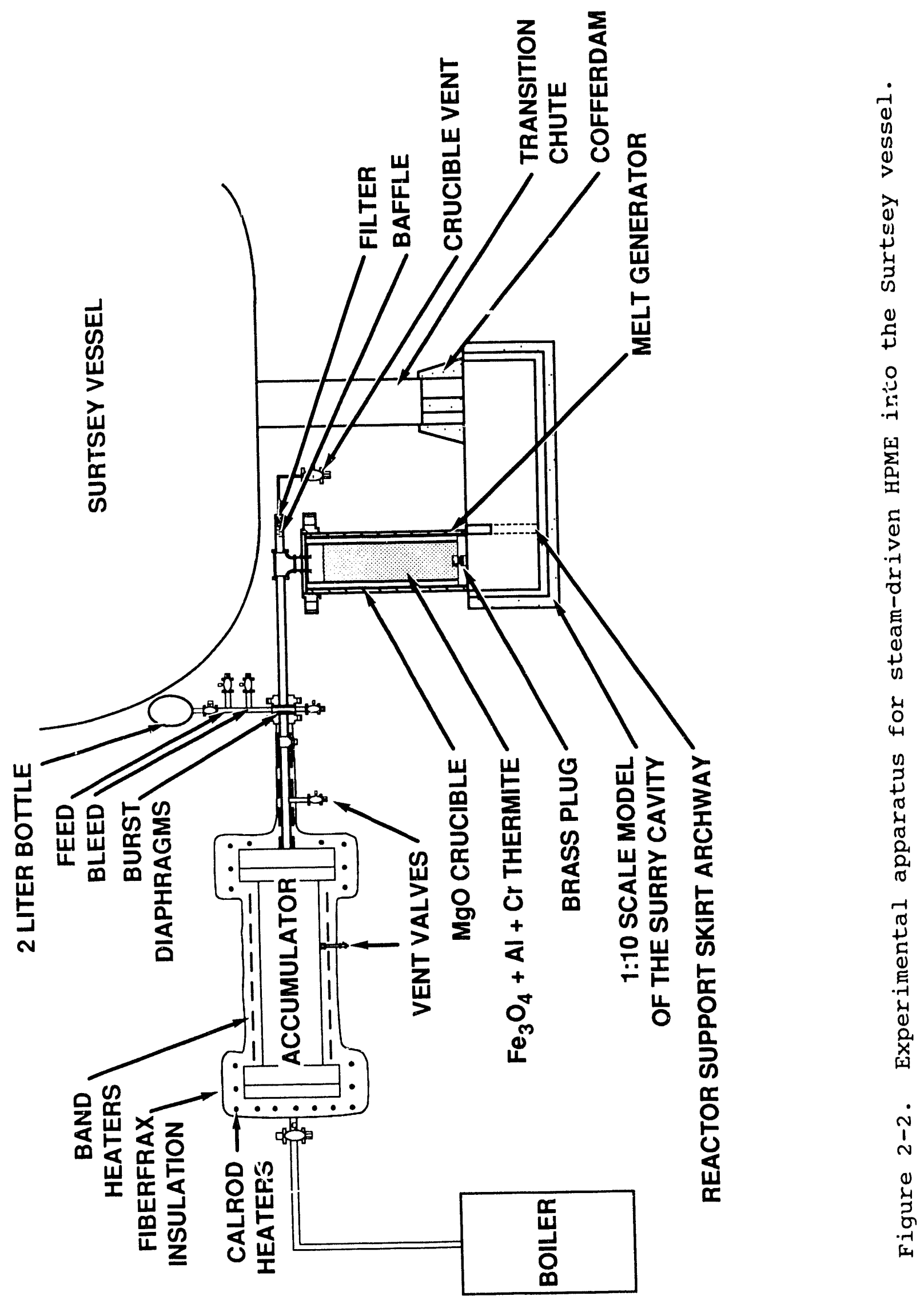




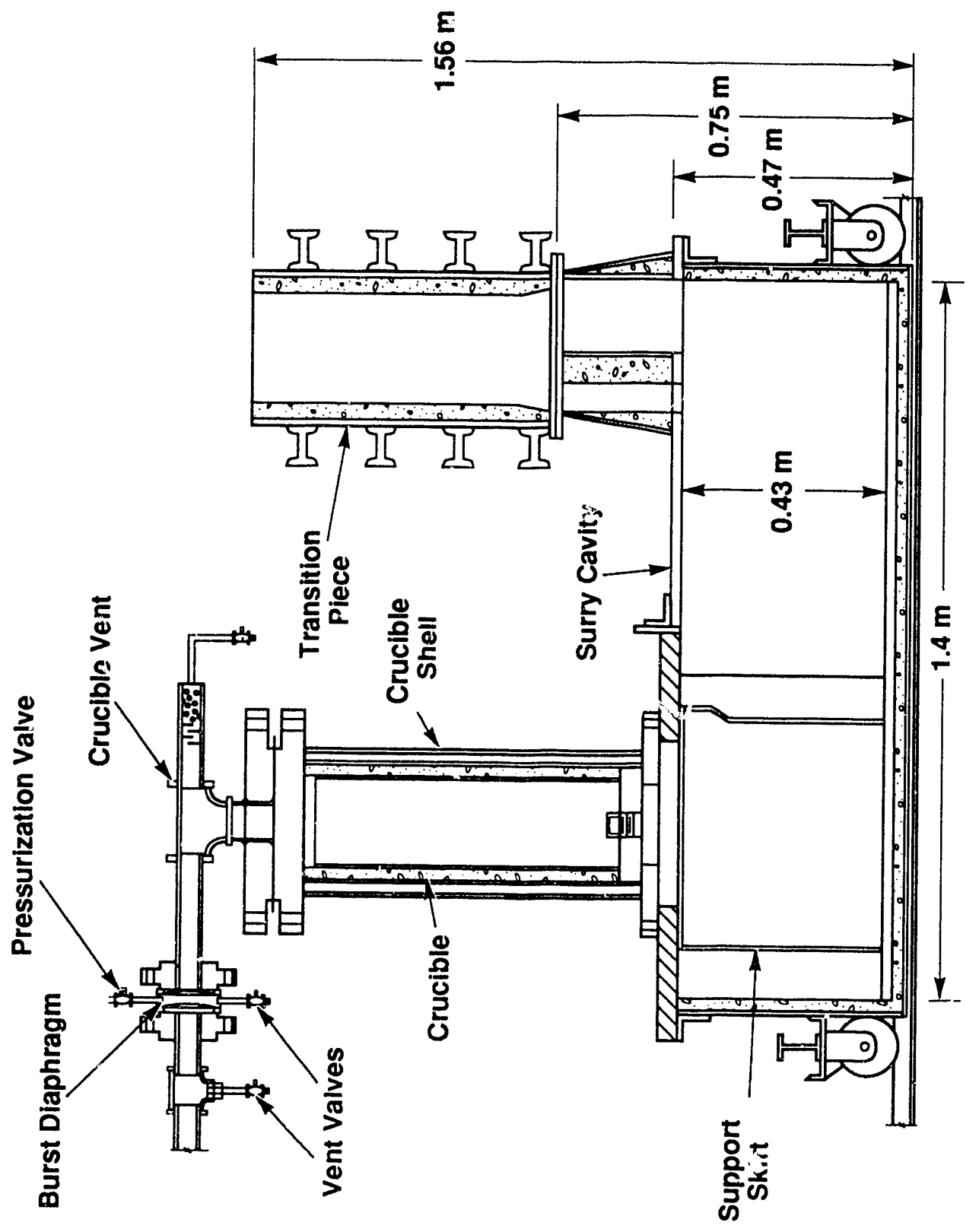

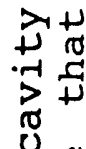

मू

苟

\%

\& 5

검

प्र.

造

峞

出趛

苟

0

मे 2 in

\&

. $>$

$\rightarrow r$

-

0 용

$\therefore$.

$\ddot{-1}+\stackrel{5}{3}$

(a)

过番

40

맘

永

$>$.

(1) 3

战至

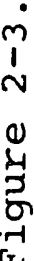




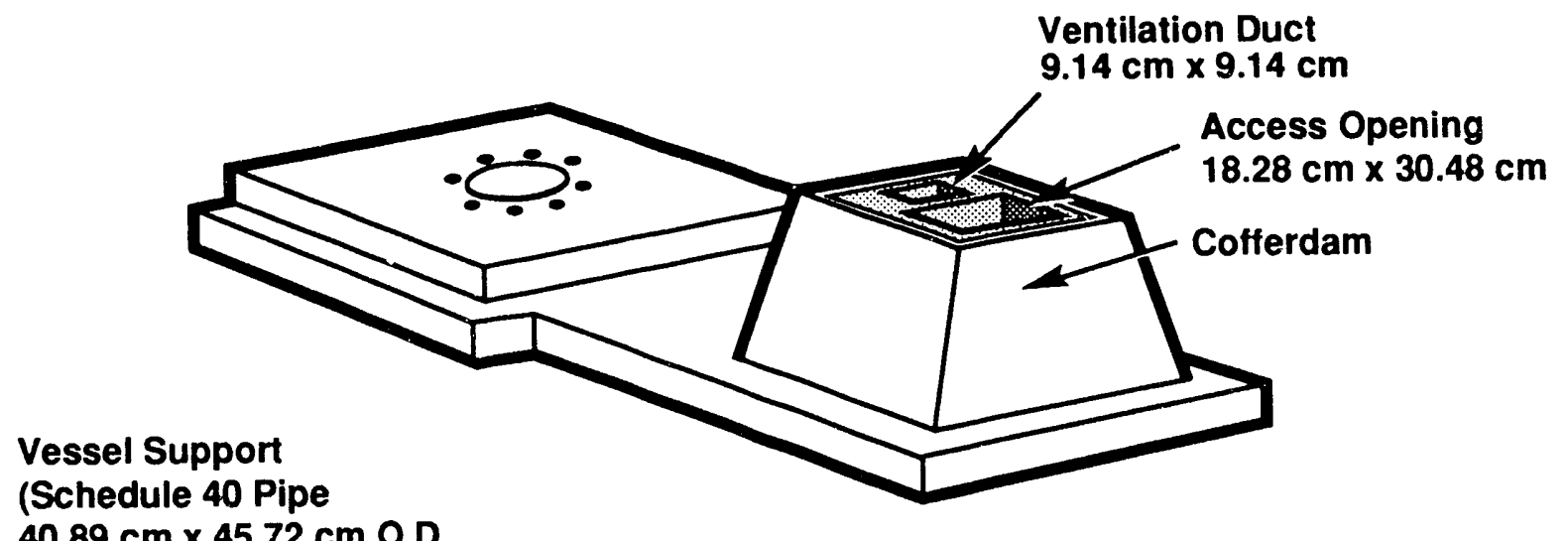

$40.89 \mathrm{~cm} \times 45.72 \mathrm{~cm}$ O.D.

Wall Thickness $=1.42 \mathrm{~cm}$ )
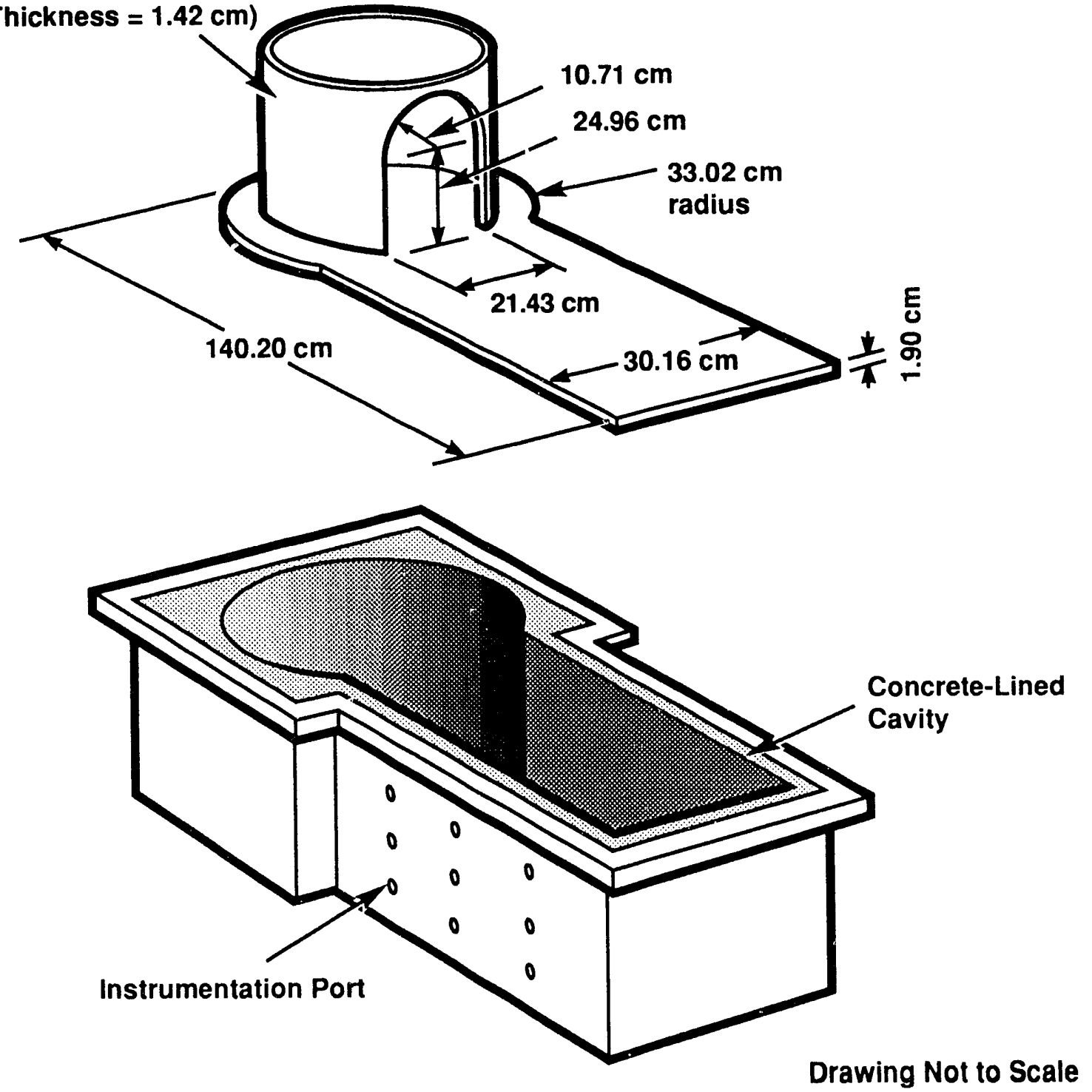

Figure 2-4. Exploded view of the 1:10 linear scale model of the surry reactor cavity. 


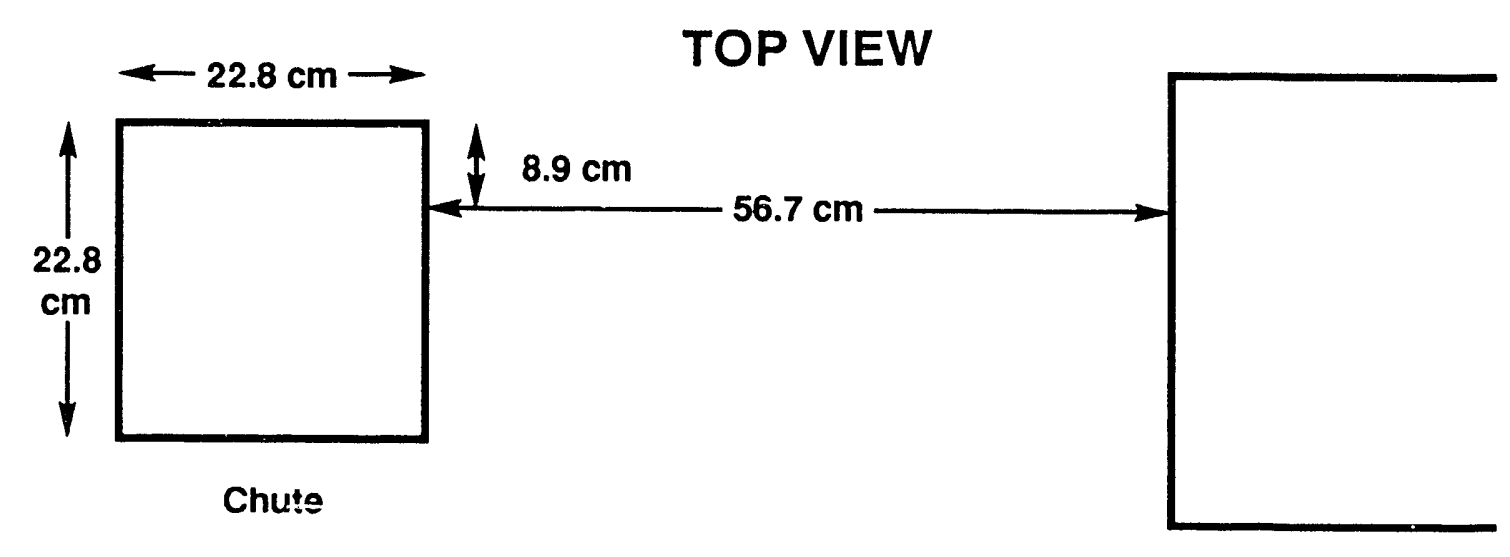

Pyrometer Box

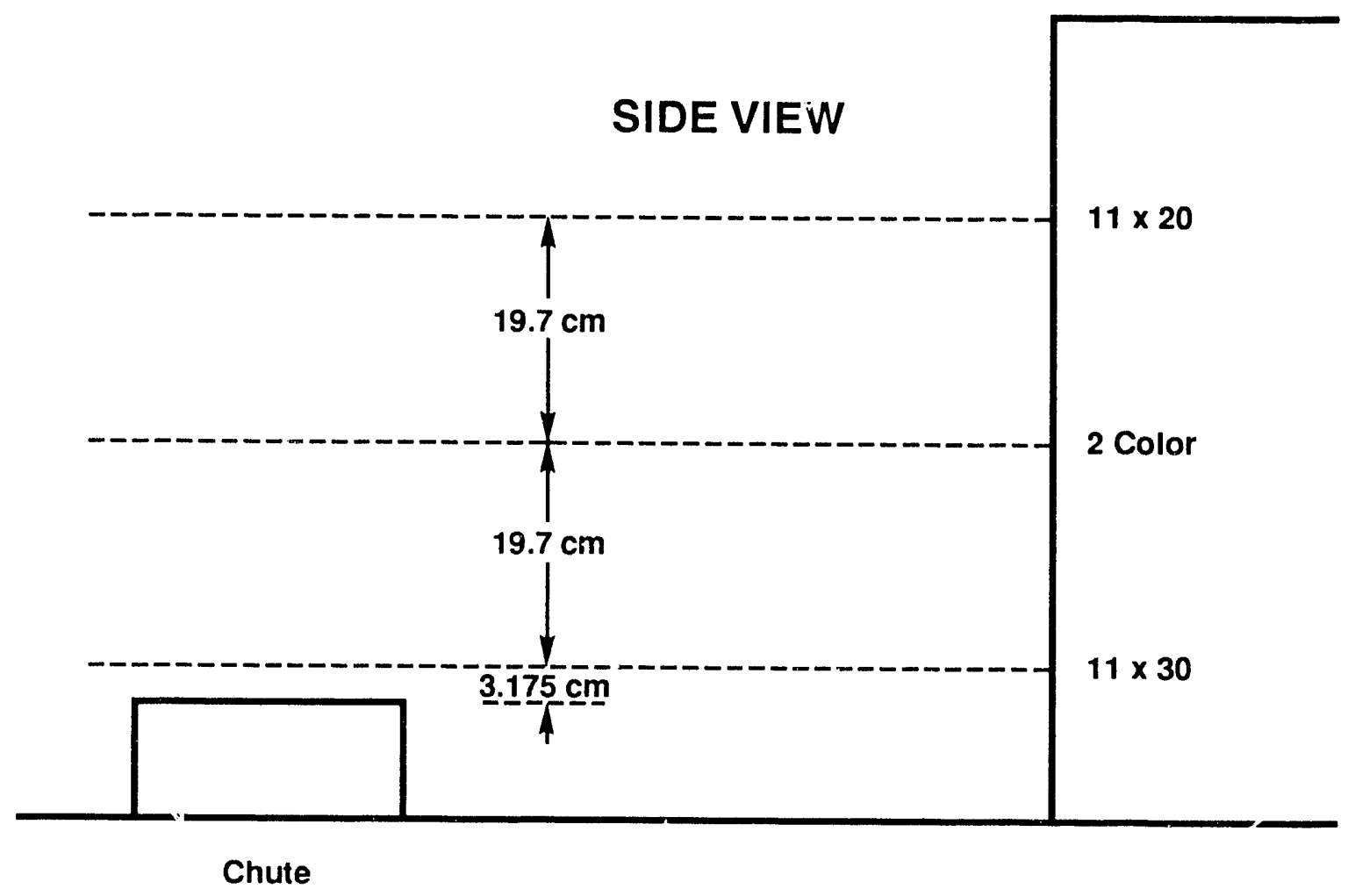

Figure 2-5. Pyrometer positions in the LFP experiments. 


\section{EXPERIMENT RESULTS}

The blowdown histories, vessel and cavity pressures, gas and debris temperatures, gas composition, debris velocity, and posttest debris recovery results are presented here.

\subsection{Blowdown Histories}

Figures 3-1 through 3-6 show the blowdown histories of the LFP experiments. The steam driving-gas pressures listed in Table 2-1 for each LFP experiment were determined from the blowdown histories shown in Figures 3-1 through $3-6$. The horizontal dotted lines across these figures show the steam driving-gas pressure at the initiation of the HPME. In the $50 \mathrm{~kg}$ experiments, the initial driving pressures varied between 2.6 and $3.6 \mathrm{MPa}$. The ciriving pressures were lower than those of the TDS test series $7(\approx 4 \mathrm{MPa})$ due to the additional volume in the top of the crucible left by reducing the initial charge mass from 80 to $50 \mathrm{~kg}$. There was also some condensation of steam in the space between the crucible outer wall and the inside wall of the melt generator.

For each experiment the number of moles of steam driving gas at the initiation of the HPME was calculated from the measured steam pressure and temperature in the accumulator tank (Table 2-1). The measured steam pressure was the driving gas pressure 1 isted in Table 2-1. The steam temperature was measured with two type-K thermocouples that protruded into the accumulator tank. The steam volume was the accumulator volume $\left(0.29 \mathrm{~m}^{3}\right)$ plus the free volume downstream of the burst diaphragm $\left(0.04 \mathrm{~m}^{3}\right)$. The number of moles of steam driving gas was calculated from the specific volume of superheated steam given in standard thermodynamic tables.

Figures 3-1 through 3-6 give an indication of how long steam was in contact with the molten thermite prior to the HPME. In

Allen, The TDS Test Series 1991. 
general, in the $\operatorname{TDS}^{8}$ and LFP experiments, the steam was in contact with the molten thermite between 3 and $6 \mathrm{~s}$. In LFP-1A and LFP-2B, burst diaphragm failure apparently occurred at about the same time as the initiation of the HPME.

Steam/thermite contact time may affect debris dispersal. In Surtsey DCH experiments (and in real nuclear power plant [NPP] accidents) the driving gas is a mixture of steam and hydrogen produced by steam/metal interactions. In addition, debris expulsion from a reactor pressure vessel may be accompanied by codispersed water. Because of the large difference in molecular weights between steam ( $\mathrm{MW}=18 \mathrm{~g} / \mathrm{mole}$ ) and hydrogen $(\mathrm{MW}=2 \mathrm{~g} / \mathrm{mole})$, the driving gas composition affects the entrainment of debris from the cavity. Longer steam/thermite contact times may increase the hydrogen:steam ratio in the driving gas and thus may have an effect on debris entrainment.

Figures 3-1 through $3-6$ show the time required for steam blowdown in the LFP experiments. In tests with an exit hole diameter of $3.5 \mathrm{~cm}$ (i.e., LFP-1B, LFP-2A, and LFP-8A) the blowdown lasted approximately $3 \mathrm{~s}$. In experiments with an exit hole diameter of $\approx 6 \mathrm{~cm}$ (i.e., LFP-1A and LFP-2B) the blowdown lasted approximately $2 \mathrm{~s}$. In LFP-2C, which had an exit hole diameter of $8.57 \mathrm{~cm}$, the blowdown lasted approximately $1 \mathrm{~s}$. This trend appears to be logical. Exit hole size is important. because a shorter blowdown time results in higher cavity pressures and higher entrainment rates.

\subsection{Pressure Measurements}

Metal diaphragm, strain gauge-type pressure transducers were used to measure the pressure in the surtsey vessel and the pressure in the cavity due to the HPME transient. The sections below describe the data measured by these transducers.

8 Allen, The TDS Test Series 1991. 


\subsubsection{Surtsey Vessel pressure}

Figures 3-7 through 3-12 show the absolute pressure in the Surtsey vessel versus experiment time for the LFP experiments. These figures have a horizontal dotted line across the graph at the initial pressure in surtsey pricr to the HPME transient. The initial pressures ranged from 0.158 and $0.161 \mathrm{MPa}$ and are listed in the table of initial conditions (Table 2-1). Figures 3-7 through 3-12 also have a horizontal dotted line across the graph at the peak pressure caused by the HPME. The pressure increase (i.e., $\triangle \mathrm{P}$ in $\mathrm{MPa}$ ) is listed in each of these figures.

\subsubsection{Cavity Pressure}

Figures 3-13 through 3-18 show the cavity pressure and vessel pressure versus experiment time for the LFP experiments. In the experiments with a $3.5 \mathrm{~cm}$ hole diameter (LFP-1B, LFP-2A, and $(F P-8 A$ ), the maximum difference between the cavity pressure and vessel pressure was approximately $0.04 \mathrm{MPa}$. In the tests with a nominal hole diameter of $6 \mathrm{~cm}$ (LFP-1A and LFP-2B), the difference between the cavity pressure and vessel pressure was about 0.20 and $0.16 \mathrm{MPa}$, respectively. It appears that these pressure differences may have resulted in choked flow froin the cavity into the vessel. In the experiment with a hole diameter of $8.57 \mathrm{~cm}(\mathrm{LFP}-2 \mathrm{C})$, the difference was $5.4 \mathrm{MPa}$. This pressure difference definitely resulted in choked flow out of the cavity.

A comparison of the cavity pressure to the vessel pressure in Figures 3-13 through 3-18 also provides information on the debris ejection interval. The debris ejection interval was about $0.7 \mathrm{~s}$ in the experiments with a $3.5 \mathrm{~cm}$ hole diameter (IJFP-1B, LFP-2A, and LFP-8A), $0.6 \mathrm{~s}$ in the experiments with a $6 \mathrm{~cm}$ hole diameter (LFP-1A and LFP-2B), and $0.4 \mathrm{~s}$ in the experiment with a $8.57 \mathrm{~cm}$ hole diameter (LFP-2C). The debris ejection interval and the onset of debris dispersal increased as the exit hole diameter decreased. In the experiments with a $3.5 \mathrm{~cm}$ hole diameter (LFP-1B, LFP-2A, and LFP-8A), debris ejection appeared to start at $\simeq 0.9 \mathrm{~s}$. In the tests with a nominal hole diameter of $6 \mathrm{~cm}$ (LFP-1A and LFP-2B), debris 
ejection began at $\simeq 0.45 \mathrm{~s}$. In LFP-2C, which had an exit hole diameter of $8.57 \mathrm{~cm}$, debris ejection started at $\approx 0.25 \mathrm{~s}$.

\subsection{Gas Temperature Measurements}

Figures 3-19 through 3-24 show the gas temperatures at the vessel wall measured with aspirated thermocouples. In the experiments having short flight paths (i.e., 1 or $2 \mathrm{~m}$ ), the temperatures measured at level 1 (Figure 2-1) in the surtsey vessel were always substantially higher than the temperatures measured at levels 3 and 5. Levels 3 and 5 were above the flight path-limiting structure and only small amounts of aerosol were transported around the structure to the upper part of the surtsey vessel. The majority of the debris remained below the structure, and thus the gas below the structure at level 1 was substantially hotter than the gas at levels 3 and 5. In LFP-8A, the structure was located at $\approx 8 \mathrm{~m}$, which is about level 5. The $30.5 \mathrm{~cm}$ overhangs on the structure apparently blocked debris from passing by the aspirated thermocouples at level 5 , and thus the highest gas temperatures were measured at level 3 and the next highest at level 1 .

\subsection{Debris Temperature Measurments}

Temperatures of the debris as it exited the chute were measured in the LFP experiments by two automatic optical pyrometers and a two-color pyrometer. Figures 3-25 through 3-38 show the debris temperature as a function of experiment time for the LFP experiments. The $11 \times 30$ optical pyrometer was focused $3.175 \mathrm{~cm}$ above the chute exit, the two-color pyrometer was focused $22.8 \mathrm{~cm}$ above the chute exit, and the $11 \times 20$ optical pyrometer was focused $41.5 \mathrm{~cm}$ above the chute exit. In the LFP-1A experiment no data were obtained from the two-color pyrometer. In the LFP-2A experiment no temperature data were obtained.

Figures 3-25 through 3-38 have a dotted horizontal line across the graph at $2300 \mathrm{~K}$ as a reference temperature. For the optical pyrometers there is also a horizontal dotted line across the graph at $1973 \mathrm{~K}$, and for the two-color pyrometer These temperaturontal dotted line across the graph at $1773 \mathrm{~K}$. are the lowest values are the lowest values for which the pyrometers were calibrated, 
and thus even if the pyrometers were receiving signals between 0 and $2 \mathrm{mV}$, the output is shown as a temperature of $273 \mathrm{~K}$ in these figures.

The mean peak debris temperature measured with the $11 \times 30$ optical pyrometer $3.175 \mathrm{~cm}$ from the chute was $\approx 2320 \pm 50 \mathrm{~K}$. The mean peak temperature measured with the two-color pyrometer $22.8 \mathrm{~cm}$ from the chute exit was $\approx 2230 \pm 30 \mathrm{~K}$. The mean peak temperature measured with the $11 \times 20$ optical pyrometer $41.5 \mathrm{~cm}$ from the chute exit was $\approx 2200 \pm 90 \mathrm{~K}$. These results are consistent with those measured in the TDS test series. 9 They indicate that the debris temperature decreased more than $100 \mathrm{~K}$ in the $38.3 \mathrm{~cm}$ between the $11 \times 30$ and the $11 \times 20$ optical pyrometers.

\subsection{Gas Composition Measurements}

Table 3-1 lists the results of the hydrogen concentration measurements from the gas grab samples. Eleven $500 \mathrm{~cm}^{3}$, stainless steel bottles were used to take gas samples from the cavity, from underneath the flight path-limiting structure, and from levels 2,4 , and 6 in the surtsey vessel. A 10-s background sample located at level 4 of the vessel was taken prior to ignition. In the LFP tests the surtsey vessel was purged with argon so that hydrogen produced by the steam/metal reactions would not recombine with oxygen in the surtsey atmosphere. The goal was to reduce the oxygen concentration to less than $0.10 \mathrm{~mol} . \%$. In general, the background oxygen concentration was between 0.05 and $0.08 \mathrm{~mol} \%$, with the exception of LFP-2B which had a background oxygen concentration of $0.16 \mathrm{~mol} . \%$.

Six gas grab samples were taken from the surtsey vessel. A set of gas grab sample bottles was opened by a signal from the DACS at 2 minutes after HPME and was closed $10 \mathrm{~s}$ later; these bottles were located at levels 2,4 , and 6 . A second set of gas grab sample bottles, was opened manually $30 \mathrm{~min}$ after HPME and was closed approximately $10 \mathrm{~s}$ later; these bottles were

9 Allen, The TDS Test Series 1991. 
also located at levels 2,4 , and 6 . For each of the LFP experiments, the results of all samples taken from the vessel at times of $2 \mathrm{~min}$ or $30 \mathrm{~min}$ (which includes one sample near the bottom head) are in excellent agreement. This agreement indicates that after two minutes, the hydrogen concentration was uniform throughout the surtsey vessel. The mean hydrogen concentration \pm standard deviation for each of the LFP experiments is listed in Table 3-1.

Two gas grab samples were taken from the cavity during the HPME in each LFP experiment. One bottle opened when the brass plug melted at experiment time $0 \mathrm{~s}$ and closed $2 \mathrm{~s}$ later, and the other bottle opened at experiment time $0.5 \mathrm{~s}$ and closed $2 \mathrm{~s}$ later. Table 3-2 lists the gas compositions measured in the cavity during the LFP experiments. The carbon compounds shown in Table 3-2 were generated by melt/concrete interactions, and melt interactions with paint on the concrete structure. The results of these samples should only be interpreted qualitatively since any measurement technique, in this case gas mass spectroscopy, only measures noncondensible gases. Consequently, the values in mol.o given in Table 3-2 are mole percentages of the noncondensible gases and do not include the amount of steam in the gas. A significant amount of hydrogen was measured in the cavity during the HPME, however, and this indicates that the driving gas was a mixture of steam and hydrogen.

Two gas grab samples were taken from underneath the concrete structure near the bottom head of the vessel in each LFP experiment (following the HPME) to investigate the possibility of high localized hydrogen concentrations. One bottle was opened at $2 \mathrm{~s}$ after the initiation of HPME and was closed $2 \mathrm{~s}$ later; the other bottle was opened at $2 \mathrm{~min}$ and was closed $10 \mathrm{~s}$ later. For three of the four experiments in which hydrogen measurements were obtained (LFP-1B, LFP-2B, and LFP-2C), the hydrogen concentration in the first sample taken underneath the limiting structure was higher than the average concentration from samples opened at times longer than 2 min after the HPME.

For the LFP-2A test, the hydrogen concentration in the first sample taken underneath the structure was lower than the average concentration $(0.62$ mol. $\%$ compared to 2.24 mol. $\%)$. This measurement does not match the trend and may be an 
anomaly. In general, the results of the gas analyses indicate that there were high localized concentrations of hydrogen underneath the structure and in the cavity.

Table 3-3 (line 6) lists the number of moles of hydrogen produced by steam/metal reactions. The total number of moles of hydrogen produced was a weak linear function of the mass of debris dispersed into the surtsey vessel.

\subsection{Debris Recovery summary}

Table 3-4 gives the debris recovery summary of the LFP experiments. Debris in the surtsey vessel was recovered from three locations: (1) from the underside of the structure, (2) from above the structure, and (3) from the bottom head of the vessel. Also listed in Table $3-4$ is the total molten mass available for dispersal into the vessel. This mass is usually about $20 \%$ greater than the initial iron oxide/aluminum/chromium thermite charge due to melting of the inner wall of the crucible, melting of the fusible brass plug, ablation of concrete in the cavity, and oxidation of metallic debris by steam.

The debris plume apparently impacted the structure and was deflected to the bottom head. The paint on the underside of the flight path-limiting structure was burned off in all LFP tests. In the experiments with the shorter flight paths (i.e., 1 or $2 \mathrm{~m}$ ), the debris on the bottom head of the surtsey vessel appeared to have been a molten posl that cooled and solidified. The debris was not finely divided enough for sieve analysis.

In the LFP experiments, the majority of the debris in the vessel was recovered from the bottom head. About $10 \%$ of the debris recovered from the vessel adhered to the underside of the concrete structure, and a smaller amount was recovered from above the structure. The debris recovered from above the scructure was finely divided powder, but the composition of this debris was not analyzed to investigate whether the composition was enhanced in the more volatile elements, e.g., from the brass melt plug.

The posttest sieve analysis of debris recovered from the bottom head of the surtsey vessel after the LFP-8A test is given in 
Table 3-5. The debris was lognormally distributed with a sieve mass median diameter of $\approx 1.1 \mathrm{~mm}$ and a geometric standard deviation of 5 (Figure 3-39). Figure $3-40$ shows a sample of some of the recovered debris.

\subsection{Debris Velocity}

With the tests that had a shorter flight path, accurate measurement of debris velocities was difficult to achieve. The velocity of the leading edge of the debris plume was measured using a breakwire array in the LFP-8A experiment. The average velocity between the chute exit and the concrete structure in LFP-8A was $16.1 \mathrm{~m} / \mathrm{s}$. 


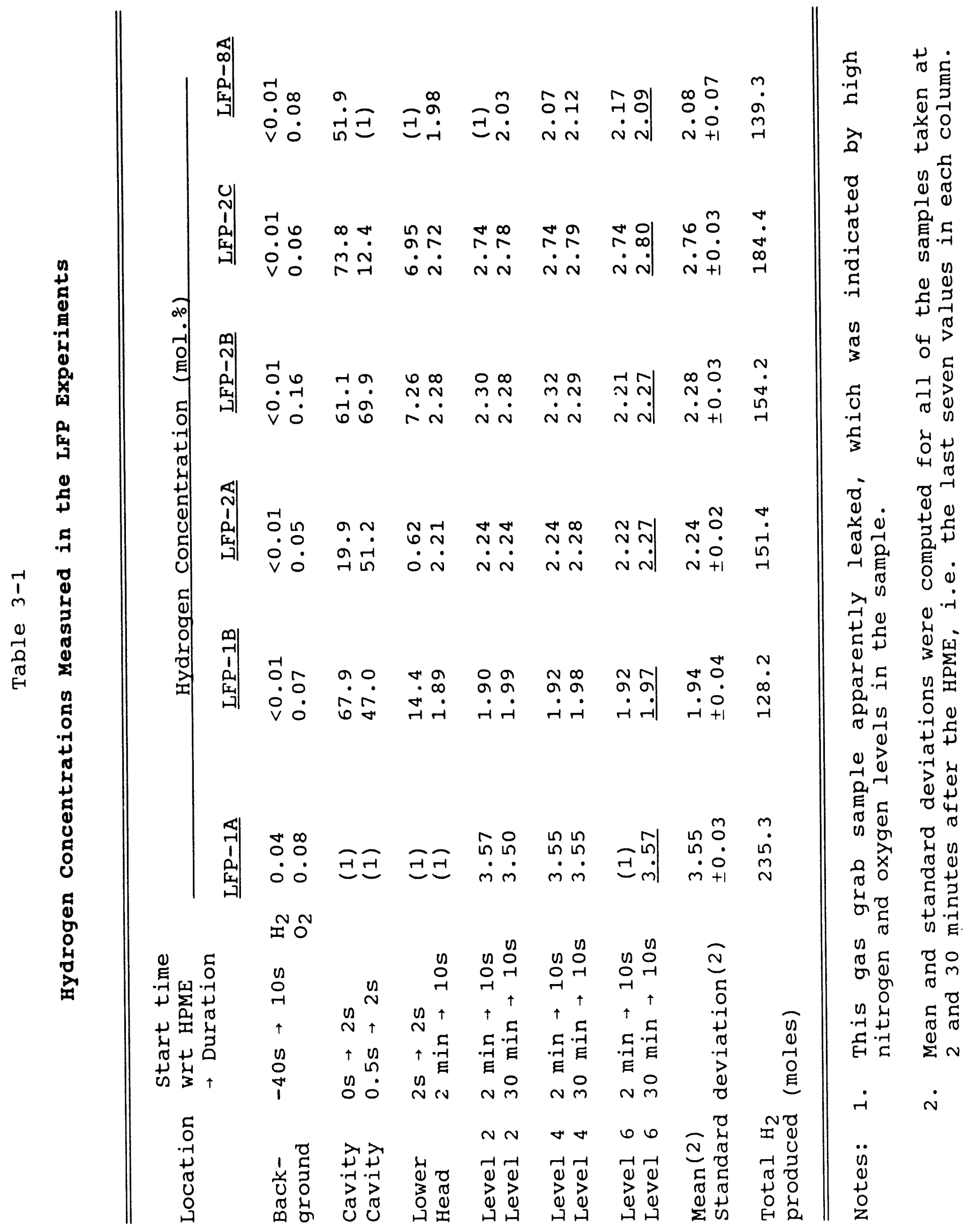




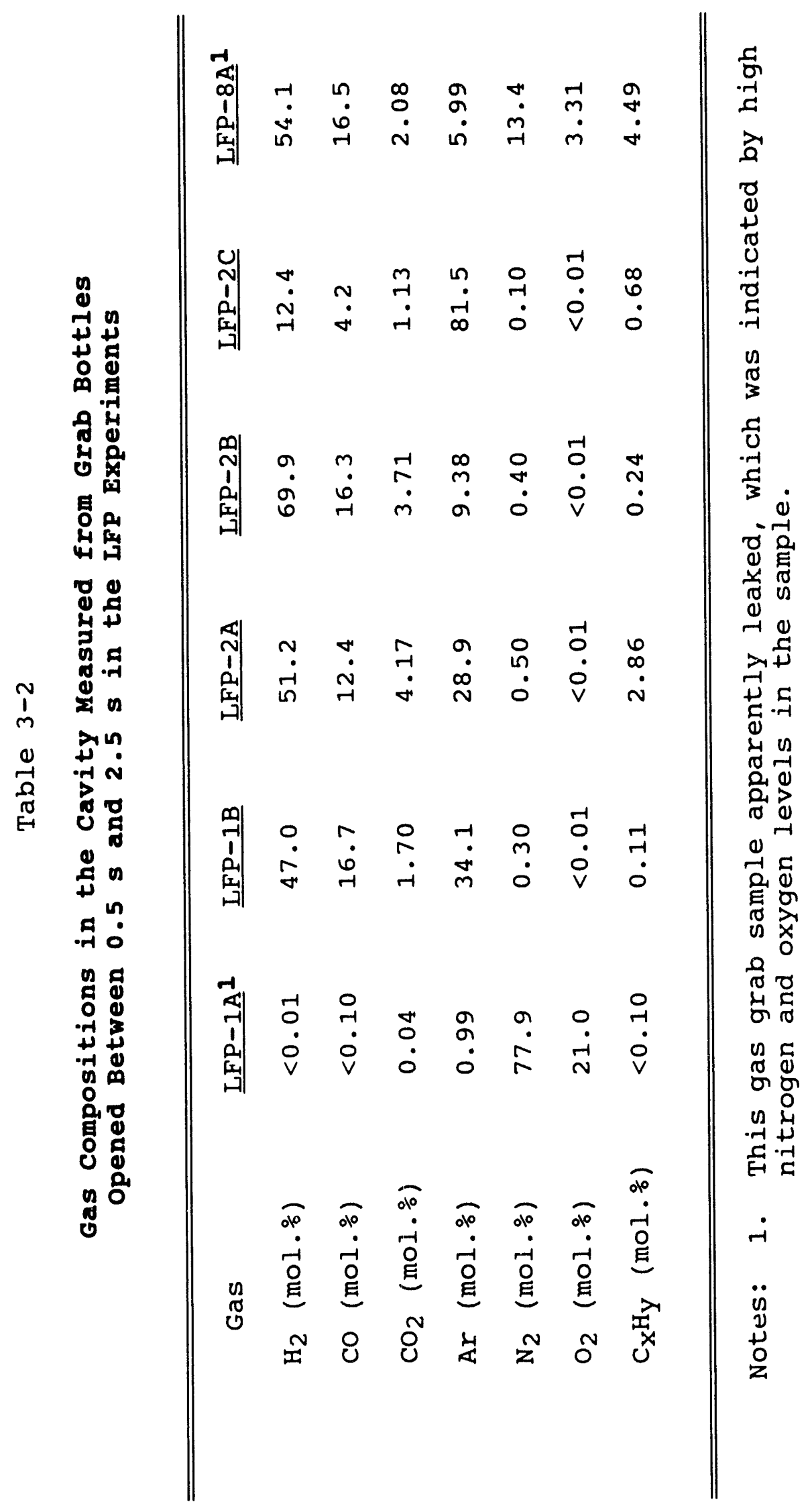




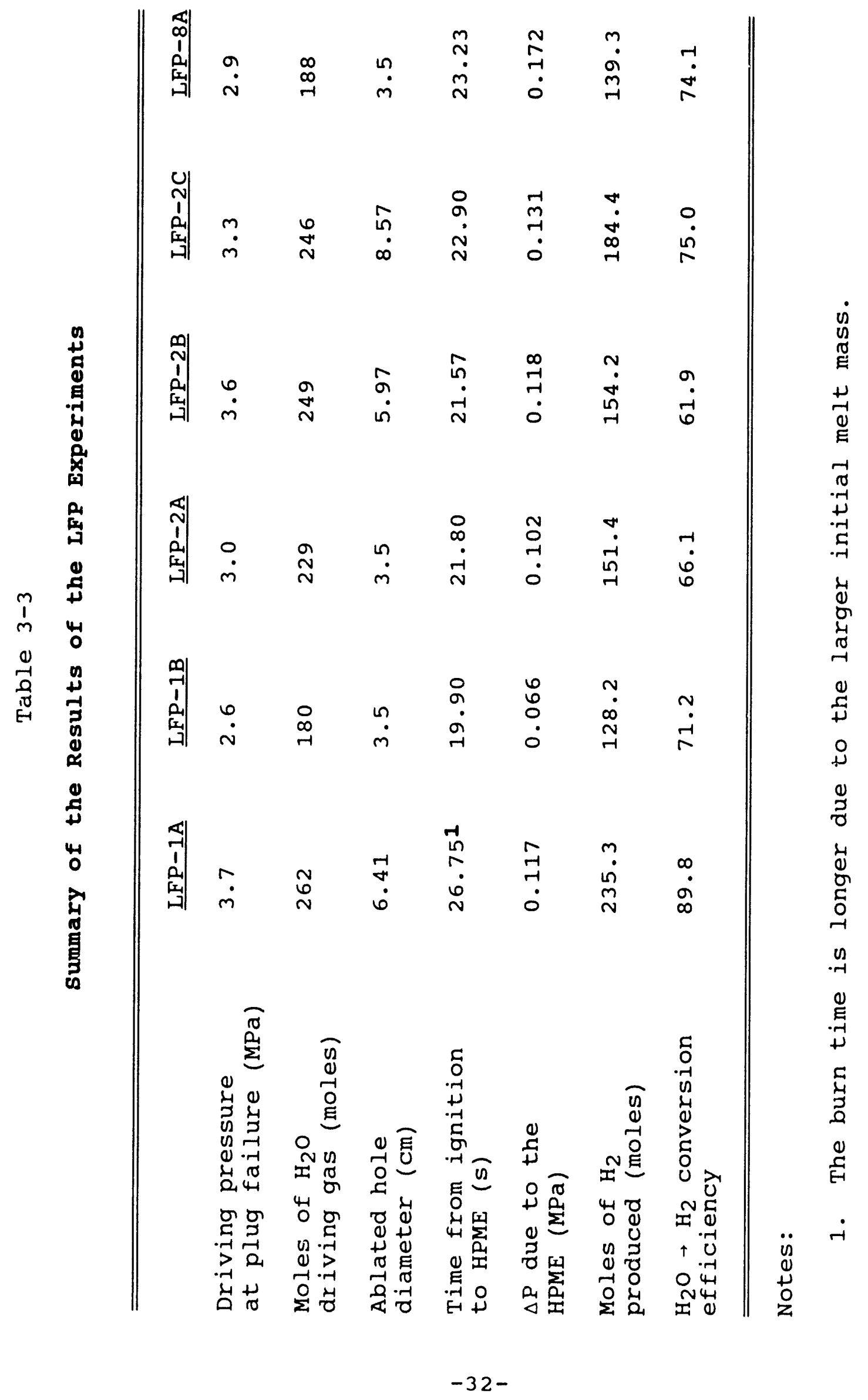




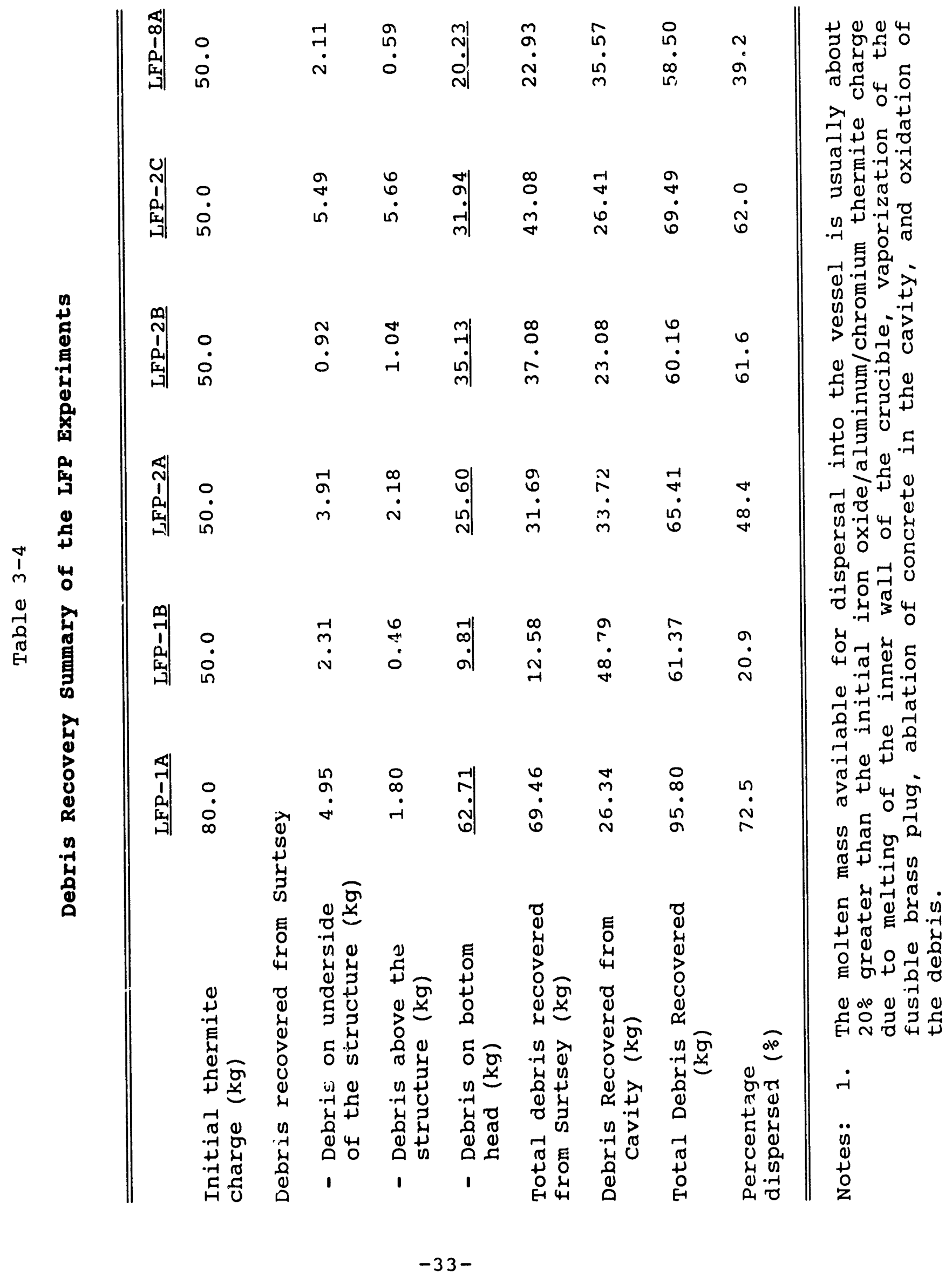


Table 3-5

sieve Analyis of LFP-8A Debris from the Bottom Head of the surtsey vessel

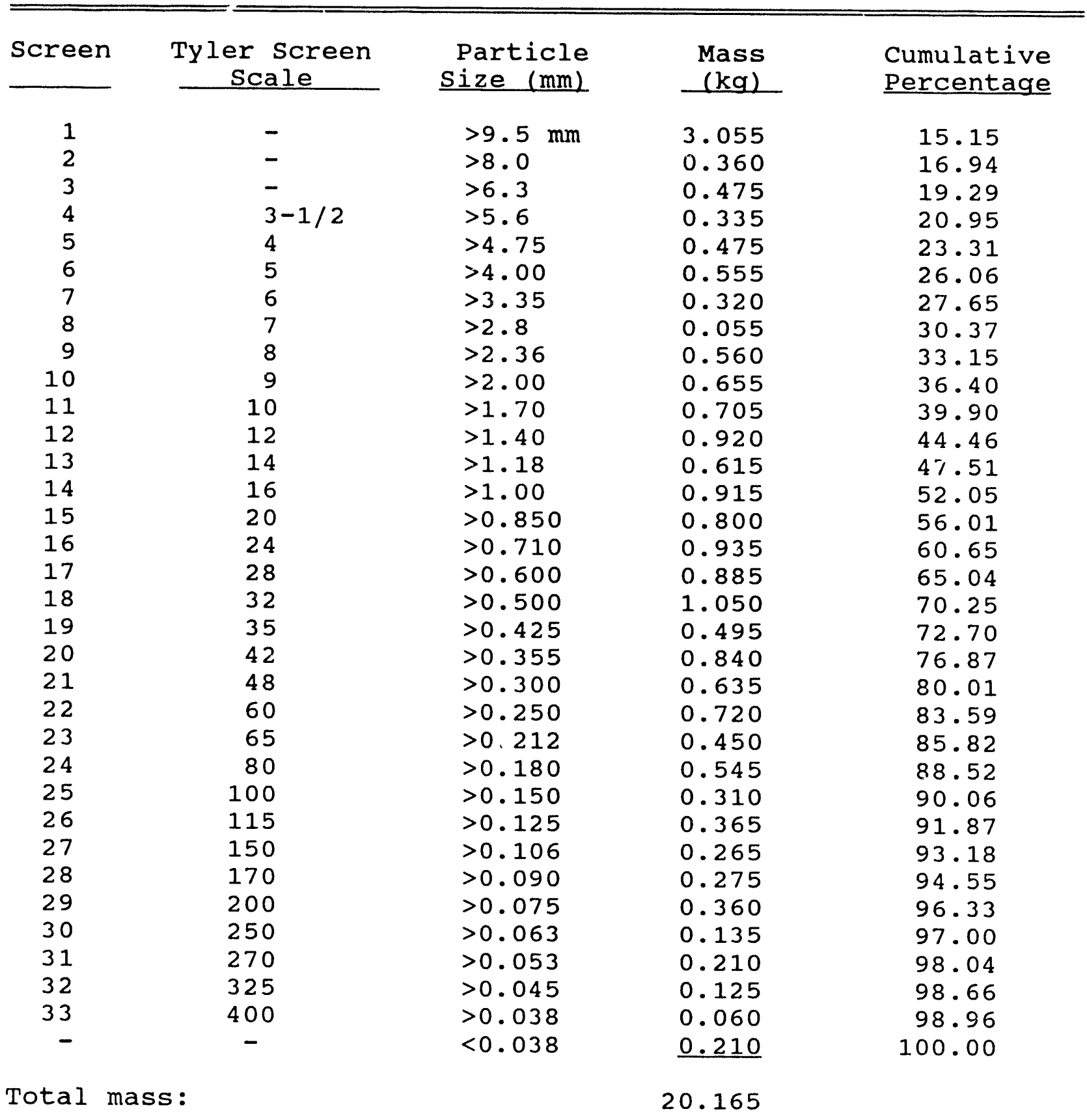

Notes: The sieve analysis summarized in this table was for debris recovered from the lower head of the surtsey vessel. 


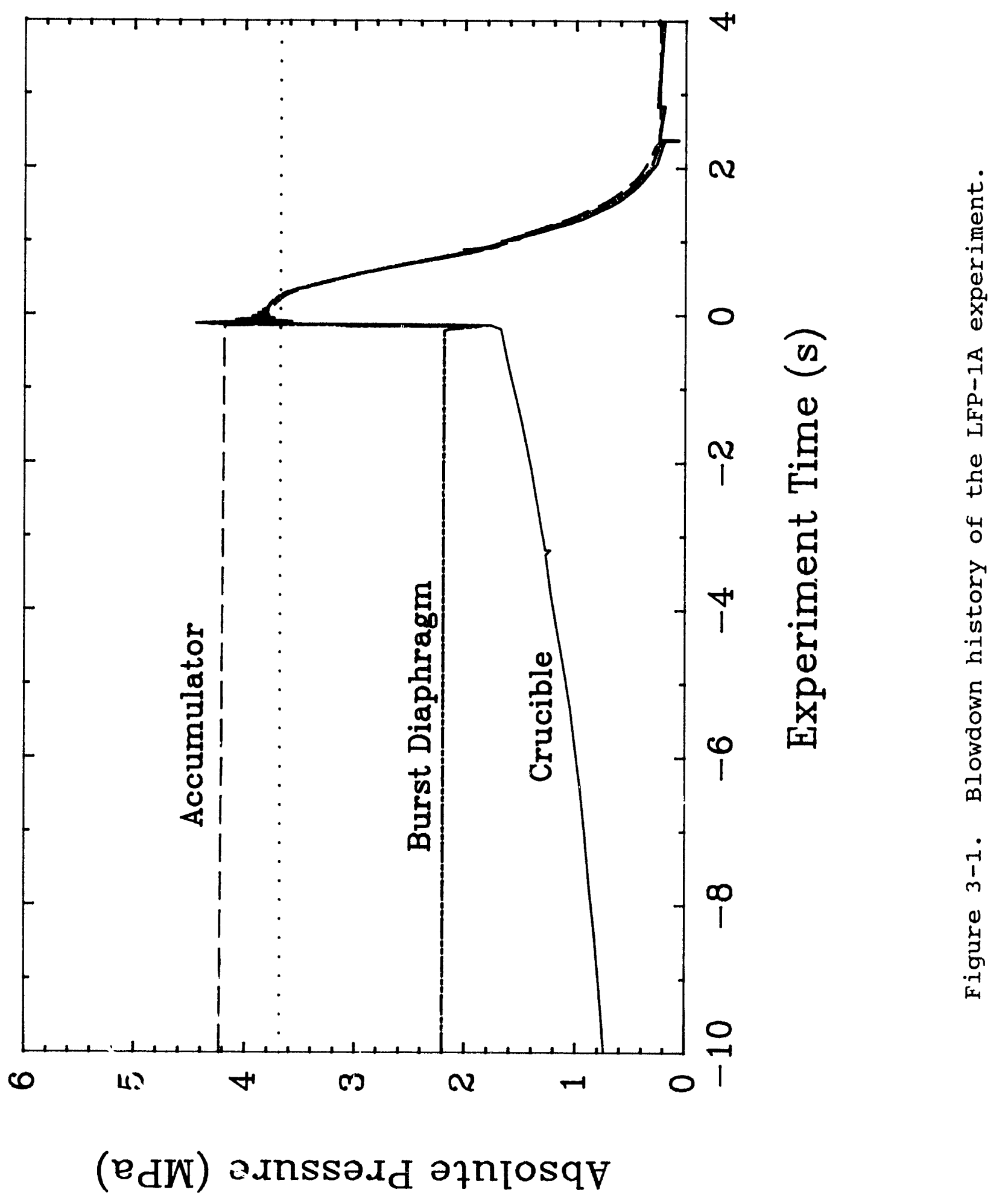




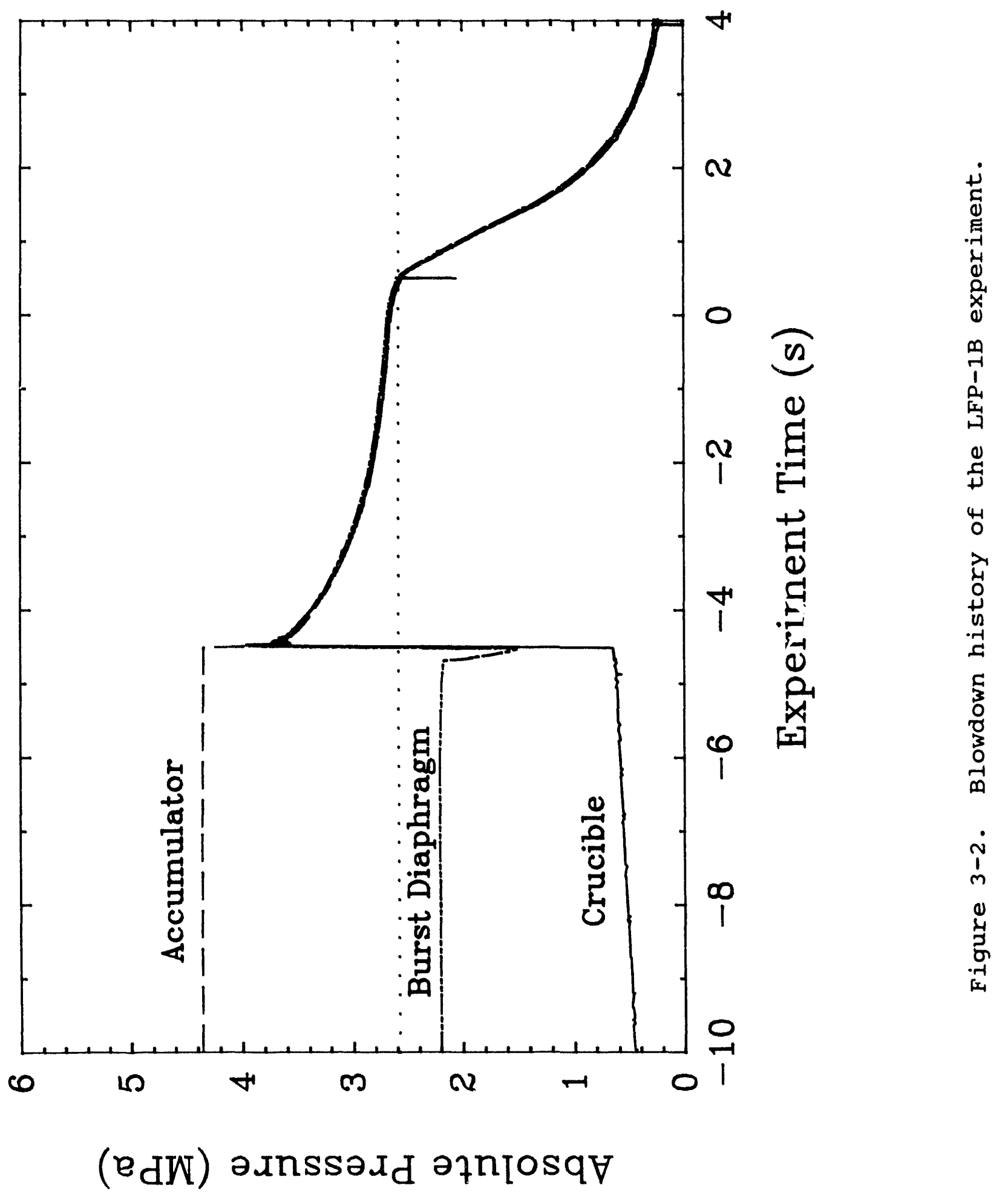




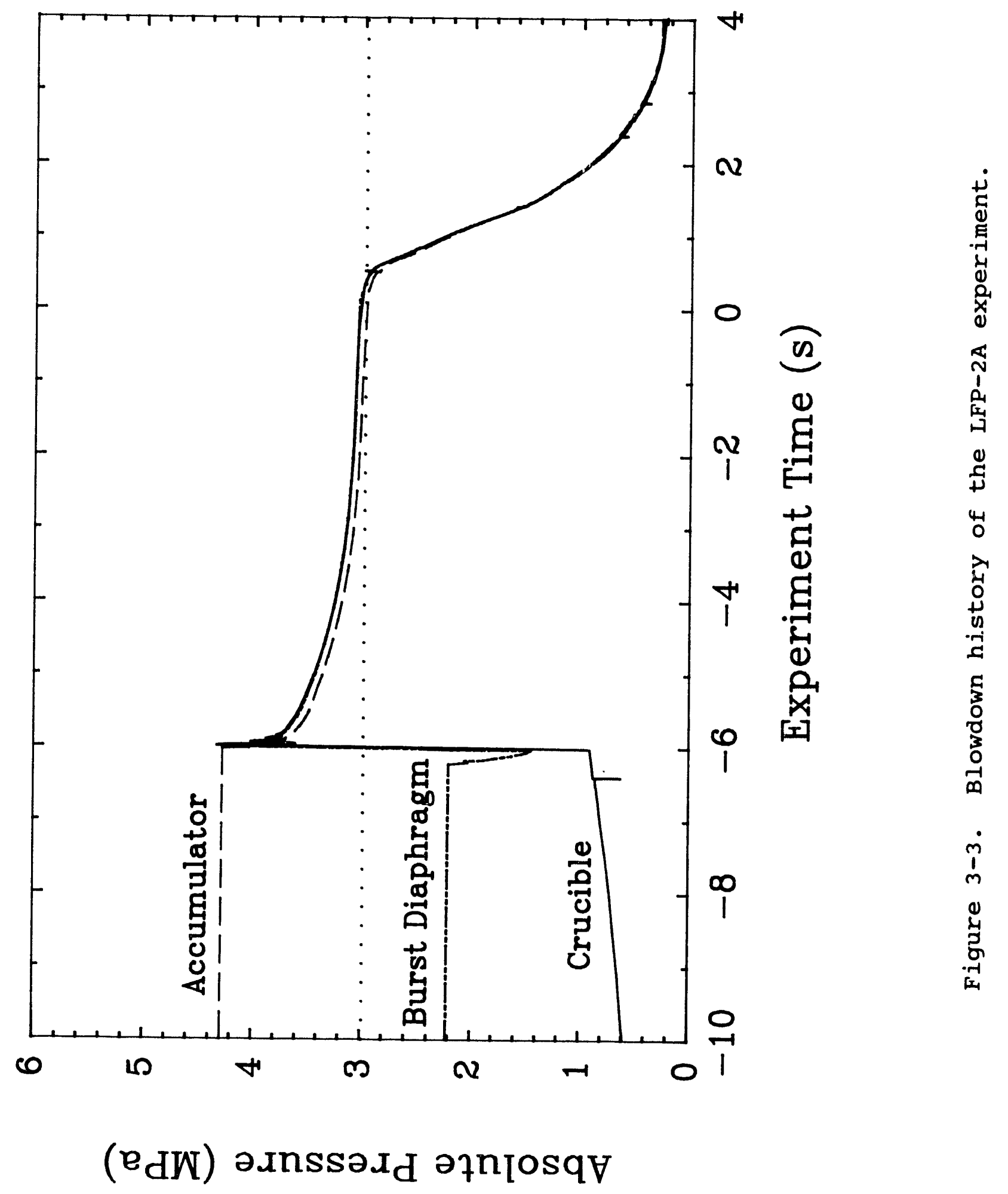




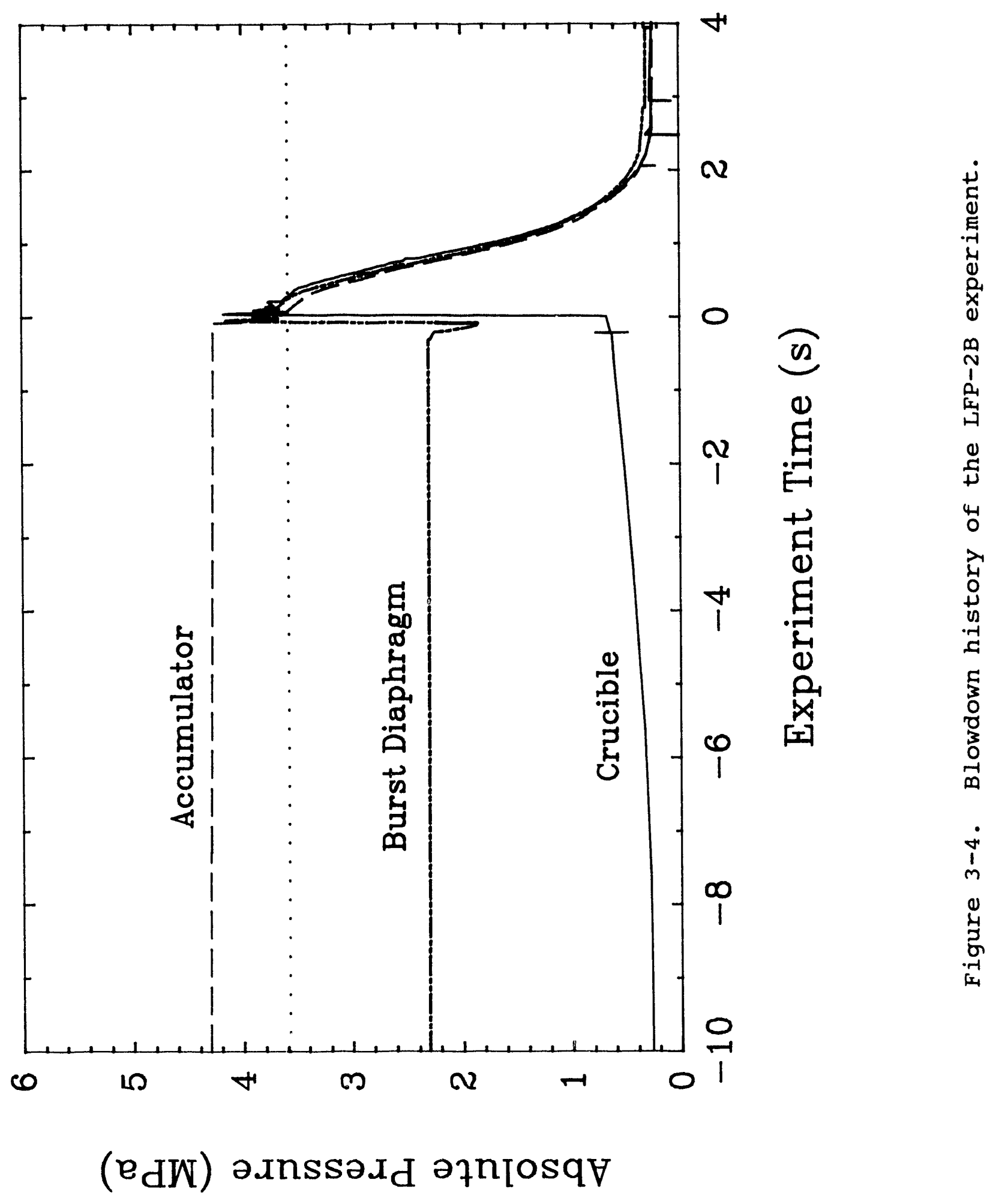




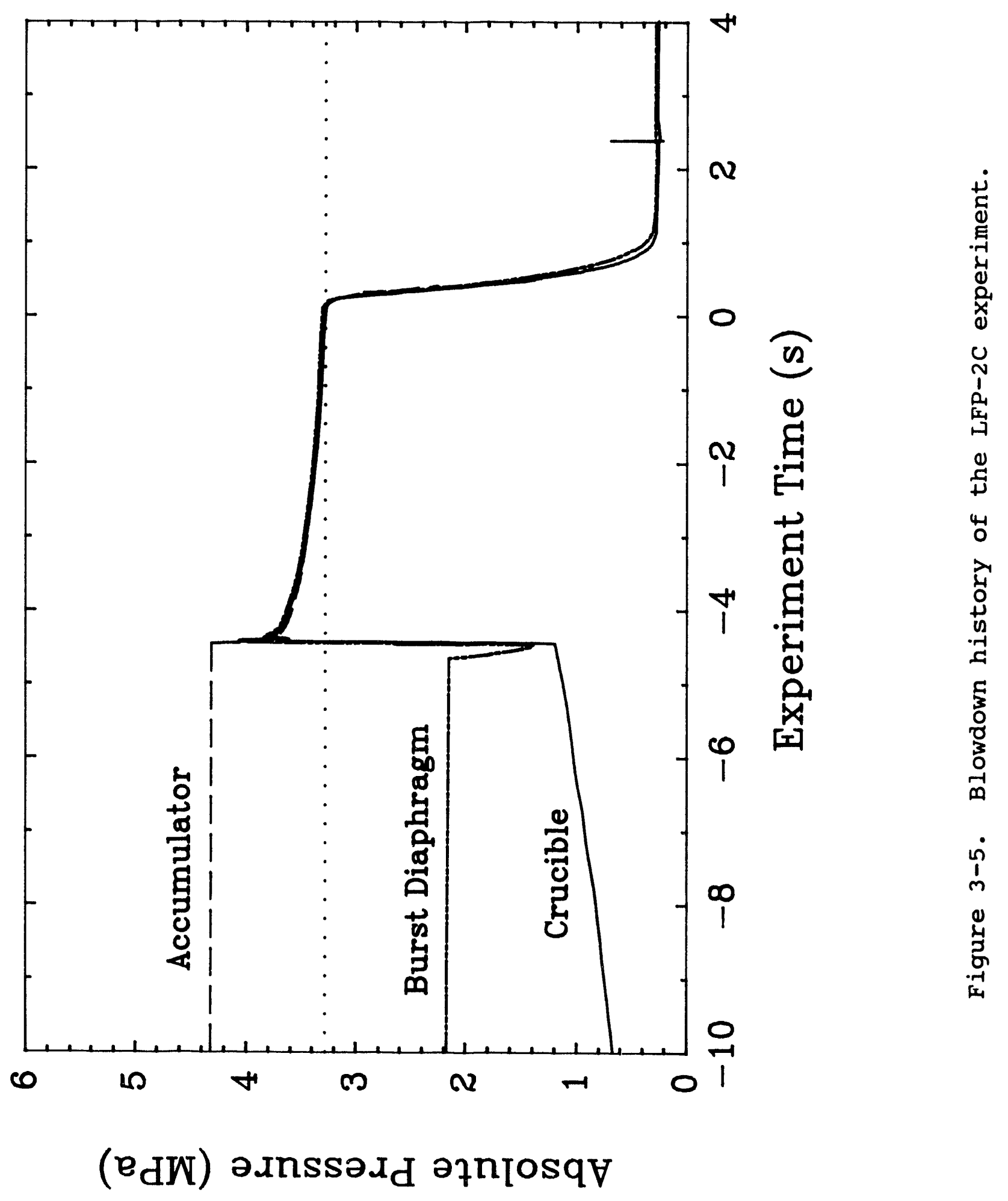




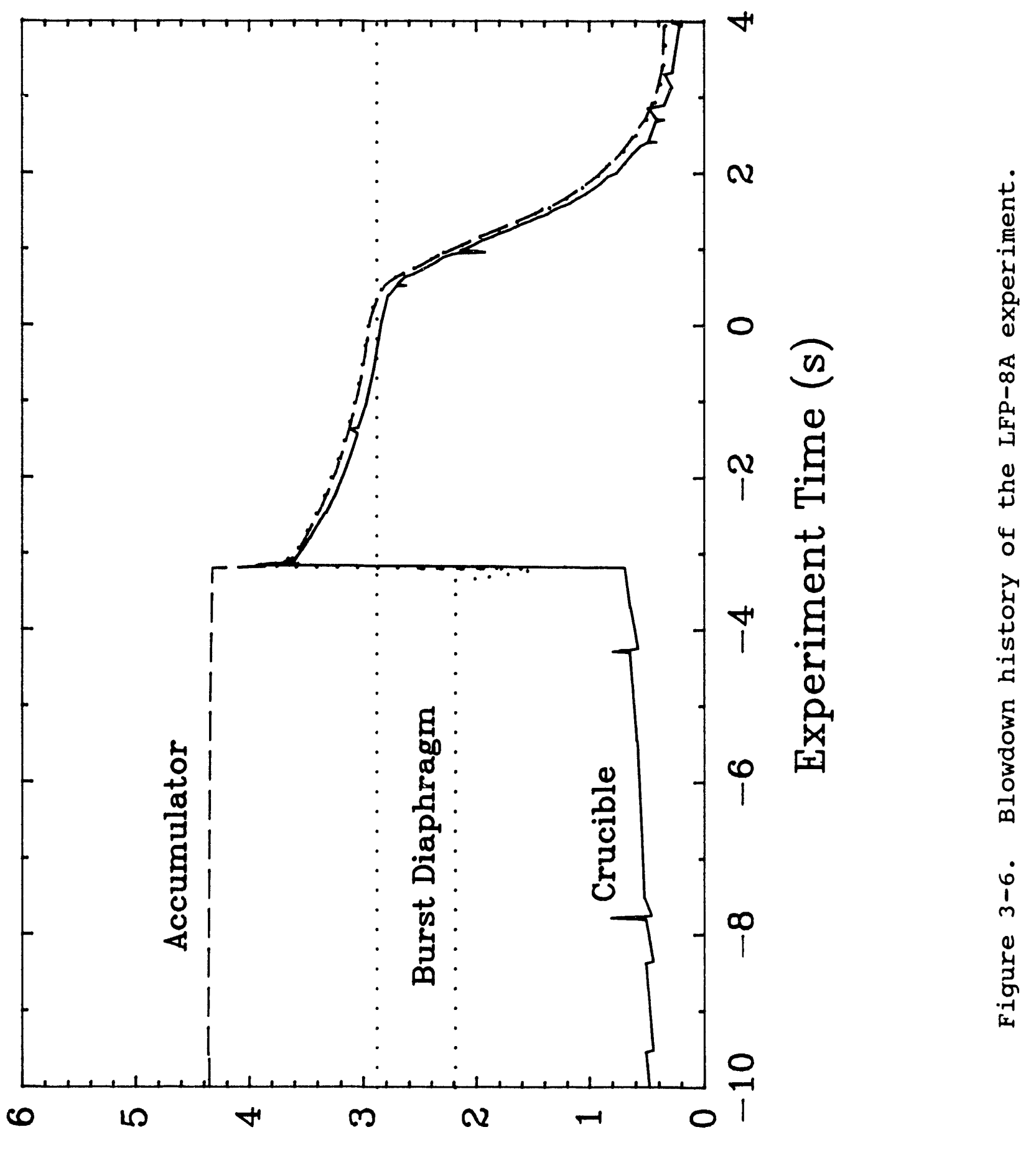

$\left(e_{d W}\right)$ əxnssa $x_{d}$ әาnโosqH 


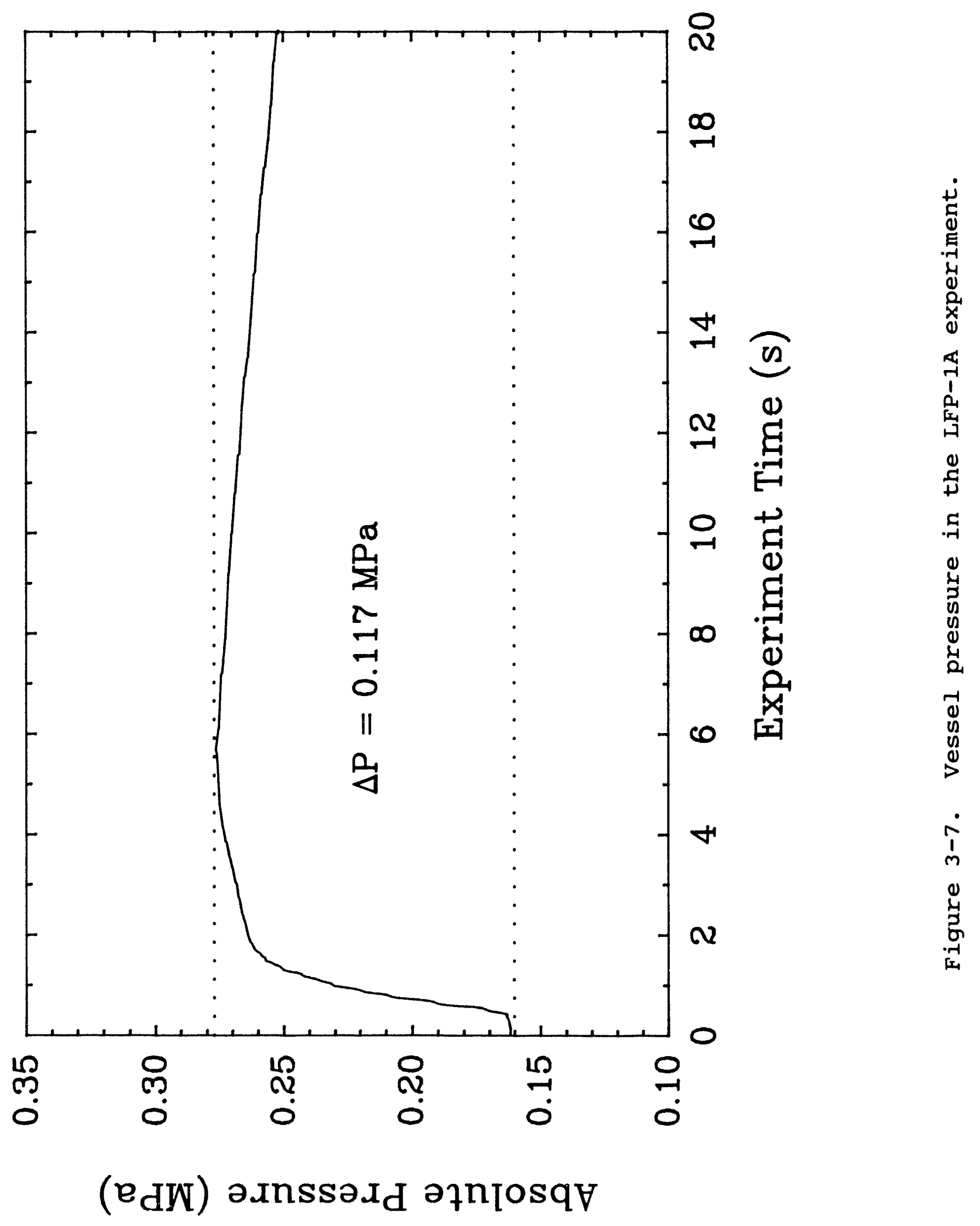




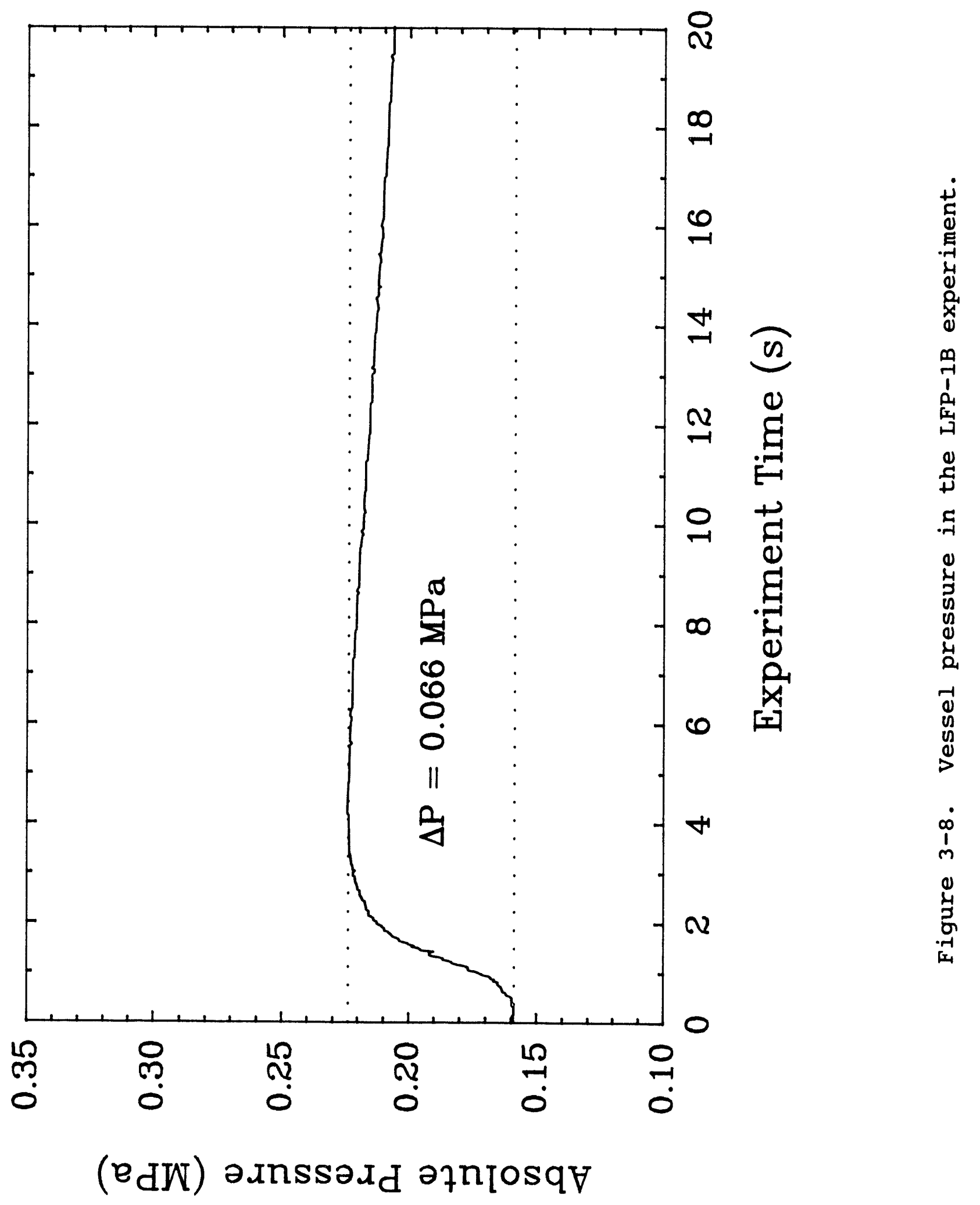




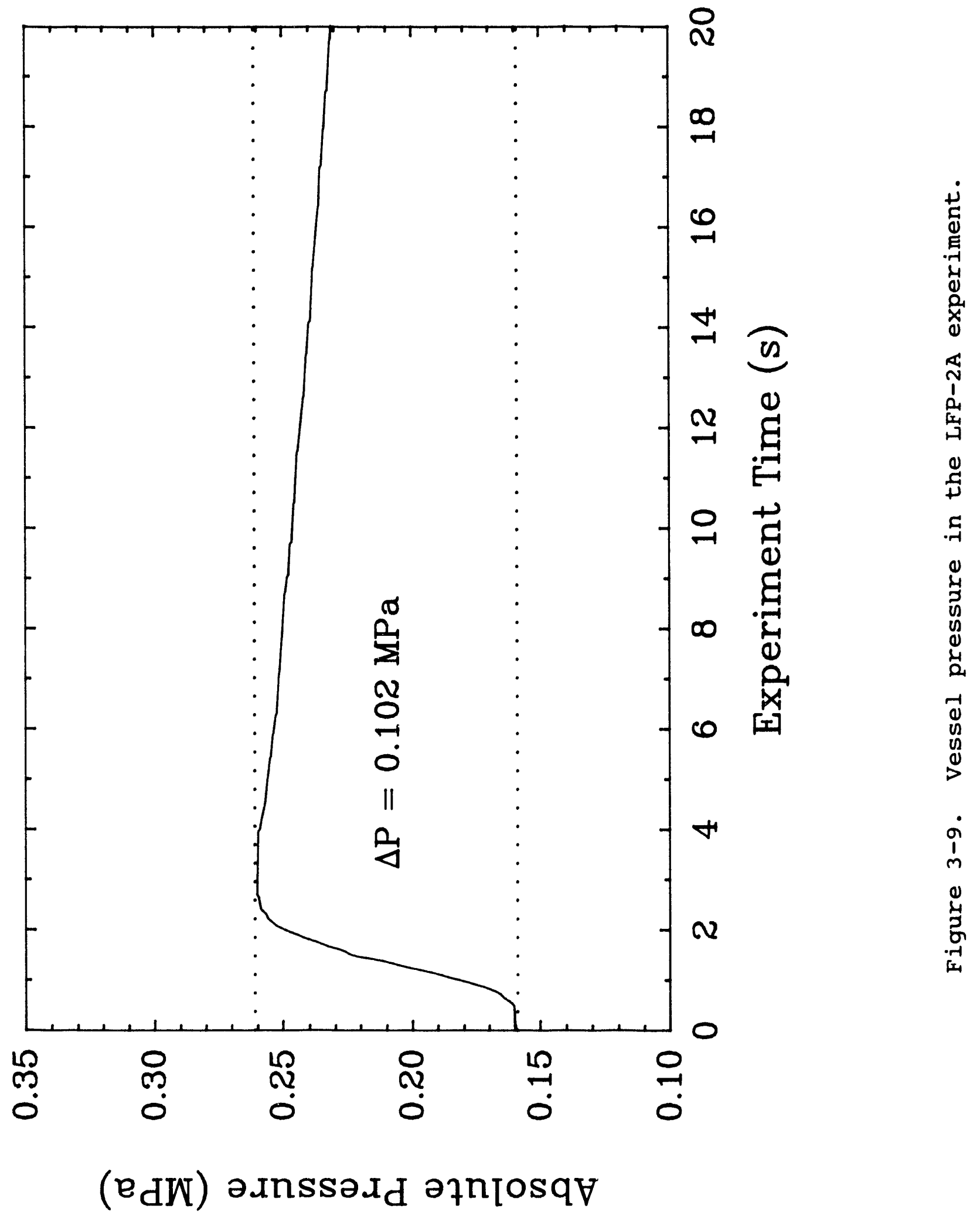




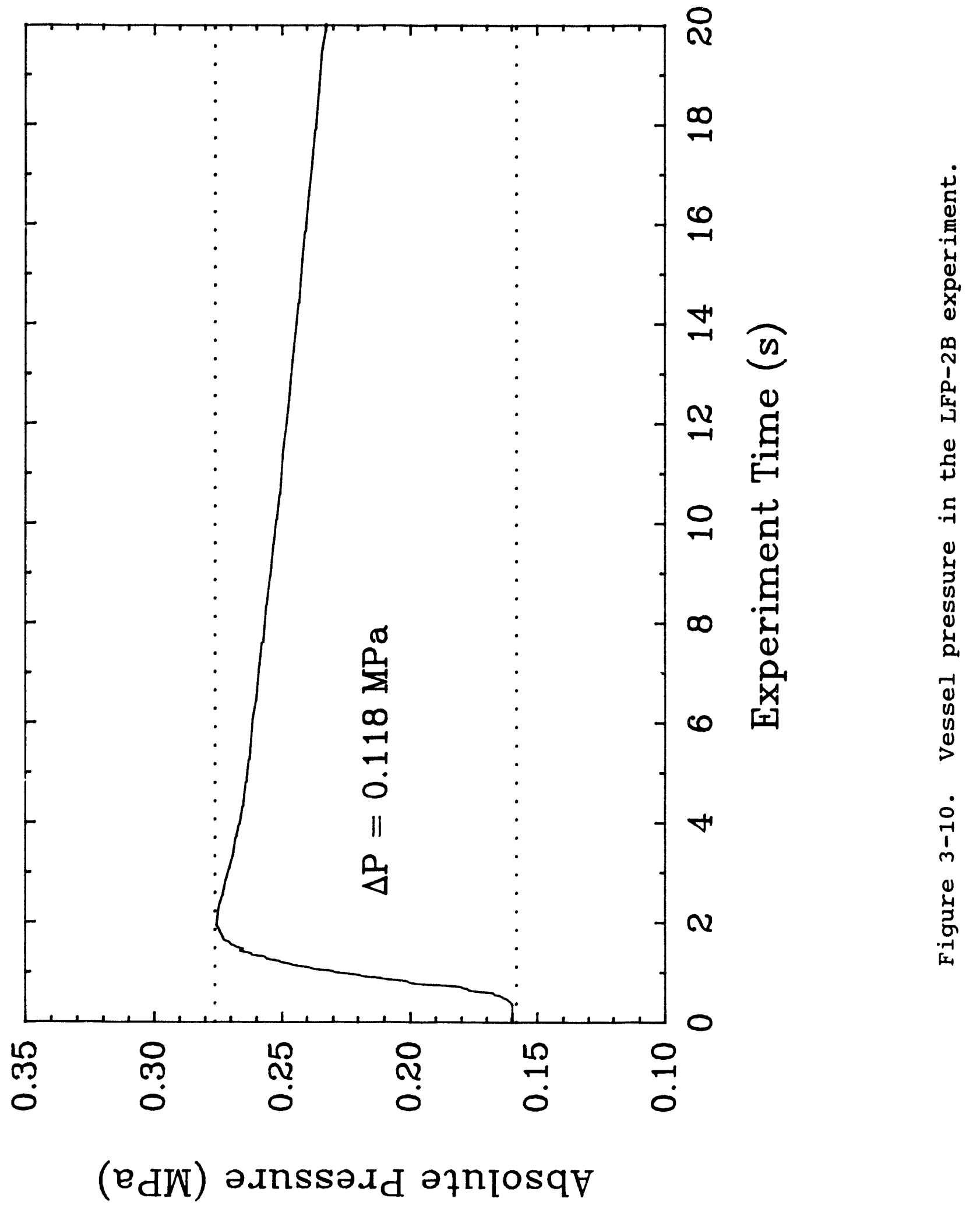




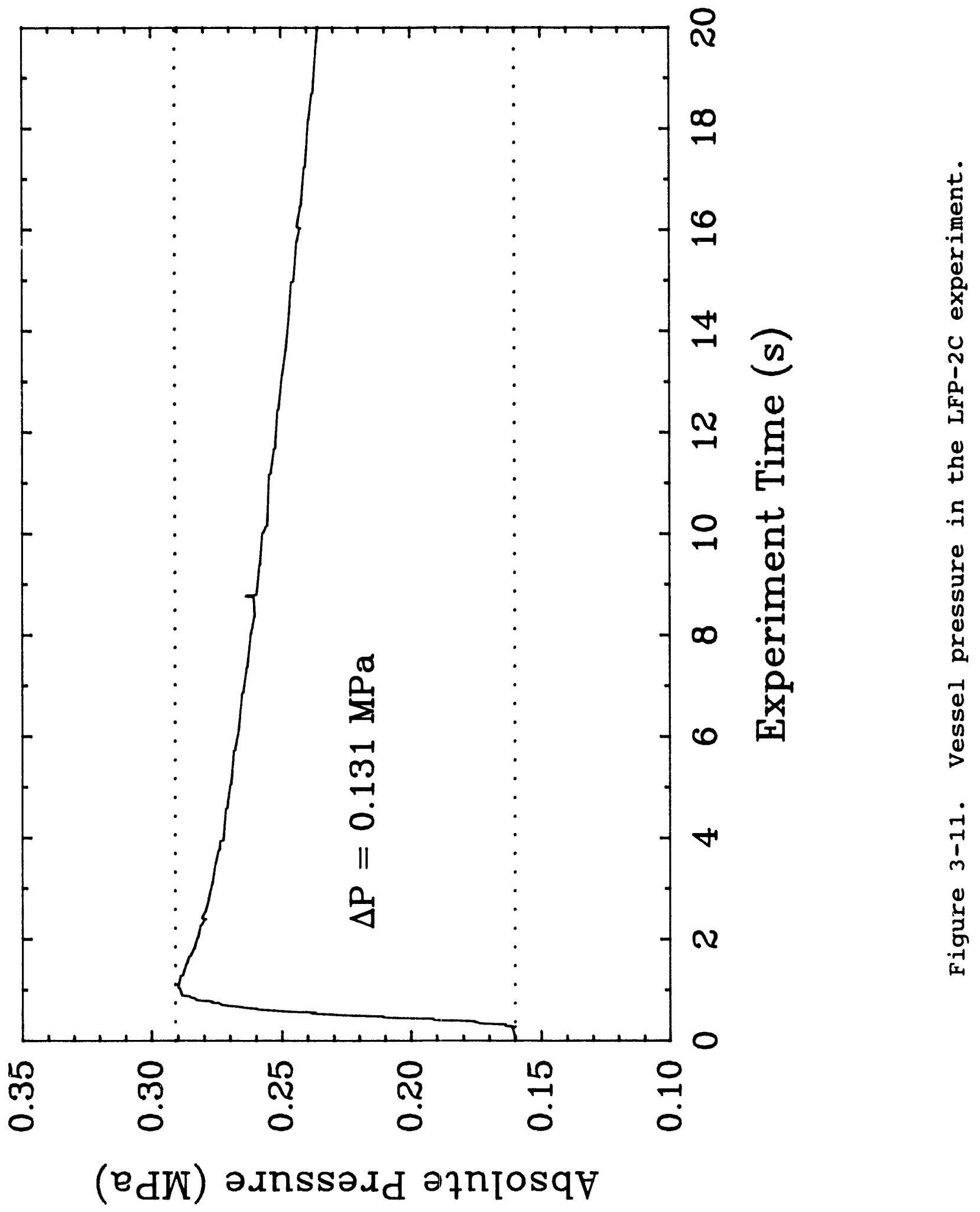




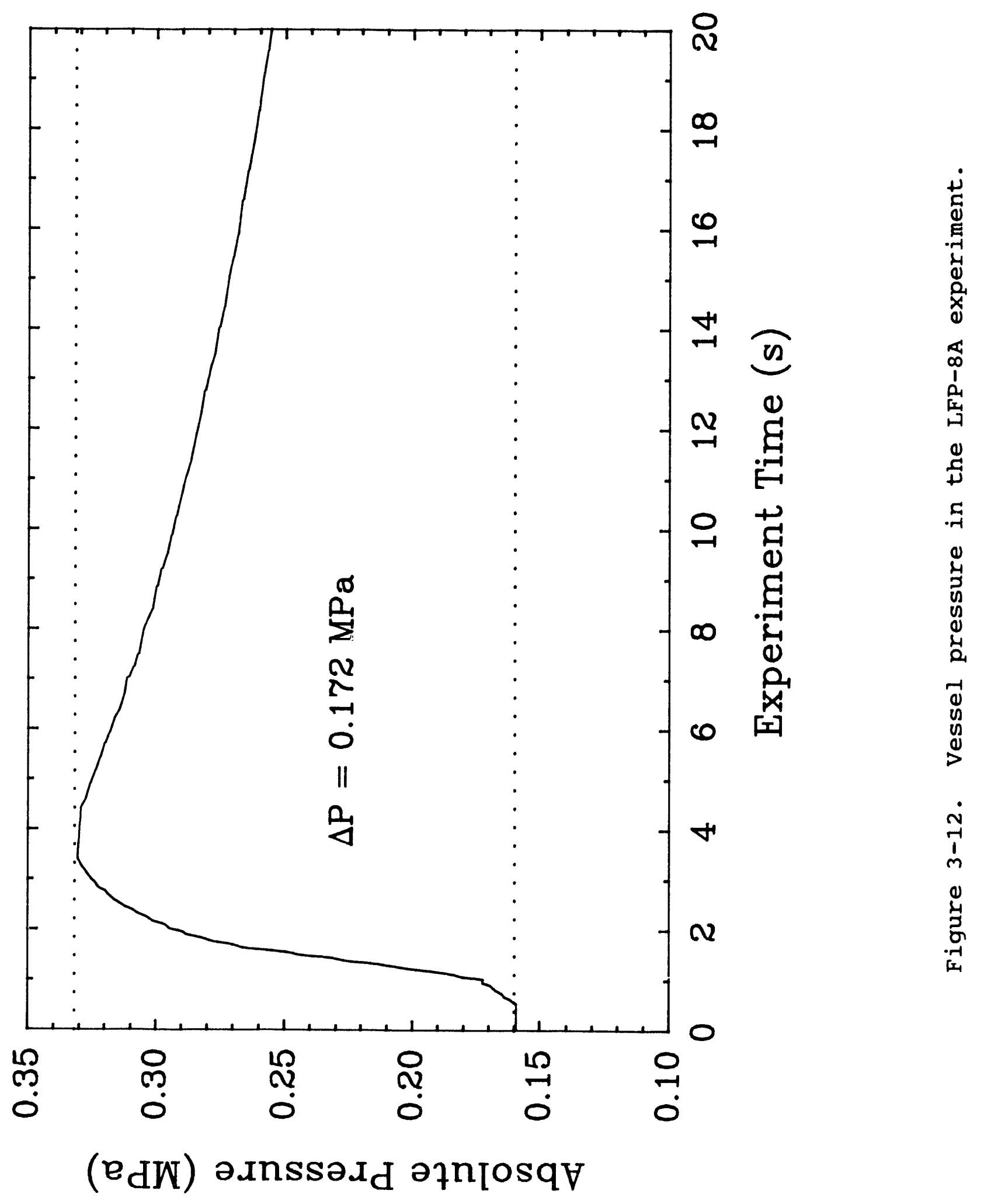




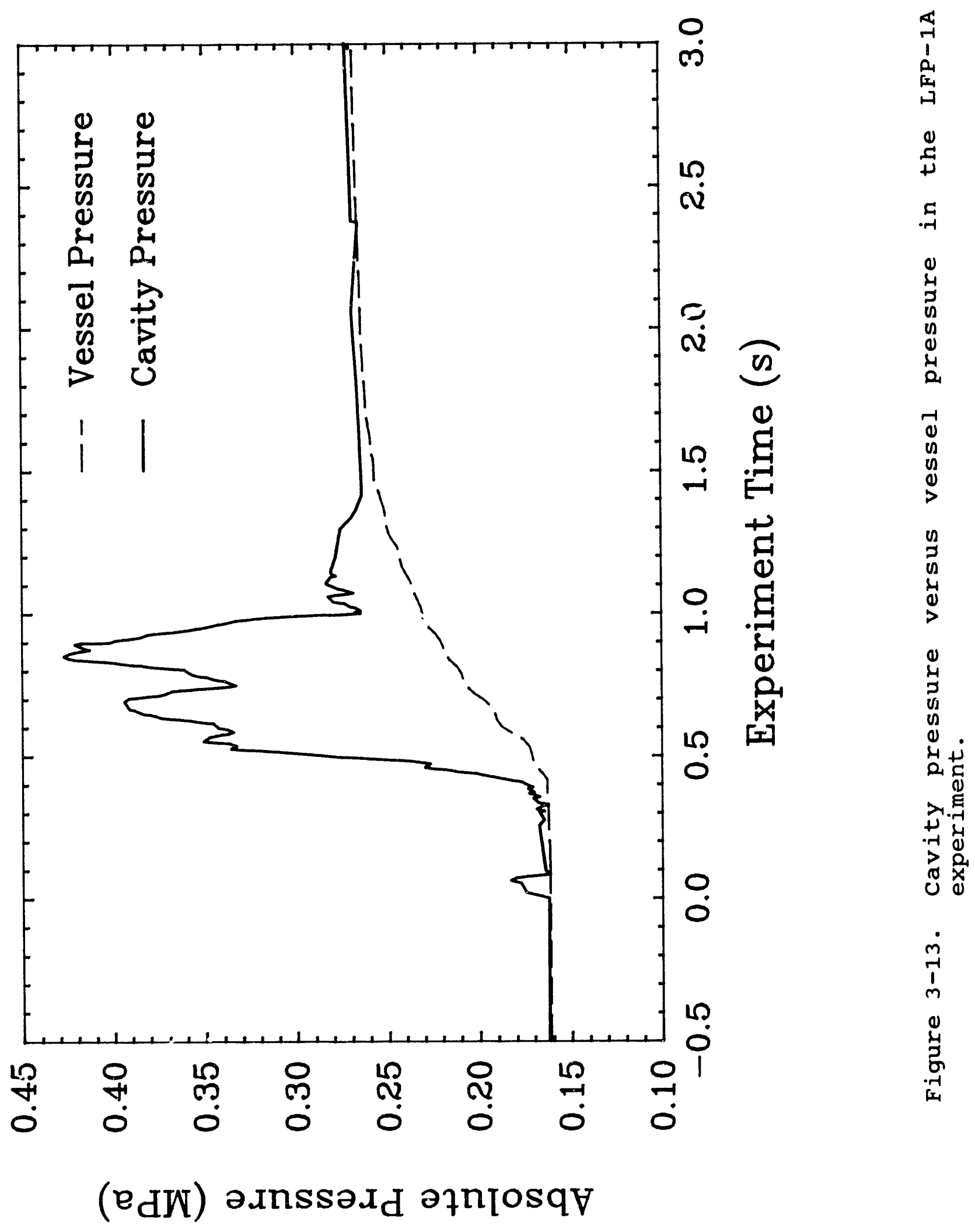




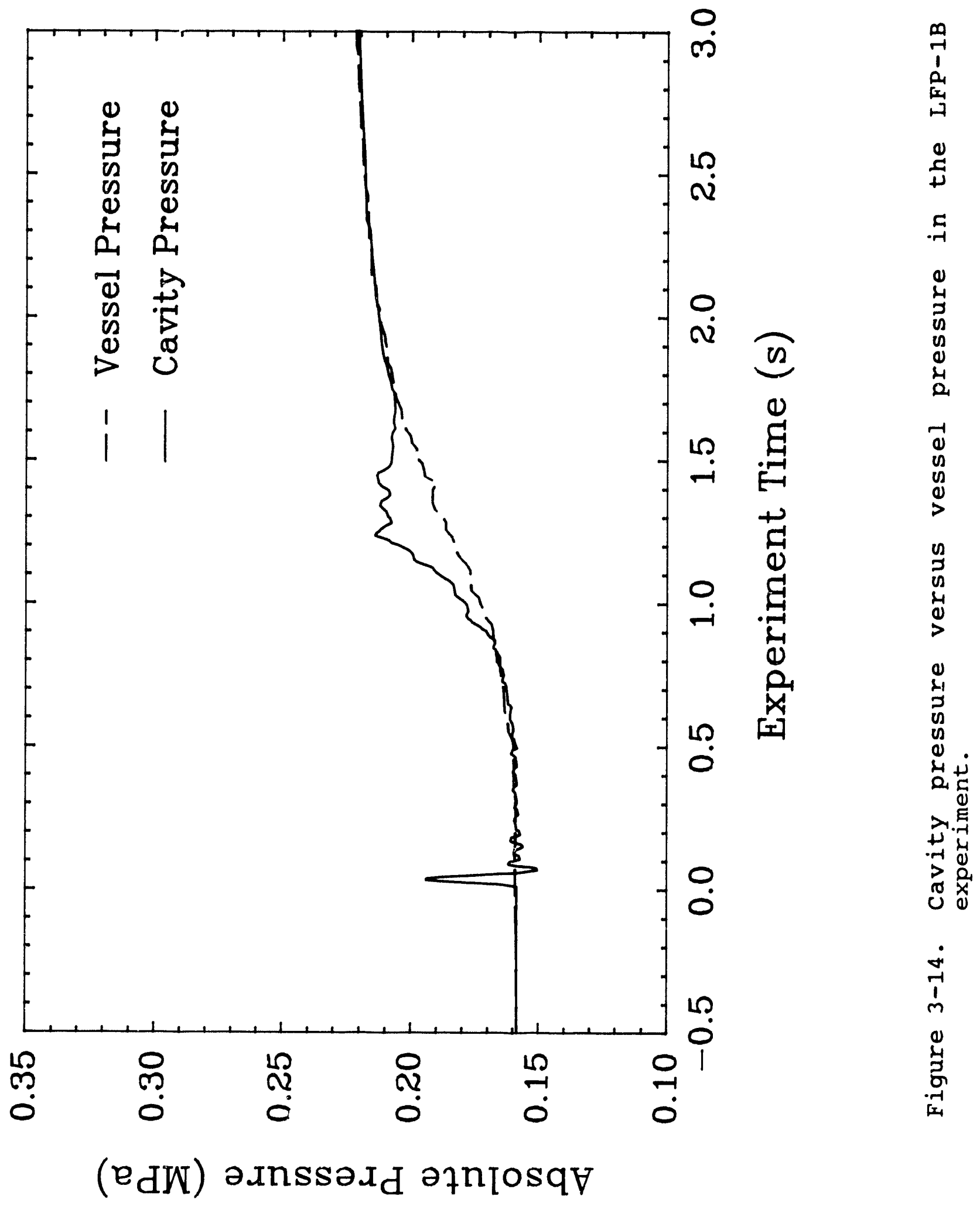




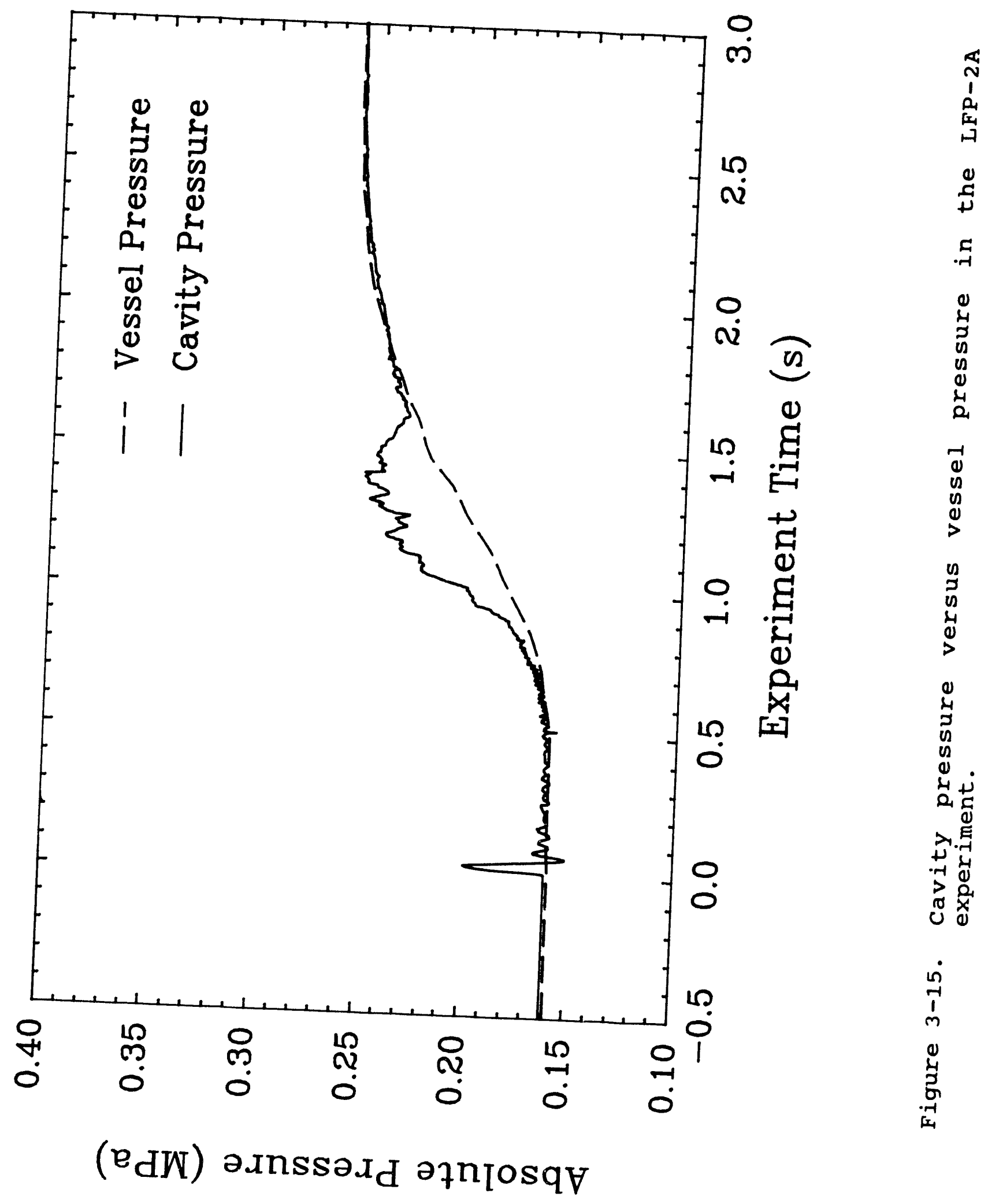




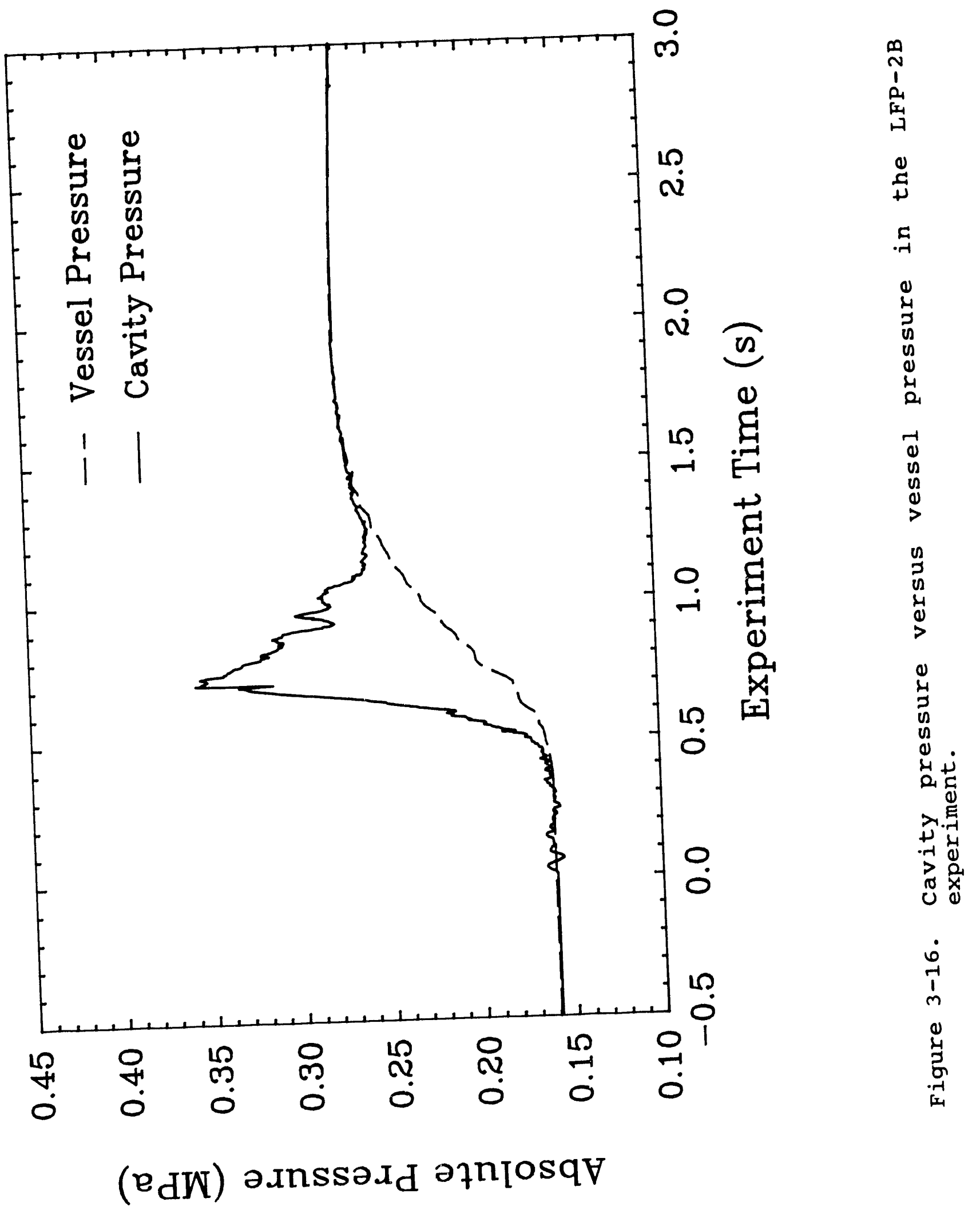




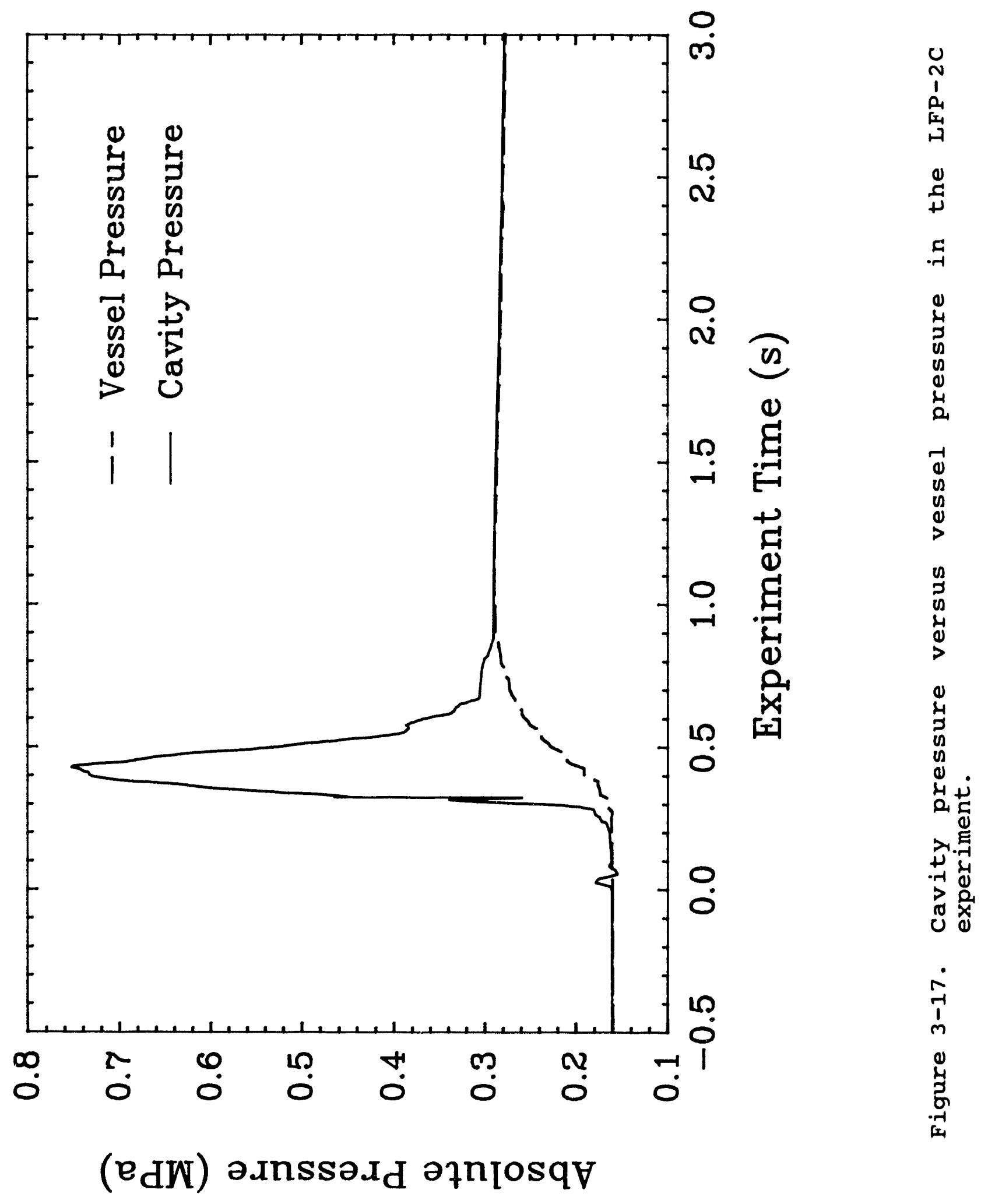




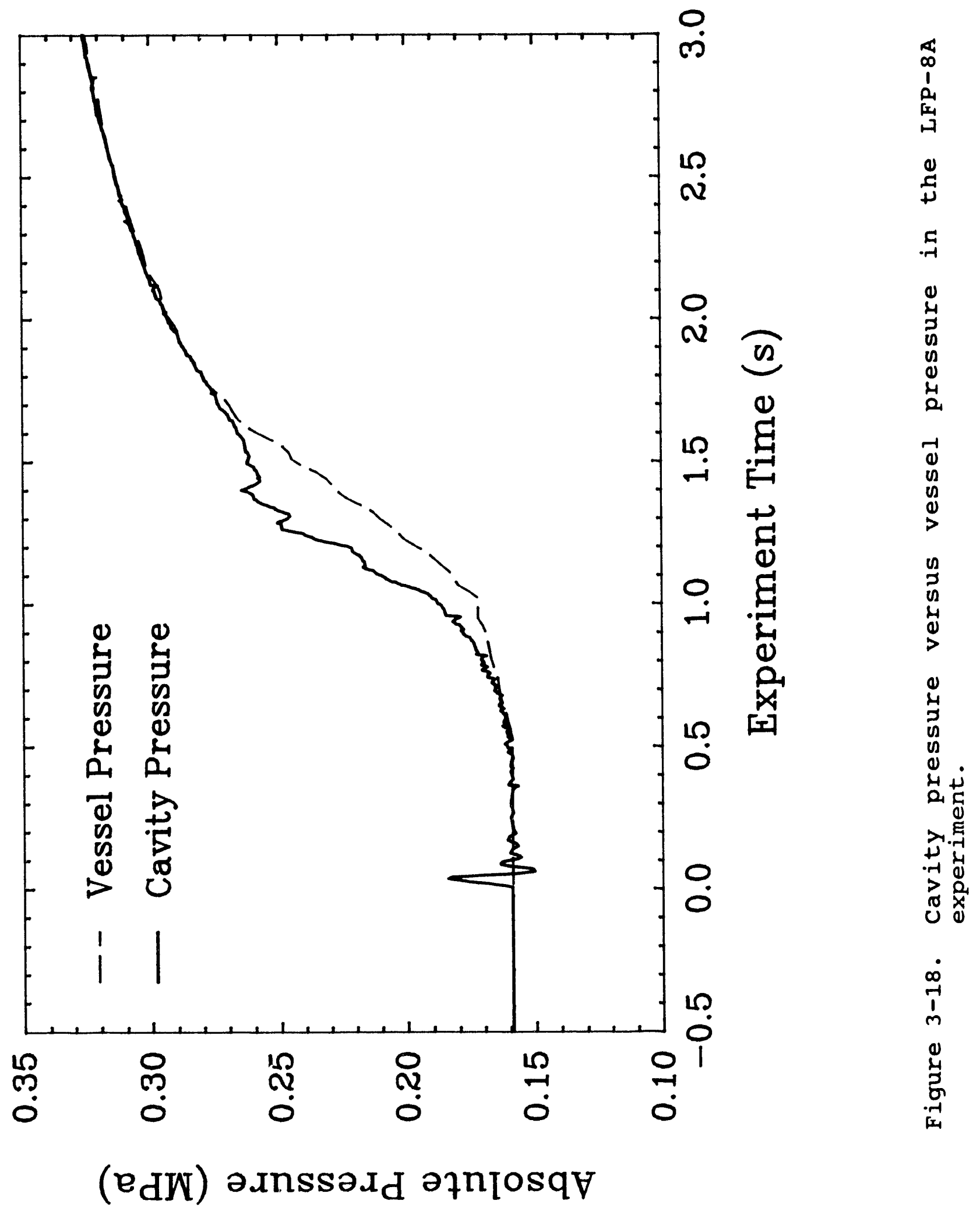




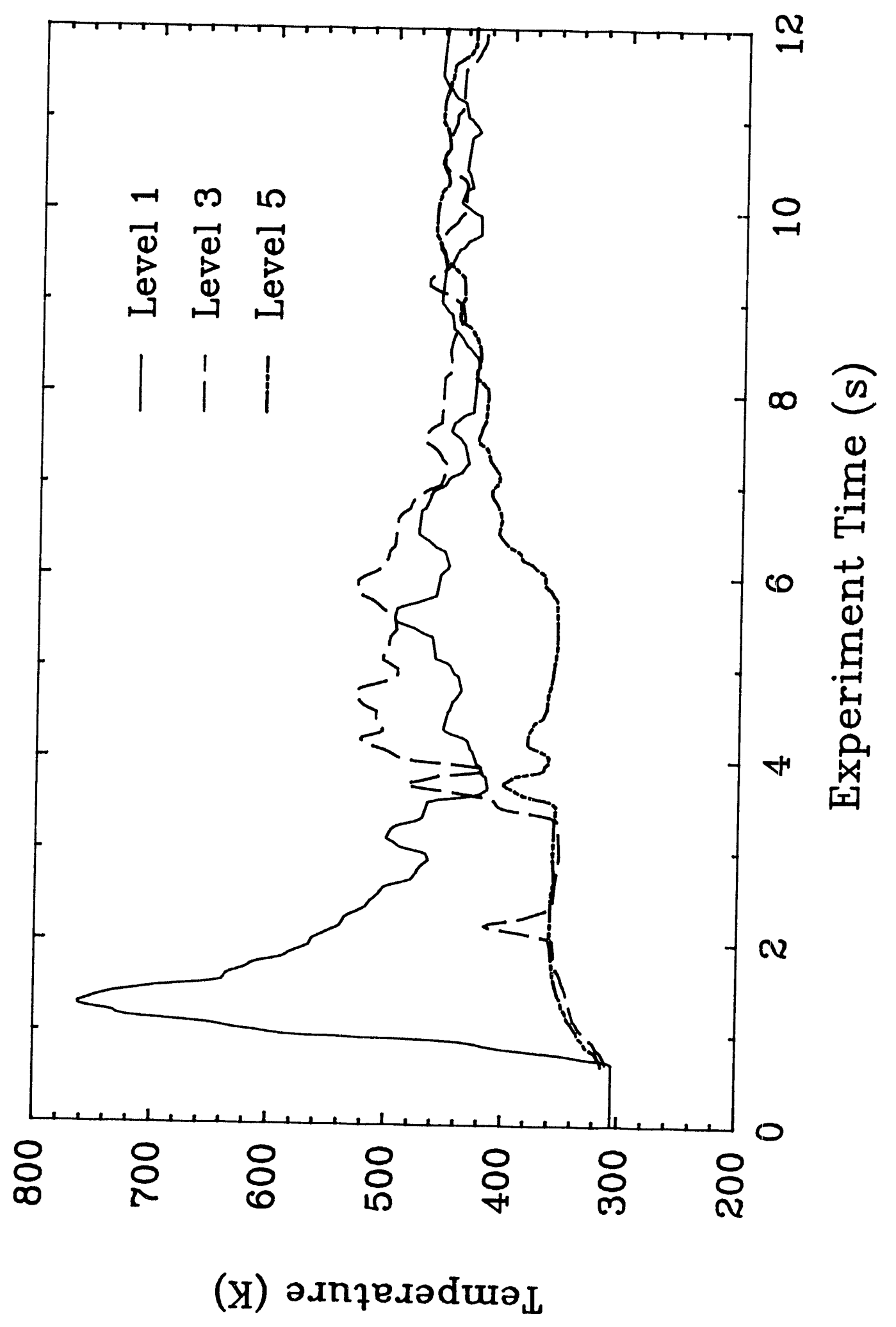

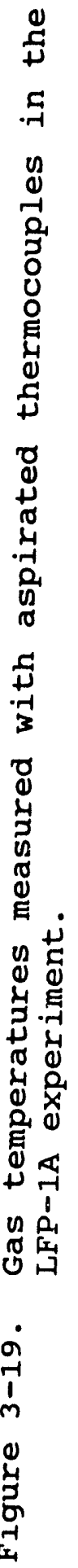




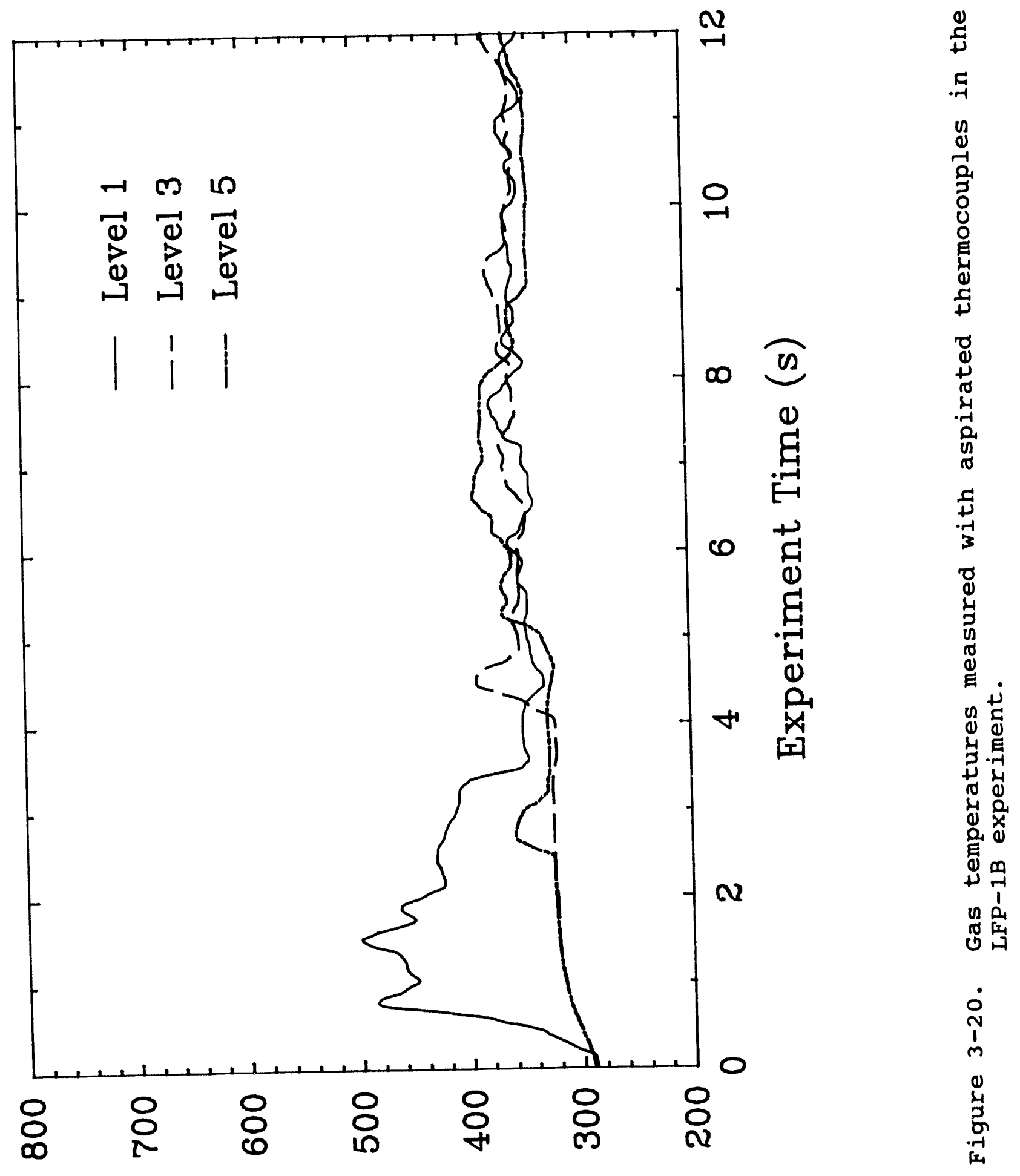

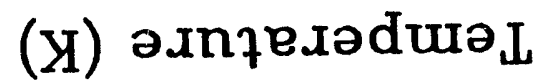




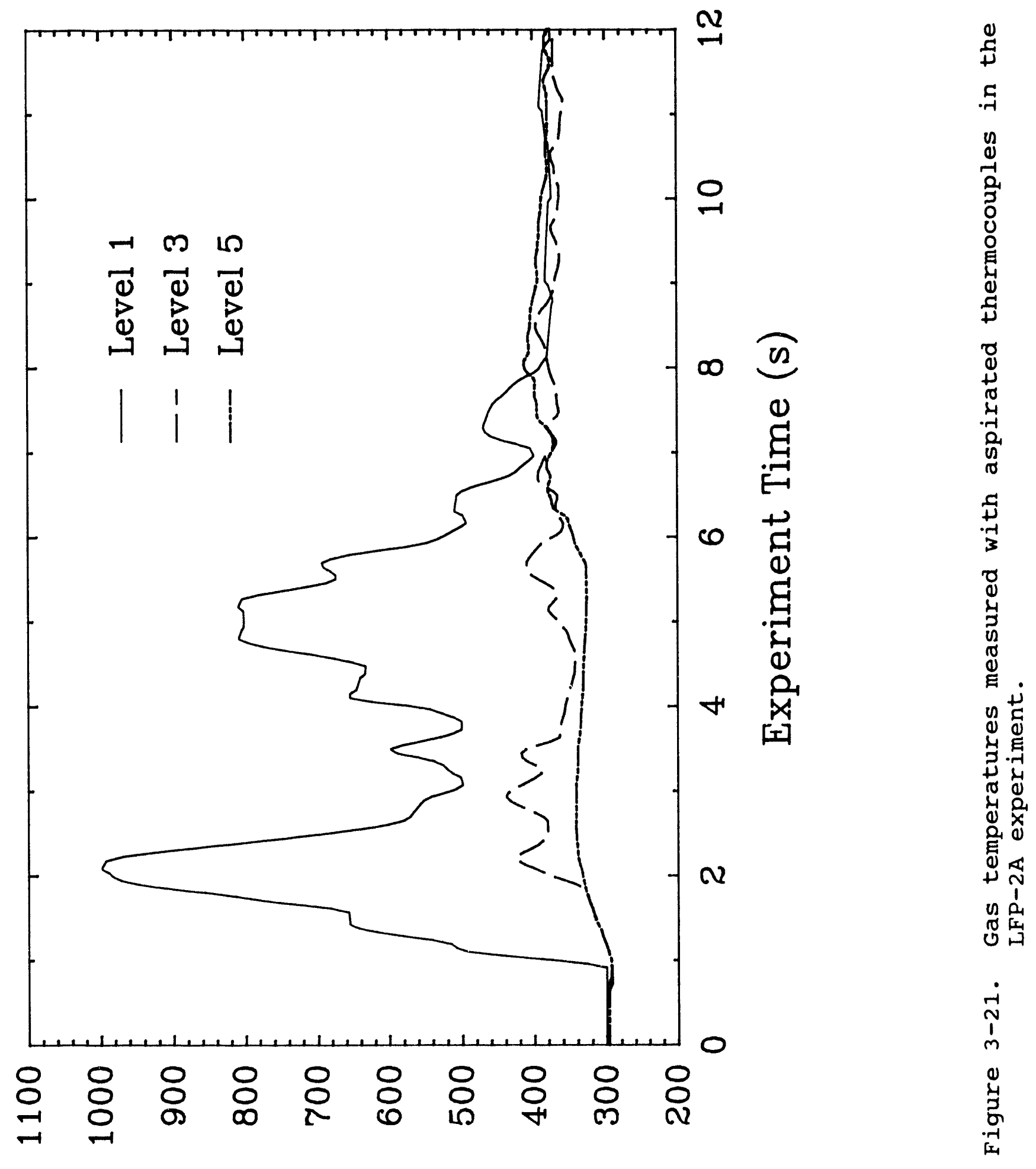

(צ) әлnреләduั 


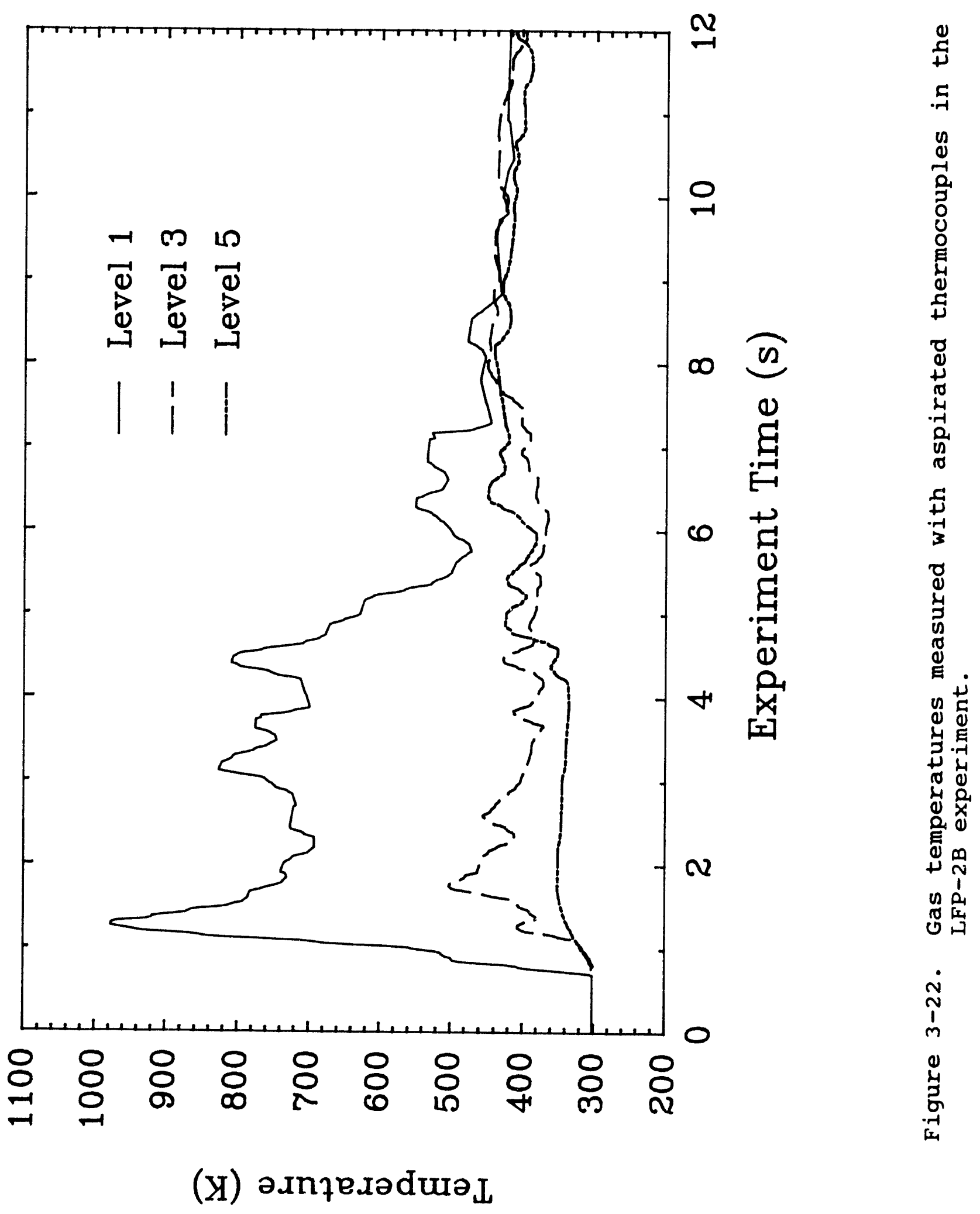




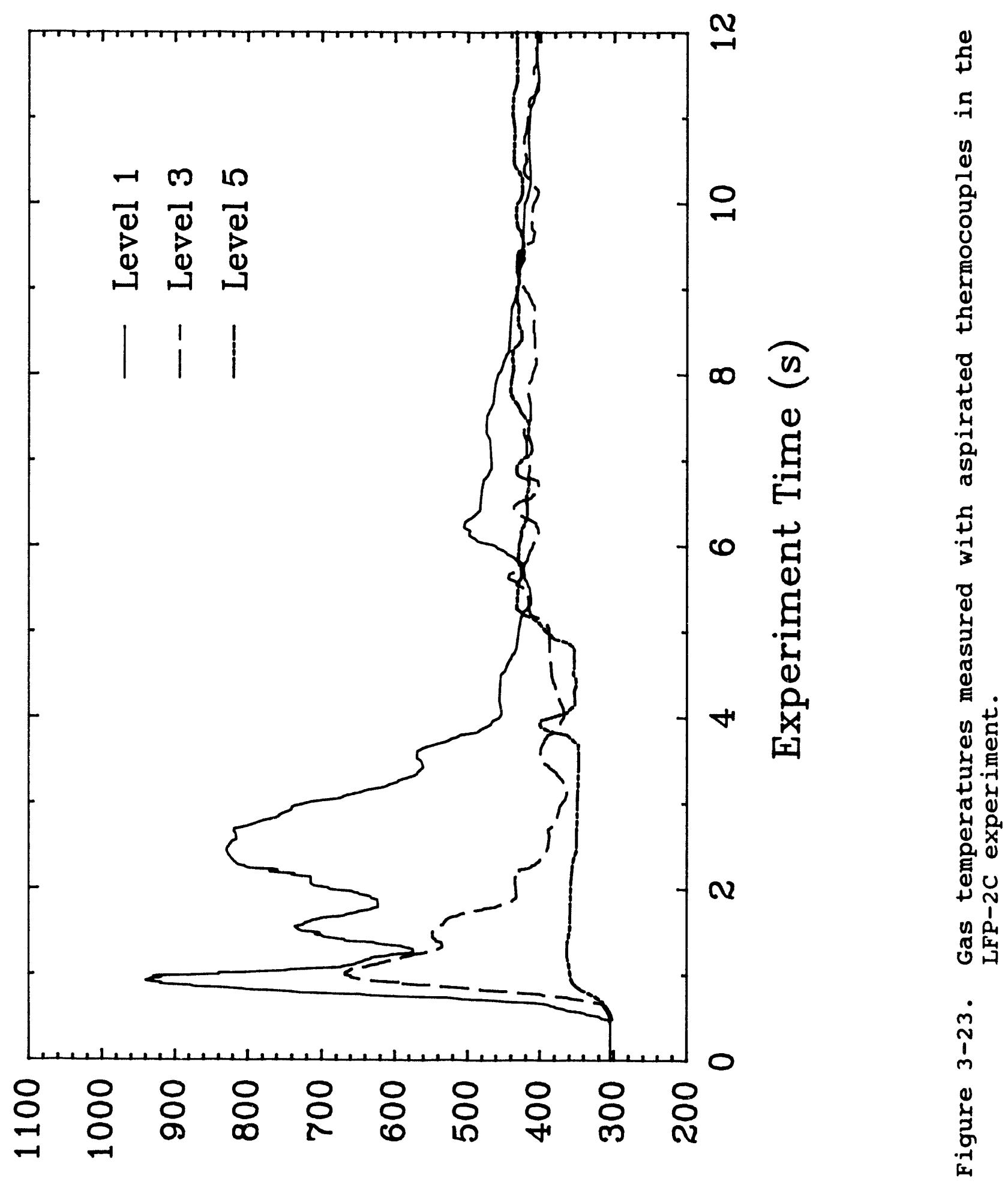

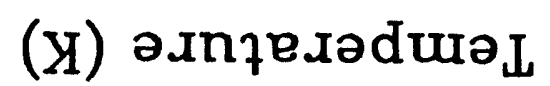




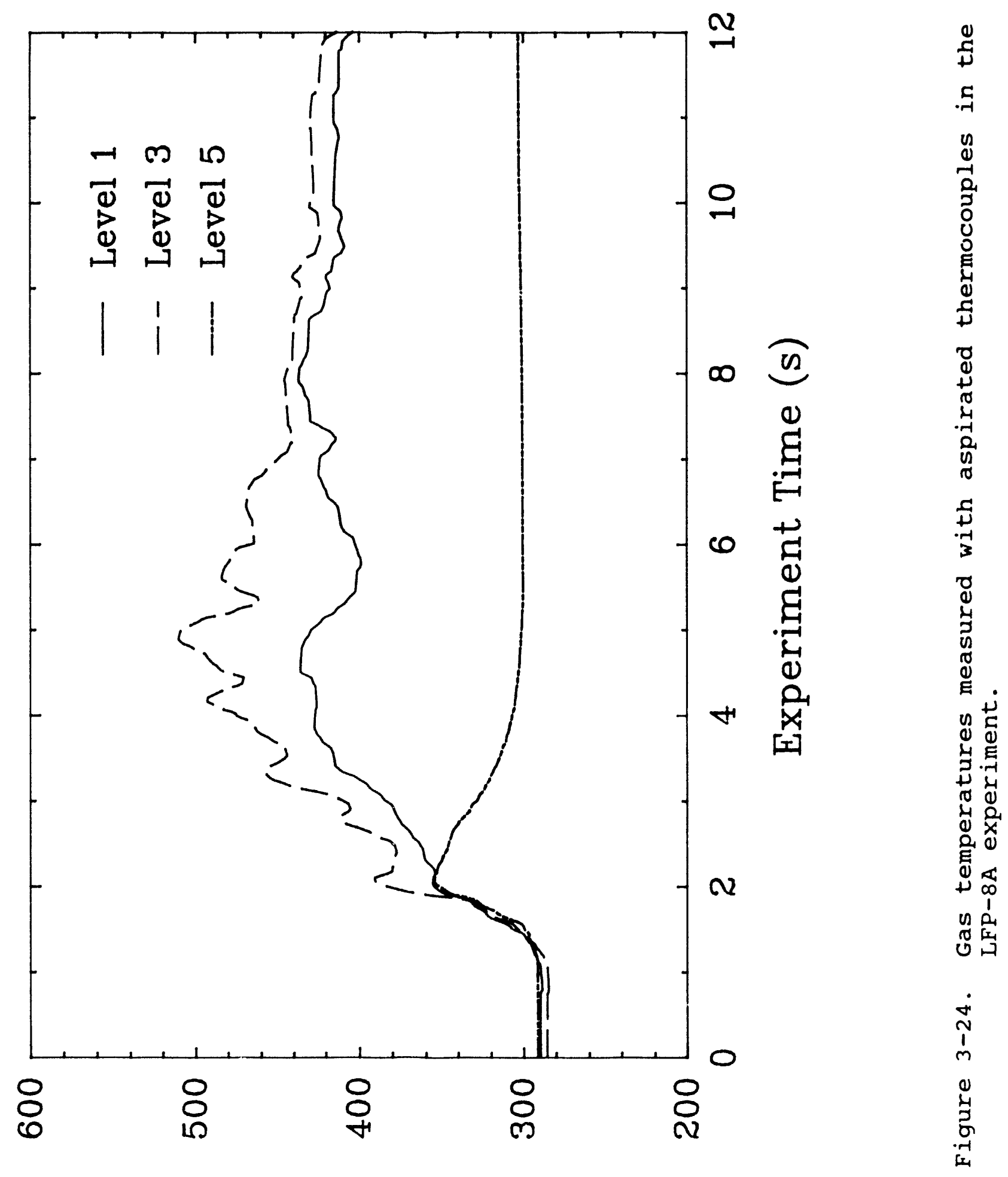

(צ) ә.пһеләduә 


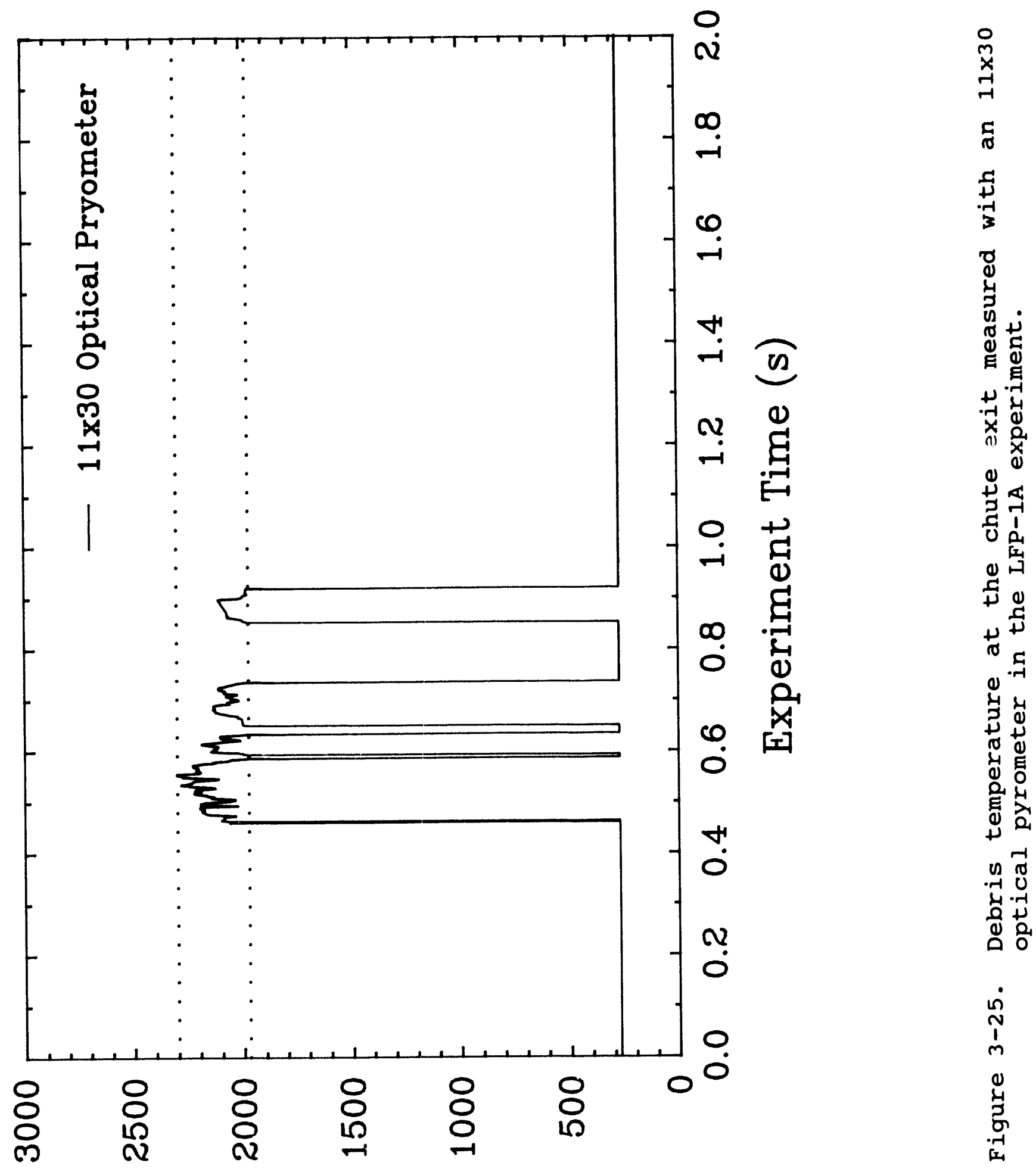

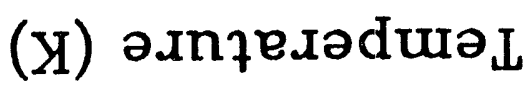




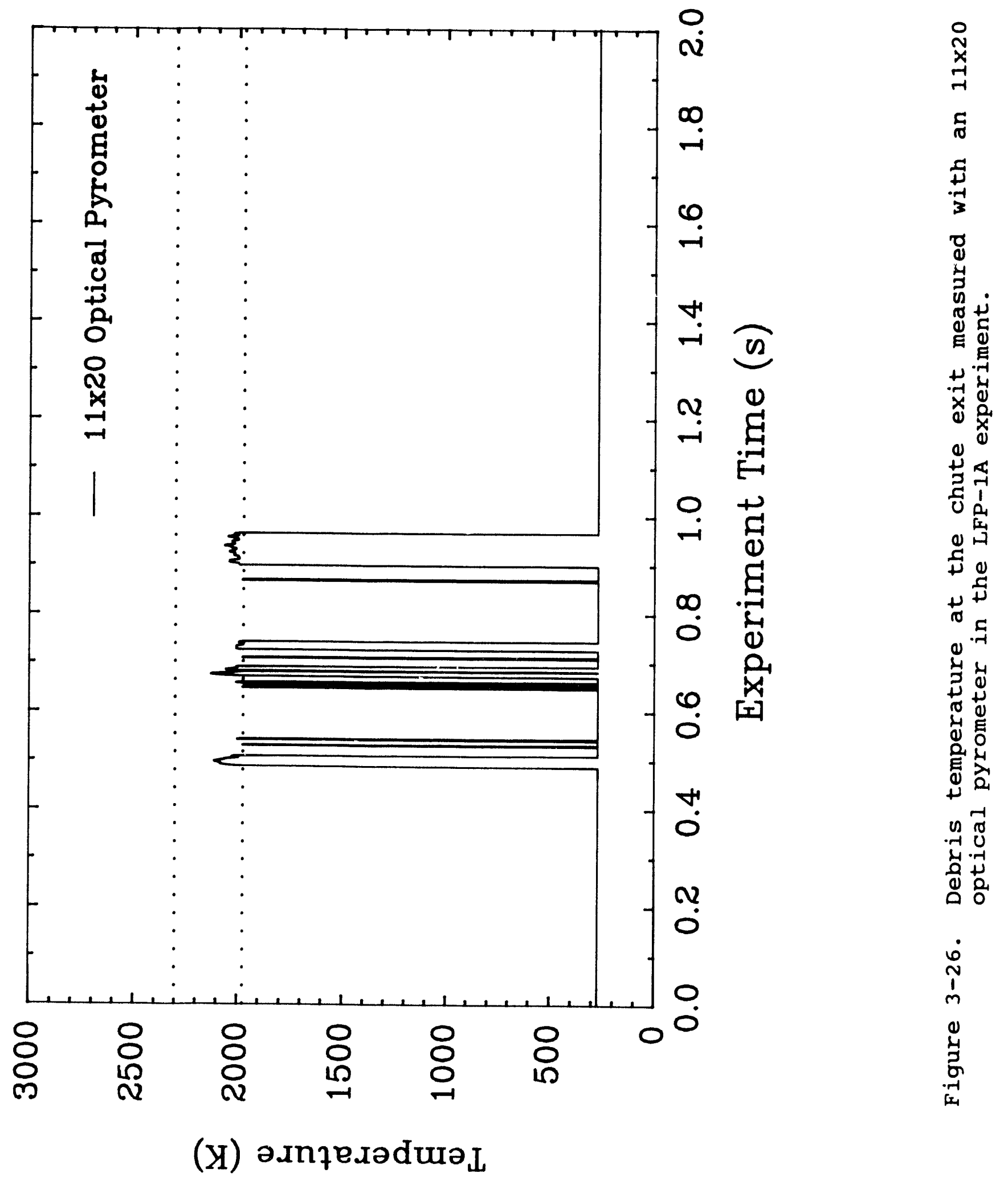




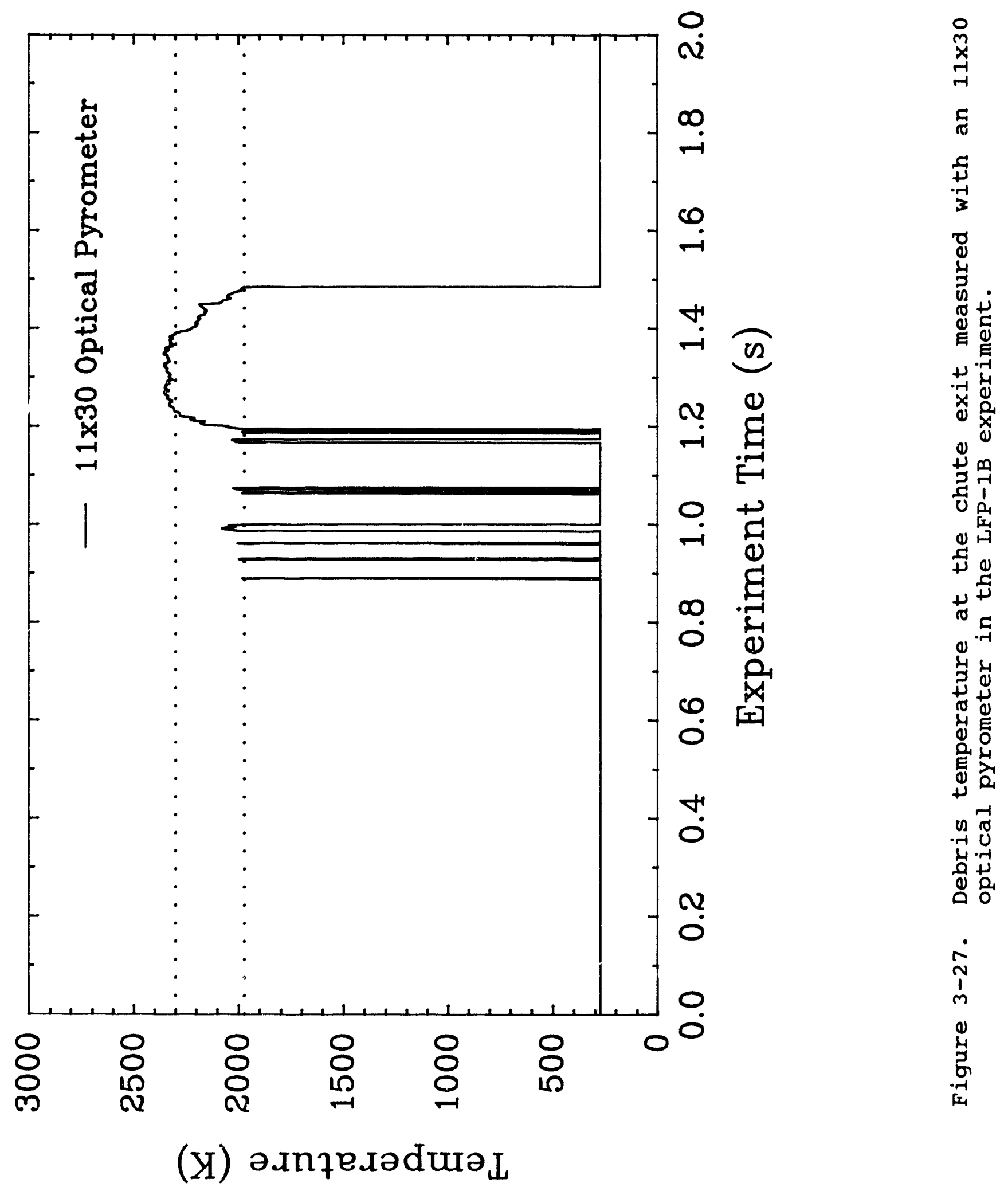




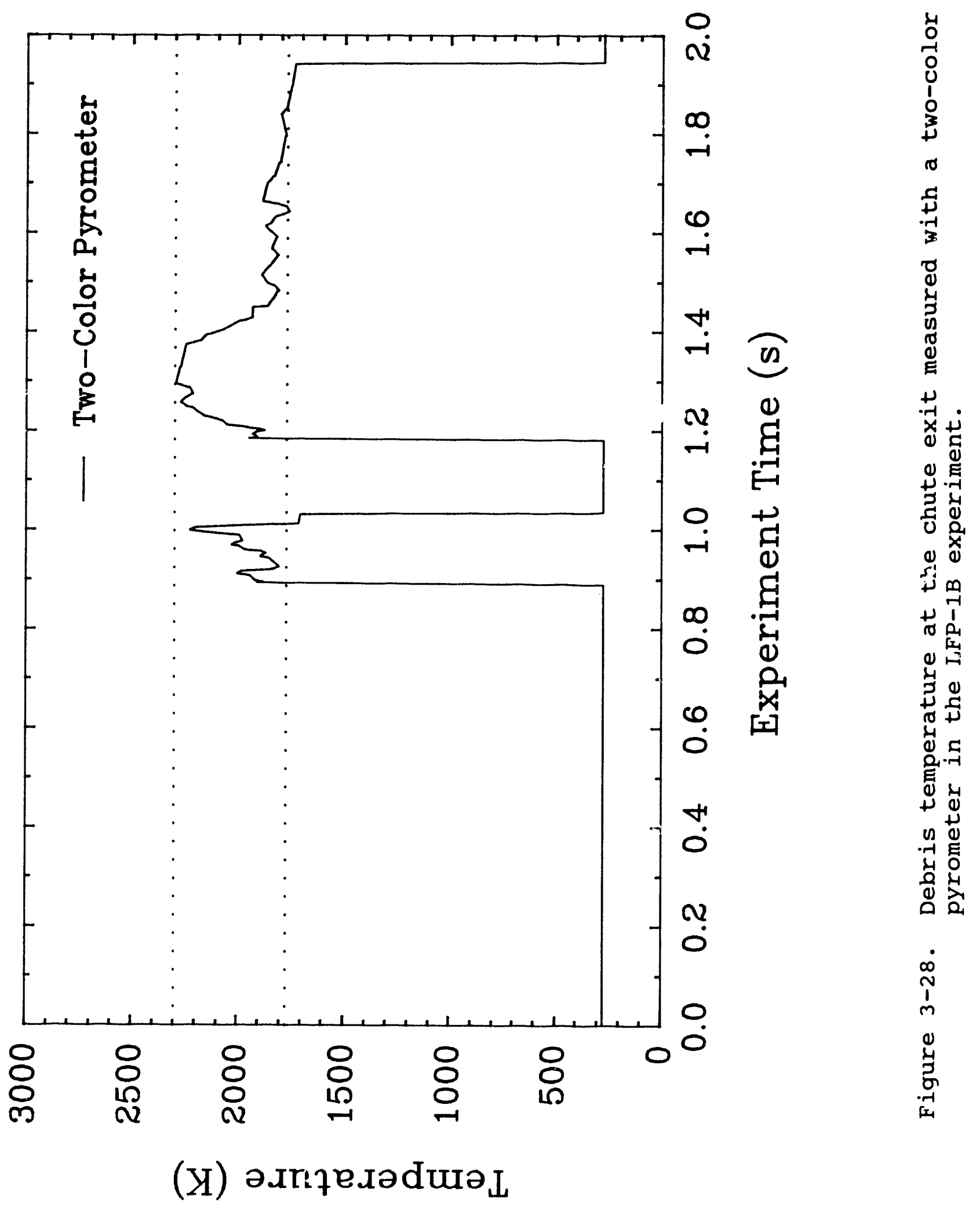




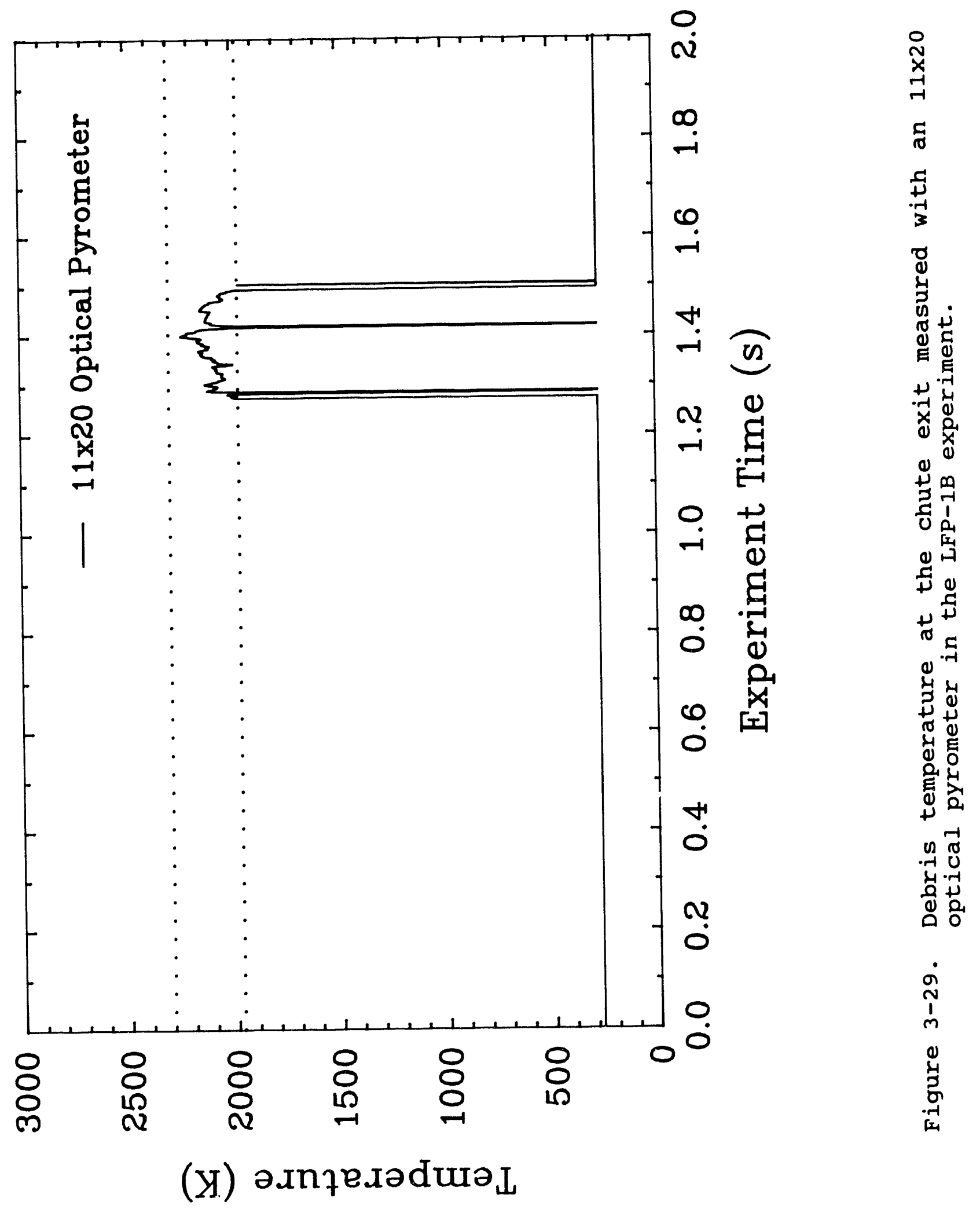




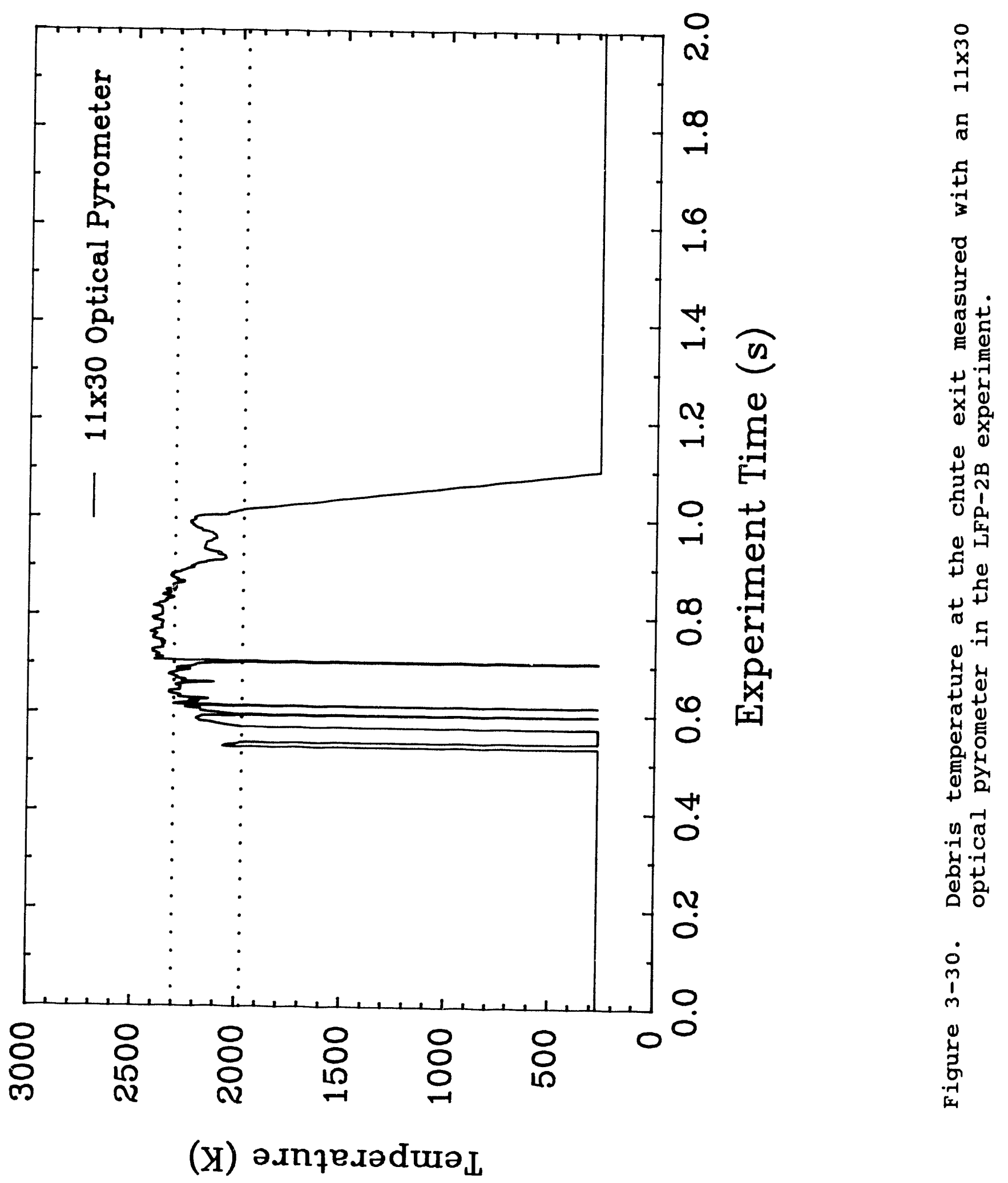




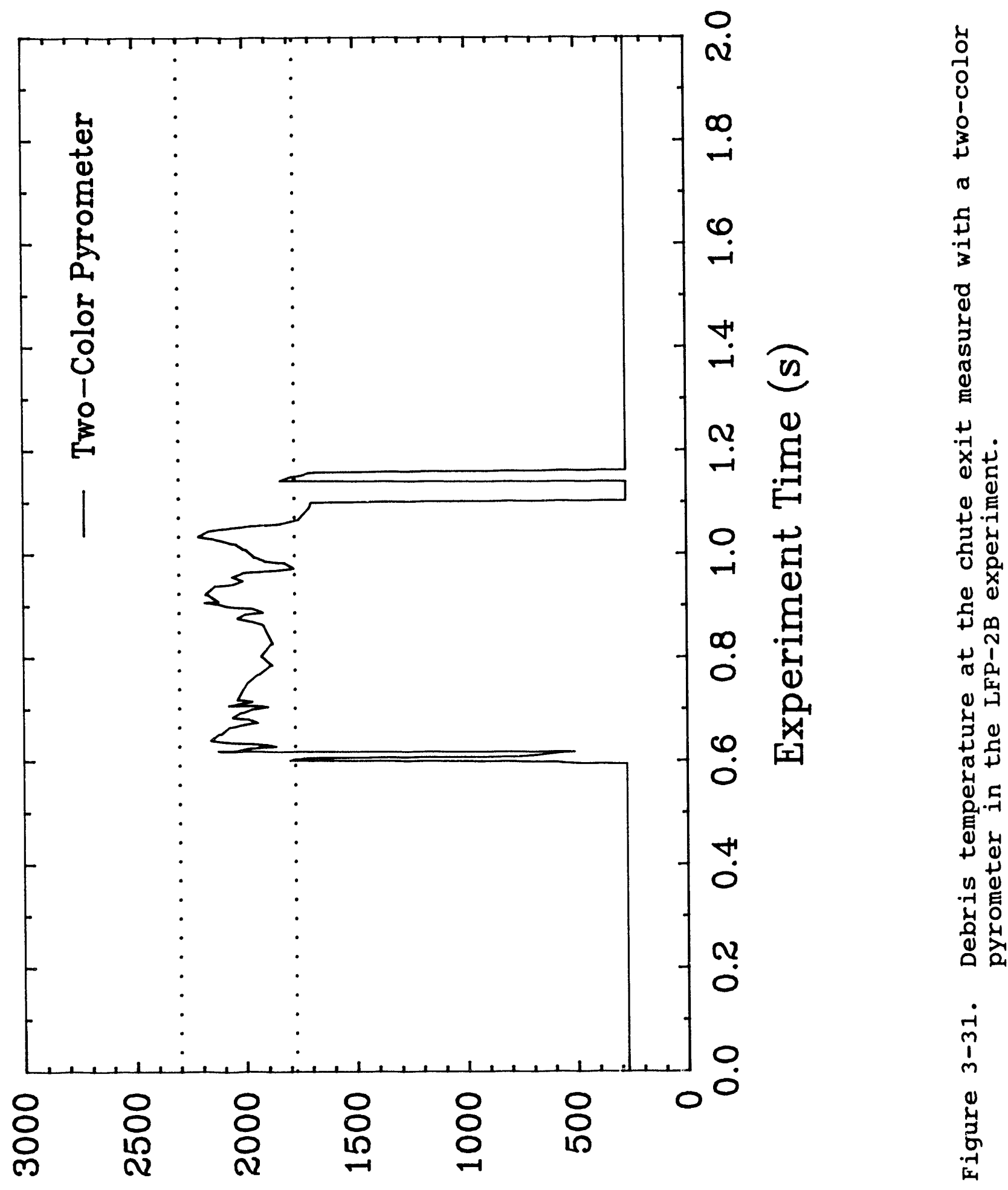

(Y) ә.пүеләduә 


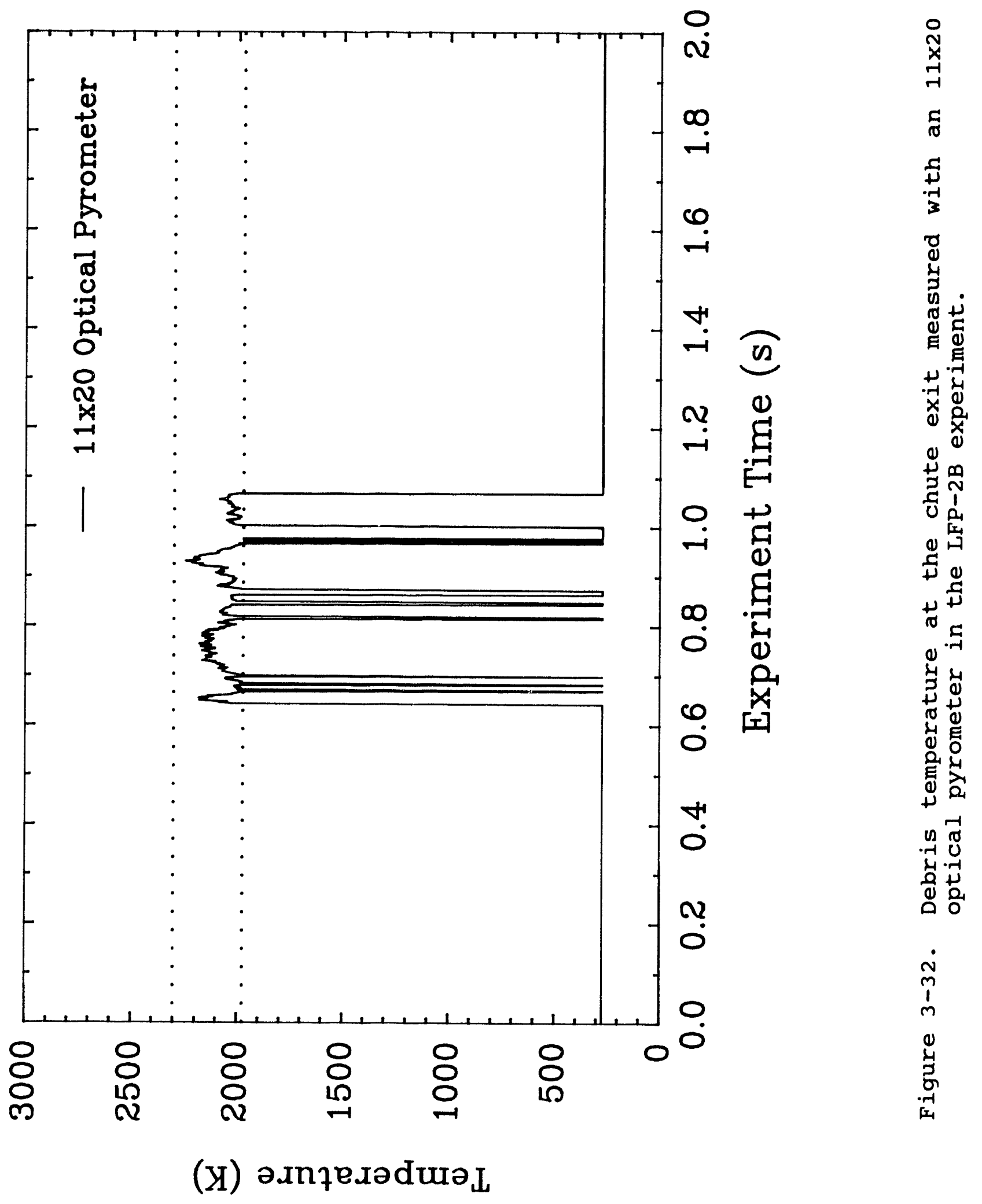




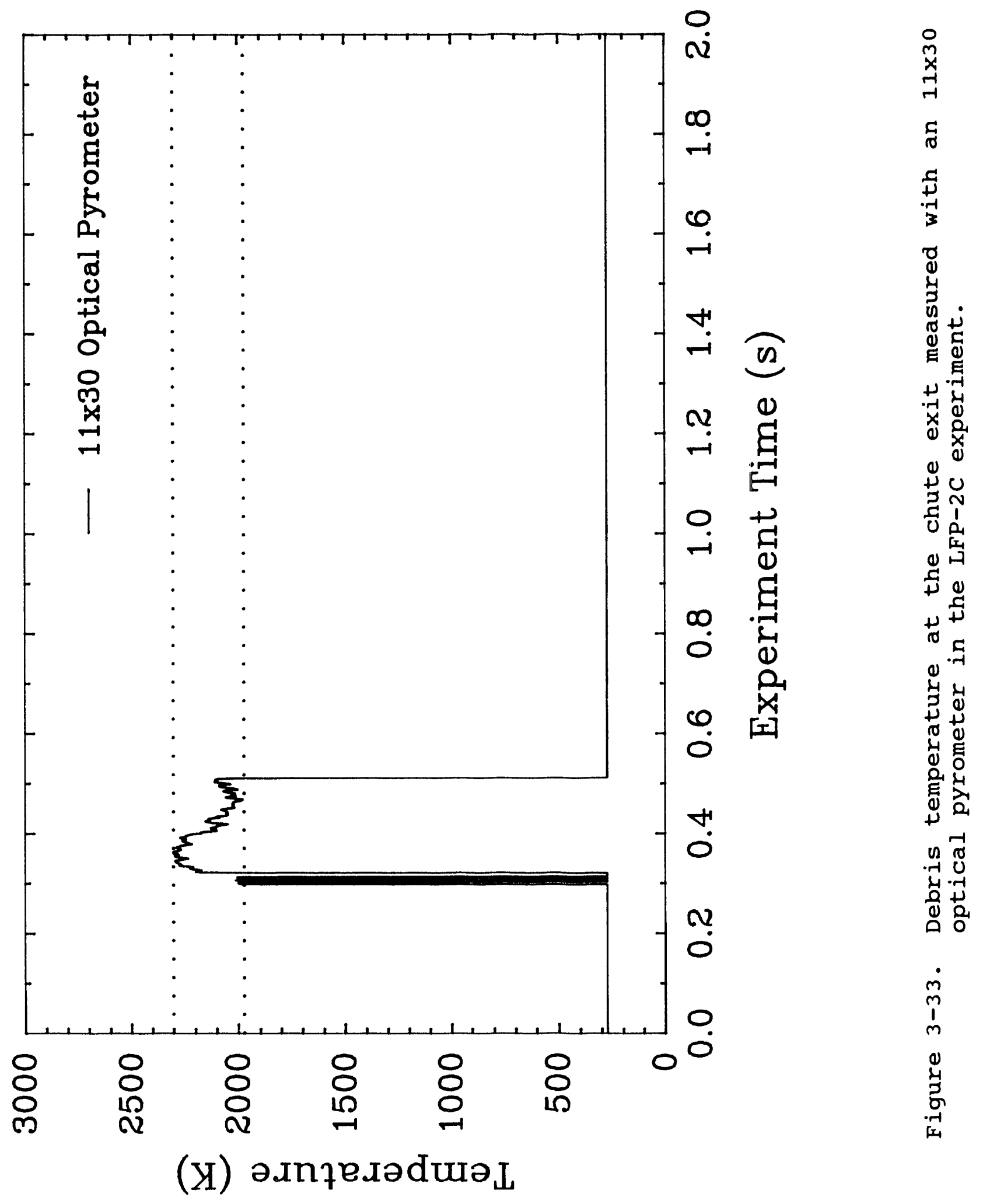




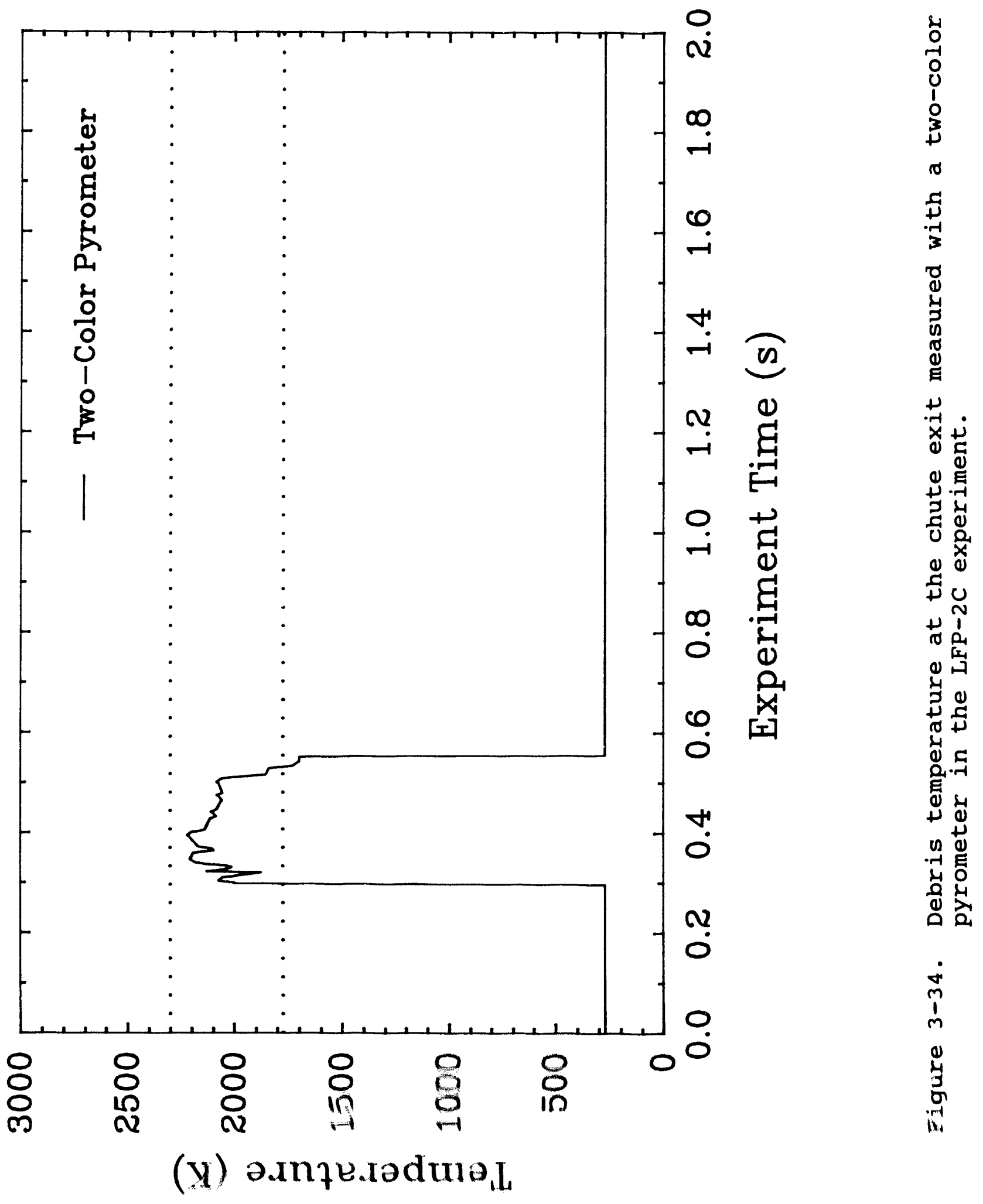




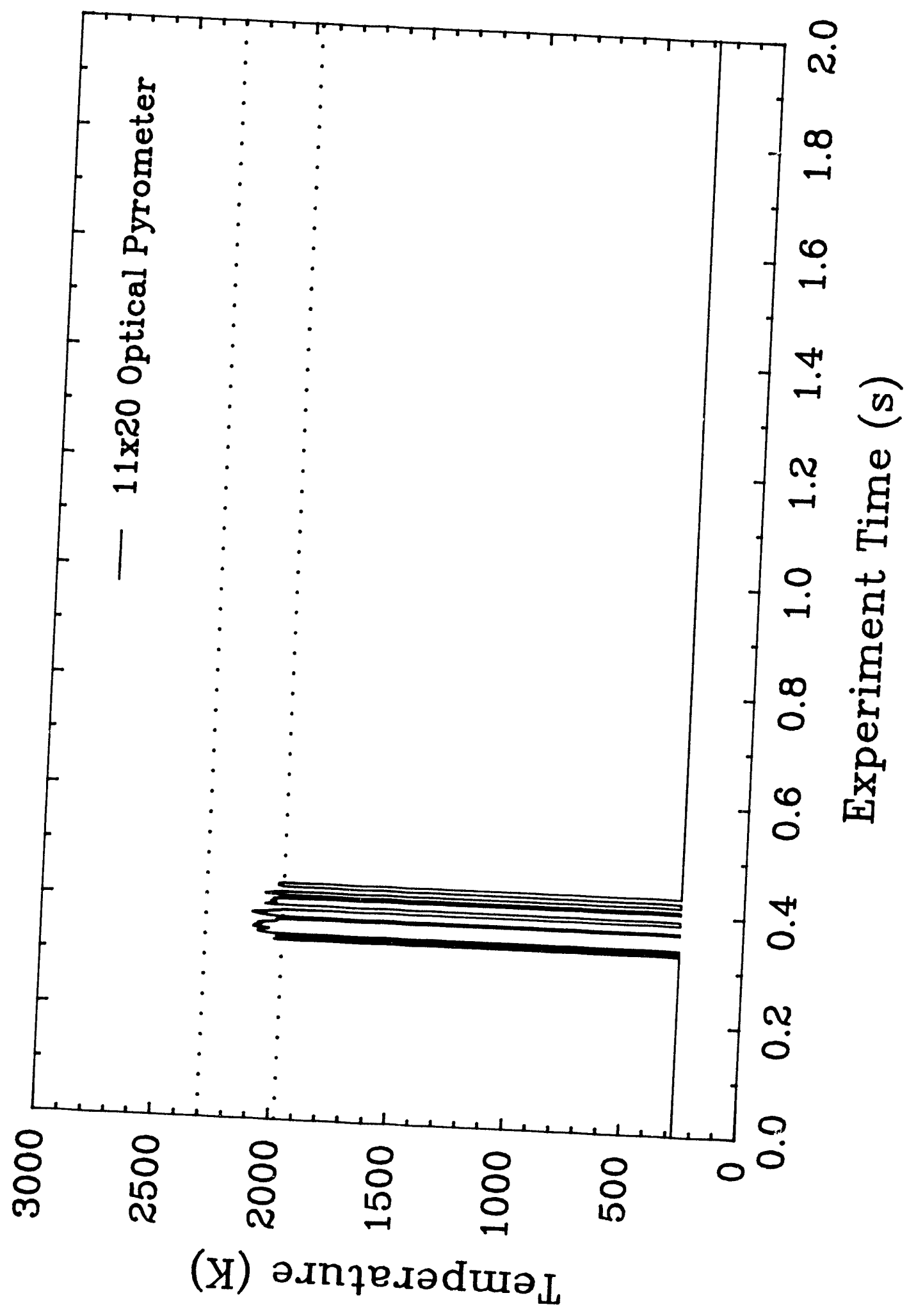

0
X
-1

⿷匚

章

ن.

岂

疍

o

岳

ب

(1)

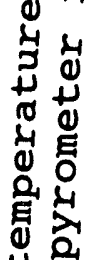

ט

- 0

造茴

ñ 


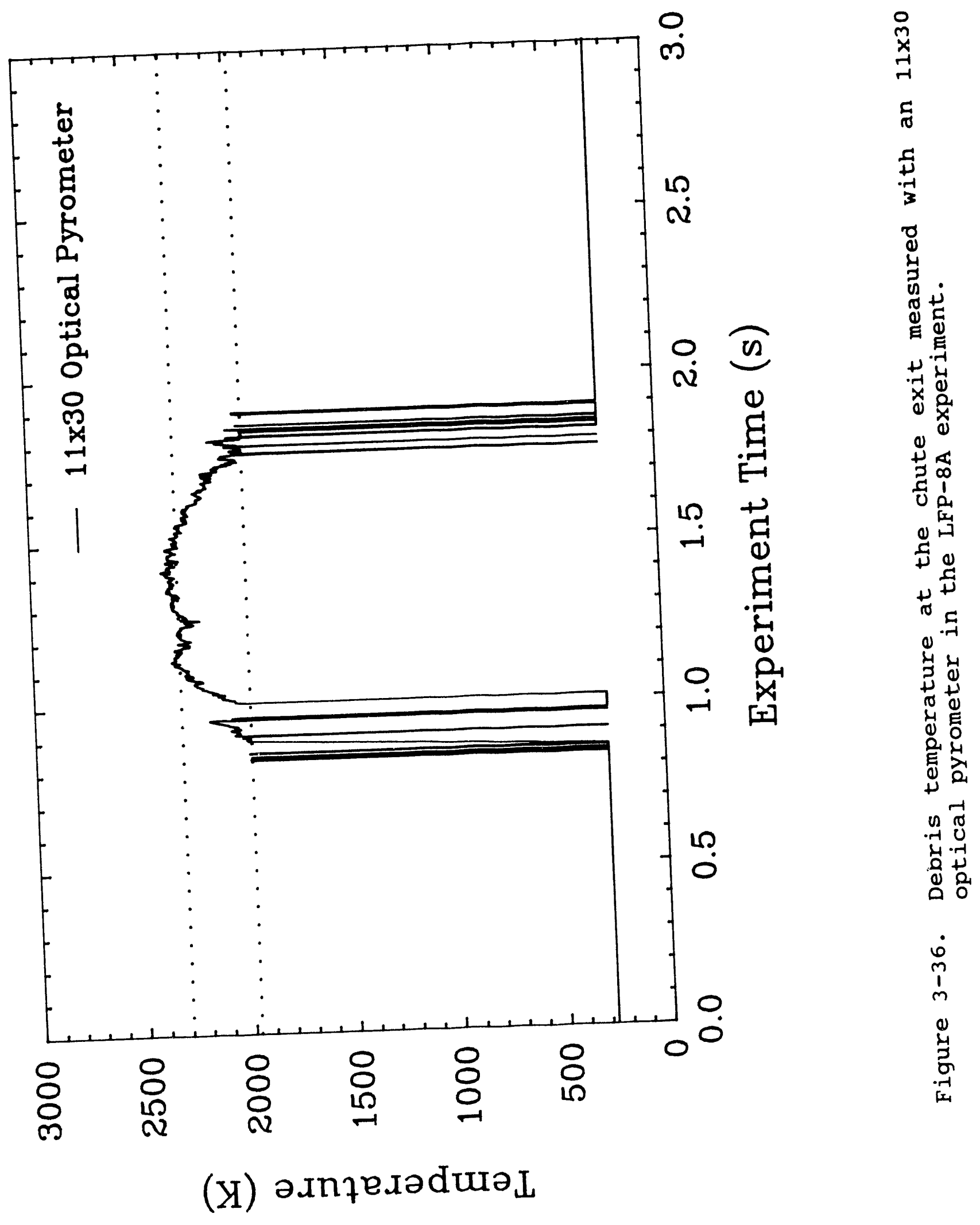




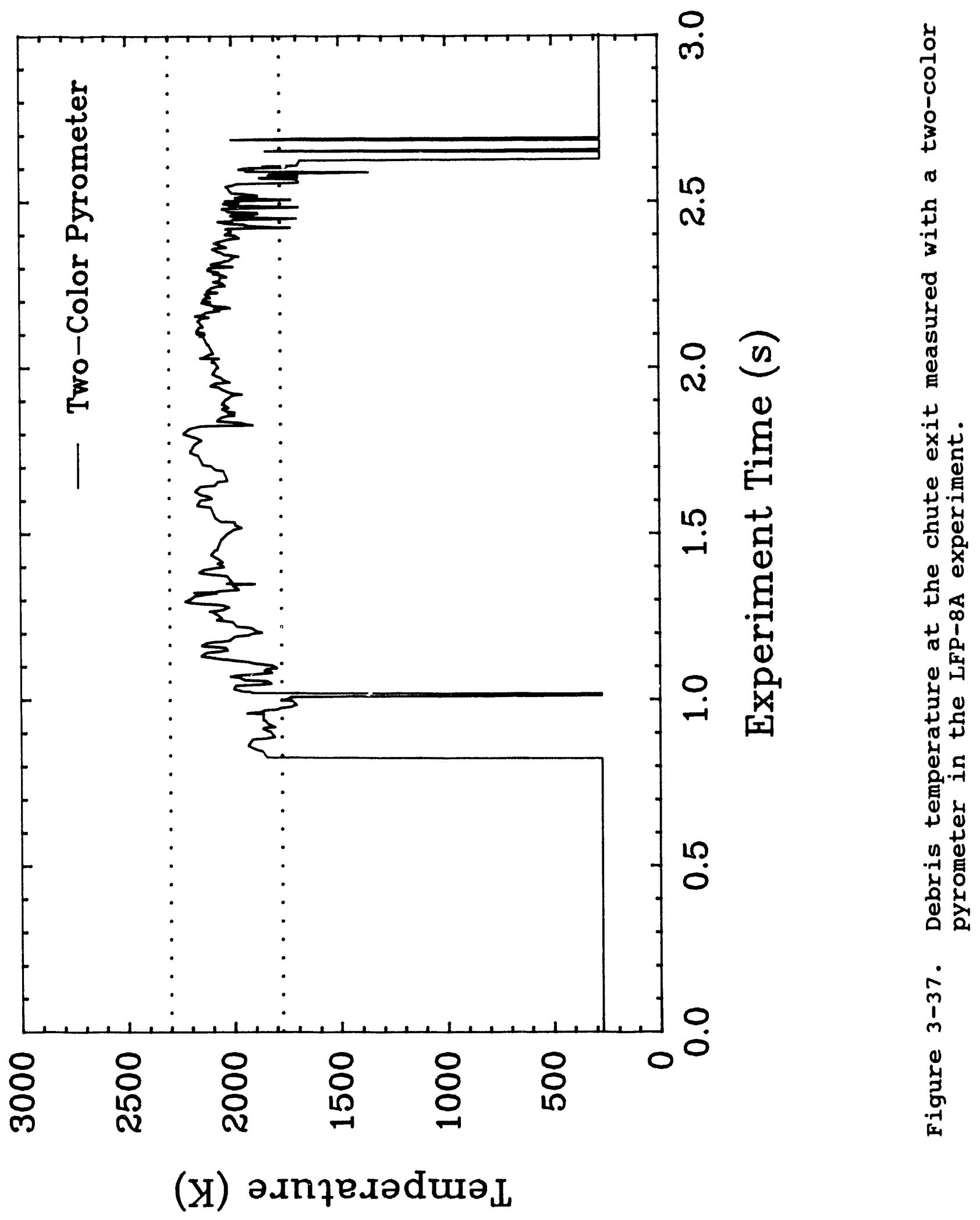




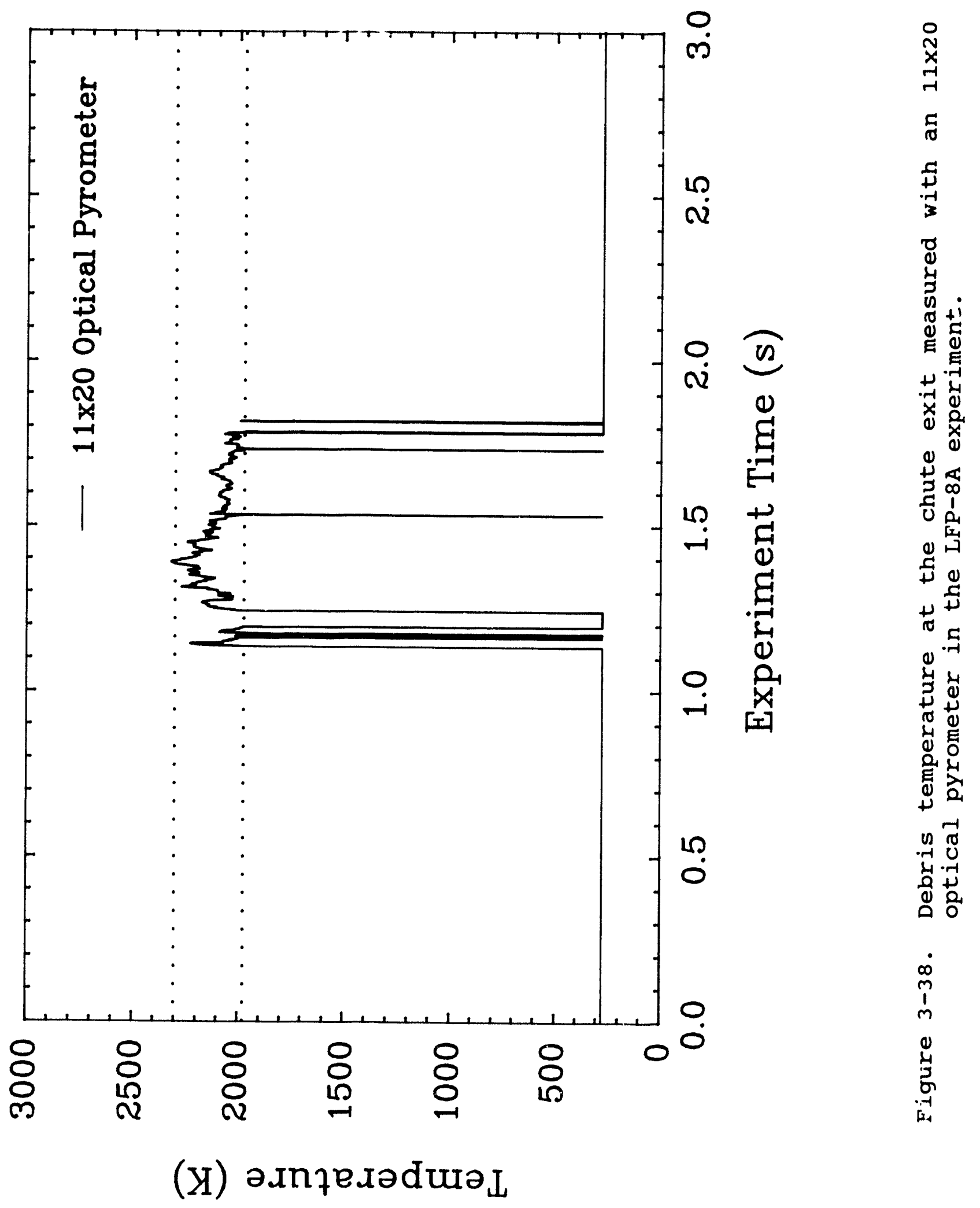




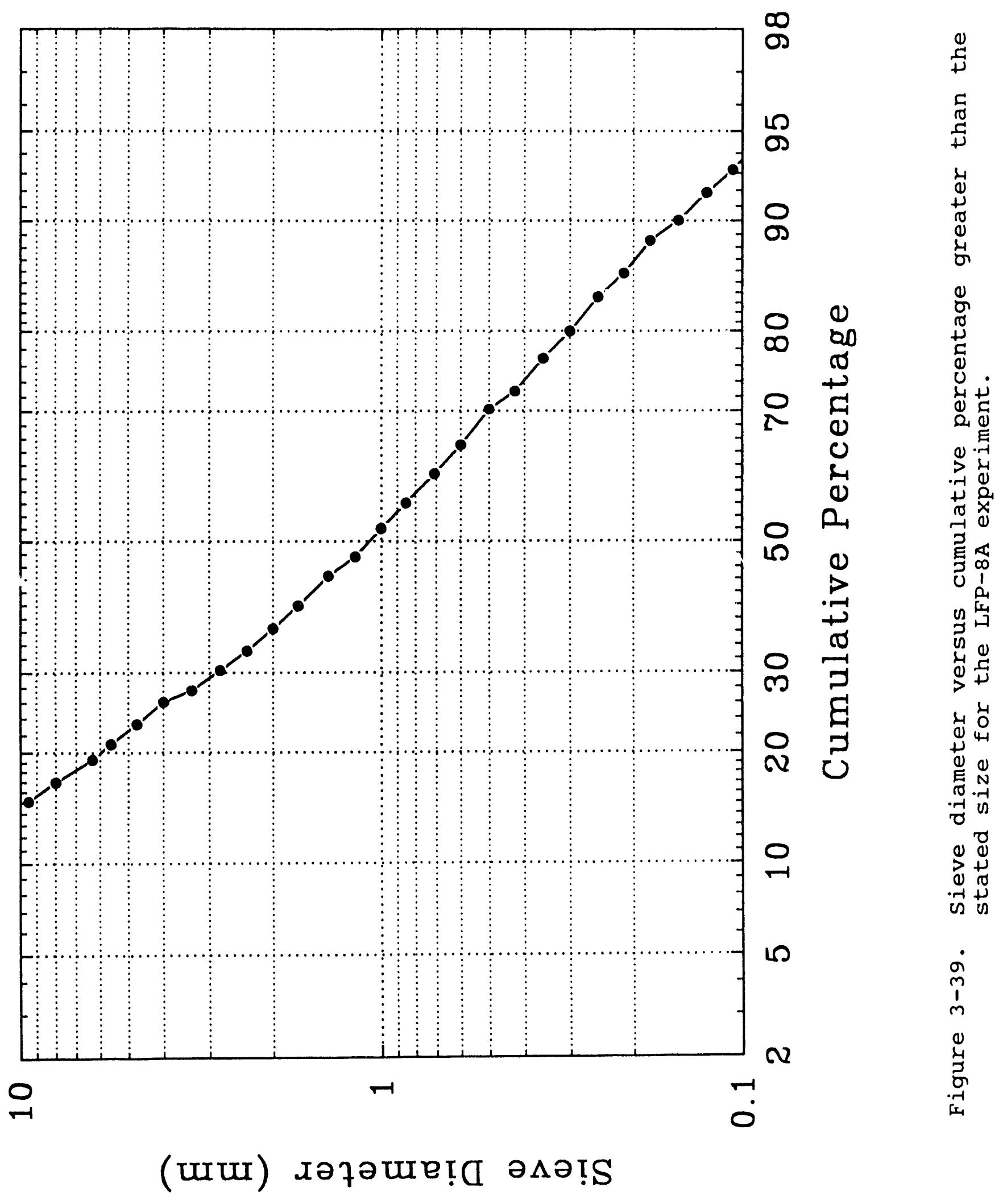




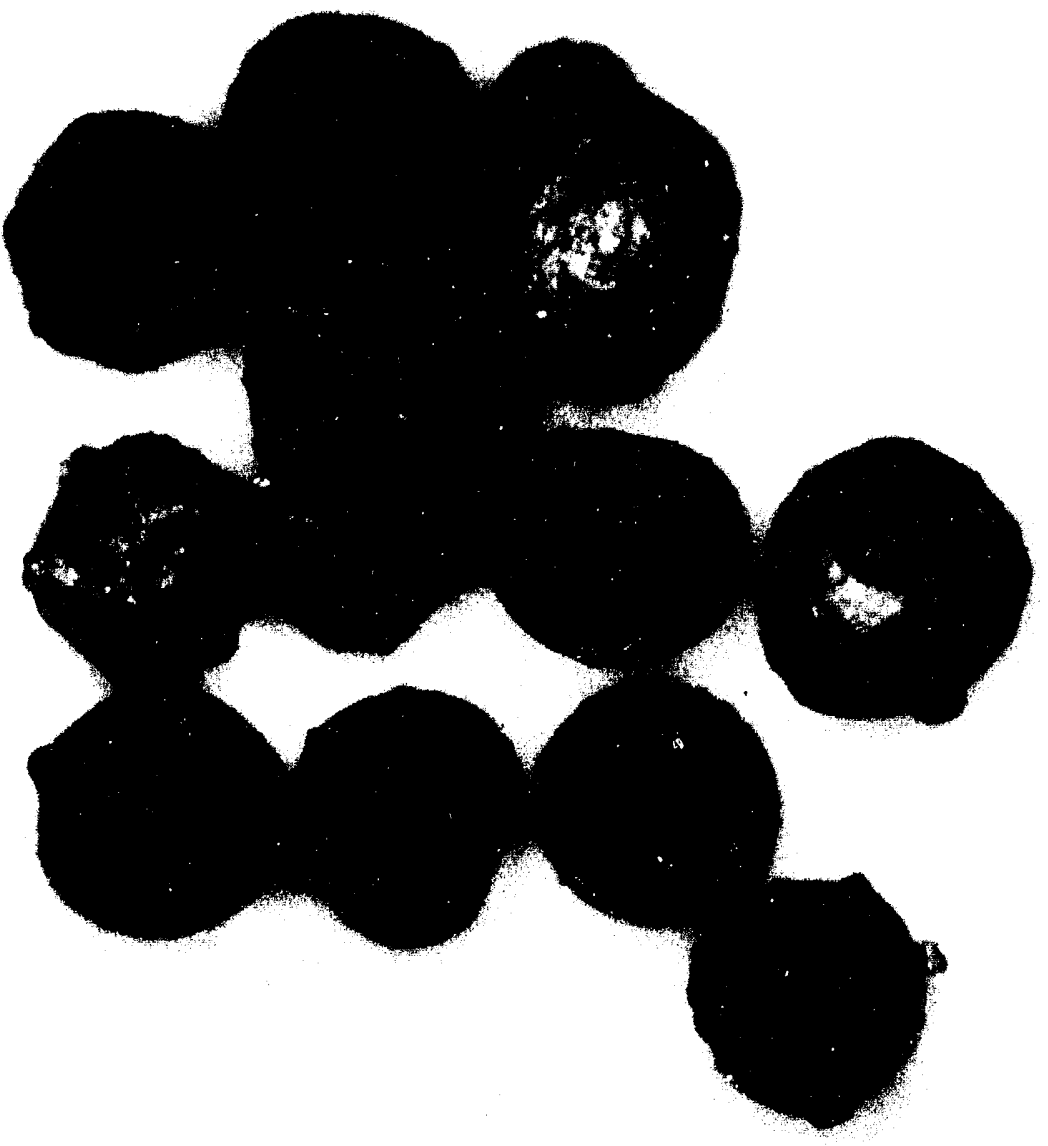

Figure 3-40. Photograph of debris collected from the LFP-8A experiment. 


\section{Liscussion}

\subsection{Debris Dispersal}

The fraction of the molten debris that was dispersed from the cavity into the surtsey vessel in the LFP experiments was quite sensitive to the initial steam driving pressure. For example, in the LFP-1B experiment, a driving pressure of $2.6 \mathrm{MPa}$ resulted in $20.9 \%$ of the debris being dispersed, while in LFP-2A a driving pressure of $3.0 \mathrm{MPa}$ resulted in $48.4 \%$ of the debris being dispersed. Previous studies [Tutu et al. 1988; Tutu et al. 1990; Ginsberg and Tutu 1990; Nichols and Tarbell 1988] have shown that the fraction of debris dispersed from the cavity in a HPME event can be a strong function of both the oriving pressure and the size of the hole in the RPV.

A plot of the fraction dispersed versus the driving pressure for three of the LFP experiments is presented in Figure 4-1. Two analytically determined dispersal curves are also shown and will be discussed below. To eliminate any hole size dependence, only the LFP-1B, LFP-2A, and LFP-8A experiments were plotted. All three experiments shared a common hole size of $3.5 \mathrm{~cm}$. As can be seen in the figure, the fraction of debris dispersed into the surtsey vessel varied from $20.9 \%$ at a driving pressure of $2.6 \mathrm{MPa}$ to $48.4 \%$ at a driving pressure of 3.0 MPa. Clearly, the fraction dispersed is extremely sensitive to the driving pressure in these three experiments. Previous work [Tutu et al. 1988 and 1990] has demonstrated that for a given hole size, the fraction of molten debris dispersed from a cavity is a s-shaped function of the driving pressure.

The two analytical dispersal curves presented in Figure 4-1 are the results of the Tutu-Ginsberg correlation [Tutu et al. 998] for the LFP experiment geometry with a $3.5 \mathrm{~cm}$ hole size. The s-shaped behavior of the dispersal function can be clearly seen. Two analytical curves were plotted because the Tutu-Ginsberg correlation is sensitive to a number of parameters, particularly the temperature of the gas that is entraining material in the cavity. The curve to the right of the experimental results was produced by assuming that the entraining gas in the cavity was at the steam accumulator temperature of approximately $500 \mathrm{~K}$. The curve to the left of 
the experimental results was produced with the assumption that the entraining gas was at the average debris temperature of approximately $2300 \mathrm{~K}$. Although the actual temperature of the gas in the cavity was not measured, it would probably lie somewhere between these two extremes. It is interesting to note that the Tutu-Ginsberg correlation brackets the experimental results within the uncertainty of the entraining gas temperatures, with the measured results being somewhat closer to the analytical curve for $2300 \mathrm{k}$ gas in the cavity.

In general, the dispersal function exhibits three distinct regions. First, there is a low pressure cuitoff point below which little or no debris is dispersed from th? cavity. When the driving steam pressure is below this cutoff pressure, steam velocities in the cavity are too low to entrain a significant amount of debris and carry it out of the cavity [Tutu et al. 1990]. Second, there is a region where small increases in the driving pressure result in large increases in the fraction of material dispersed from the cavity. Finally, driving pressures above the pressures in the second region have little effect on the fraction dispersed, since most of the material is already ejected. For the three LFP experiments with a $3.5 \mathrm{~cm}$ hole, the cutoff pressure appears to be approximately $2 \mathrm{MPa}$. All three of the points appear to lie within the secund region of the dispersal function, where small increases in the driving pressure greatly increase the fraction dispersed. The third region of the dispersal function is not shown by the data in Figure 4-1, but is hypothesized to lie above $4 \mathrm{MPa}$ of driving pressure.

\subsection{Pressure Increase}

Prior to the LFP experiments it was hypothesized that a reduced flight path for debris ejected from the cavity would result in lower peak system pressures. A reduced flight path should give less time for thermal and chemical interaction between the debris and the containment atmosphere, reducing the pressure increase in the system. However, since the initial conditions and debris dispersal in each of the LFP experiments were different, it was necessary to somehow account for these differences when examining the pressure increase data. The peak pressures were therefore compared on the basis of the total amount of energy available for heating the surtsey 
atmosphere in each experiment. The total energy was estimated to be the sum of the thermal energy in the dispersed mass of thermite and the total exothermic energy release from the production of the hydrogen measured in each experiment.

In Figure 4-2, the peak pressure increase in the surtsey vessel is plotted as a function of the total available energy for each of the experiments. The intercept for the pressure increase, with no energy released into the system, was estimater from the pressure increase in surtsey caused by steam blowdowl, assuming the steam was heated to the measured debris temperature of $2300 \mathrm{~K}$. Debris dispersal and debris chemical reactions were assumed to have no effect. As can be seen in the figure, the pressure increase in the system appears to be a function of the flight path. As expected, the smallest peak pressures occurred with the nominal $1 \mathrm{~m}$ flight path, and the largest pressure increase was measured with a nominal $8 \mathrm{~m}$ flight path. These results infer that for any given amount of available energy in a HPME, longer flight paths in the containment will produce lisrger peak pressures in the system.

The transient pressure measurements in the LFP experiments indicate that the system pressure decreases rather rapidly after a peak pressure is reached. Previous tests in the Surtsey facility have shown that the leak rate at the peak LFP test pressures is negligible over the time span of interest. The rapid decrease in system pressure following the peak pressure was therefore due almost entirely to heat transfer in the surtsey vessel. The not atmosphere in the surtsey vessel probably transferred most of its eriergy to various structures in the containment through radiation and convective heat loss mechanisms, leading to the measured decrease in the system pressure.

\subsection{Hydrogen production}

As with the peak pressure measurements, the amount of hydrogen generated in each of the LFP experiments was affected by the different initial conditions. To permit meaningful comparison of the results, the amount of hydrogen generation was examined on the basis of the mass of dispersed debris in each experiment. The resuits are presented in Figure 4-3. As can 
be seen in the figure, the amount of hydrogen generated in the various experiments steadily increased as the amount of dispersed mass increased. However, it is interesting to note that a significant amount of hydrogen was generated for cases where only small amounts of debris were dispersed. In fact, the data can be projected back to estimate that more than 100 moles of hydrogen would be produced even if no debris were dispersed from the cavity.

There are several. potential mechanisms that might explain the large amount of hydrogen generation taking place in the cavity. First, it is likely that some hydrogen generation is taking place at the interface between the molten debris and steam within the melt generator itself. It would seem that the limited surface area available for interaction between steam and molten debris within the melt generator would limit the amount of hydrogen generated by this mechanism, but churning and bubbling may enhance the process. The magnitude of the actu. 1 hydrogen generation within the melt generator is difficult to estimate, but methods of measuring this effect are being considered for use in future experimental studies.

Second, it was hypothesized that large amounts of hydrogen were being generated during the two-phase portion of the blowdown from the melt generator. During the two-phase blowdown, molten debris is probably finely atomized by the steam exiting the melt generator, leading to rapid chemical interaction. Based on analytical studies of the LFP experiments, between 12 and $15 \mathrm{~kg}$ of molten debris exit the melt generator during the two-phase portion of the blowdown. If all of this material were to react with steam, more than 170 moles of hydrogen could be produced. For example, in the LFP-8A experiment an estimated $12 \mathrm{~kg}$ of molten debris was ejected during the twophase portion of the blowdown, potentially releasing 169 moles of hydrogen. However, based on a total blowdown time of $1.8 \mathrm{~s}$ and a computed two-phase discharge time of $0.22 \mathrm{~s}$, only $12 \%$ of the total steam inventory was available to react with the $12 \mathrm{~kg}$ of debris. As a result, the maximum possible hydrogen generation during the two-phase portion of the blowdown was only 20 moles. Clearly, this mechanism cannot fully explain the large amount of hydrogen generated within the cavity.

Unless large amounts of hydrogen are being generated within the melt generator; it is likely that most of the hydrogen production in the LFP experiments occurs as the steam passes 
over the debris within the cavity itself. A third potential mechanism for hydrogen generation in the cavity is that the jet of steam exiting the melt generator actually tunnels through the molten debris pooled on the cavity floor, resulting in an extremely violent and dynamic mixing of steam and debris within the cavity. Unless future work demonstrates that massive amounts of hydrogen are generated within the melt generator itself, this mechanism is the only plausible explanation for large amounts of hydrogen generation with no material dispersed from the cavity. If valid, the hypothesis could have important ramifications for $\mathrm{DCH}$ studies and reactor safety. If the mechanism proposed above is prototypic for full-scale plants and hydrogen production is significant even when small fractions of debris are dispersed, it is possible that a nondispersive cavity alone may not be sufficient to mitigate all of the threatening effects of a HPME event.

\section{4 Choked Flow}

During the initial stages of the steam blowdown, flow from the steam accumulator and melt generator into the cavity is choked. The connection between the steam accumulator and melt generator is essentially a pipe with a diameter of $10 \mathrm{~cm}$, while the hole connecting the melt generator and cavity has a nominal diameter that ranges from 3.5 to $8.57 \mathrm{~cm}$. For the LFP-1B, $2 \mathrm{~A}$ and $8 \mathrm{~A}$ experiments, choked flow probably occurred at the melt generator/cavity connection since the hole size of $3.5 \mathrm{~cm}$ was significantly smaller than the upstream connection. However, for the larger hole sizes in the other LFP experiments, choked flow may have occurred upstream of the melt generator exit.

In the LFP-2C experiment, the melt generator exit hole was ablated to a diameter of $8.57 \mathrm{~cm}$. Since the piping connecting the steam accumulator to the melt generator was approximately $10 \mathrm{~cm}$ in diameter, it was not clear that choked flow would occur at the rielt generator exit. Figure 4-4 shows the pressures in the accumulator and melt generator as a function of time in the experiment. As can be seen in the figure, the accumulator pressure is consistently higher than the crucible pressure during steam blowdown. The result infers that choked flow in the system occurred both at the melt generator exit and at some point in the piping network between the accumulator and melt generator. 


\subsection{Particle size}

Following the LFP-8A experiment, a sieve analysis was performed on the debris particles recovered from the surtsey vessel. An analysis of debris particle size in the experiments with shorter flight paths was not performed because the recovered debris particles had melied together at the bottom of the Surtsey vessel. Figure 3-39 presents the sieve diameter as a function of the cumulative percentage of the recovered debris mass. As can be seen in the figure, the recovered paticles varied widely in size, ranging from $0.1 \mathrm{~mm}$ to nearly $10 \mathrm{~mm}$ in nominal diameter. The particle size distribution is very close to lognormal. 


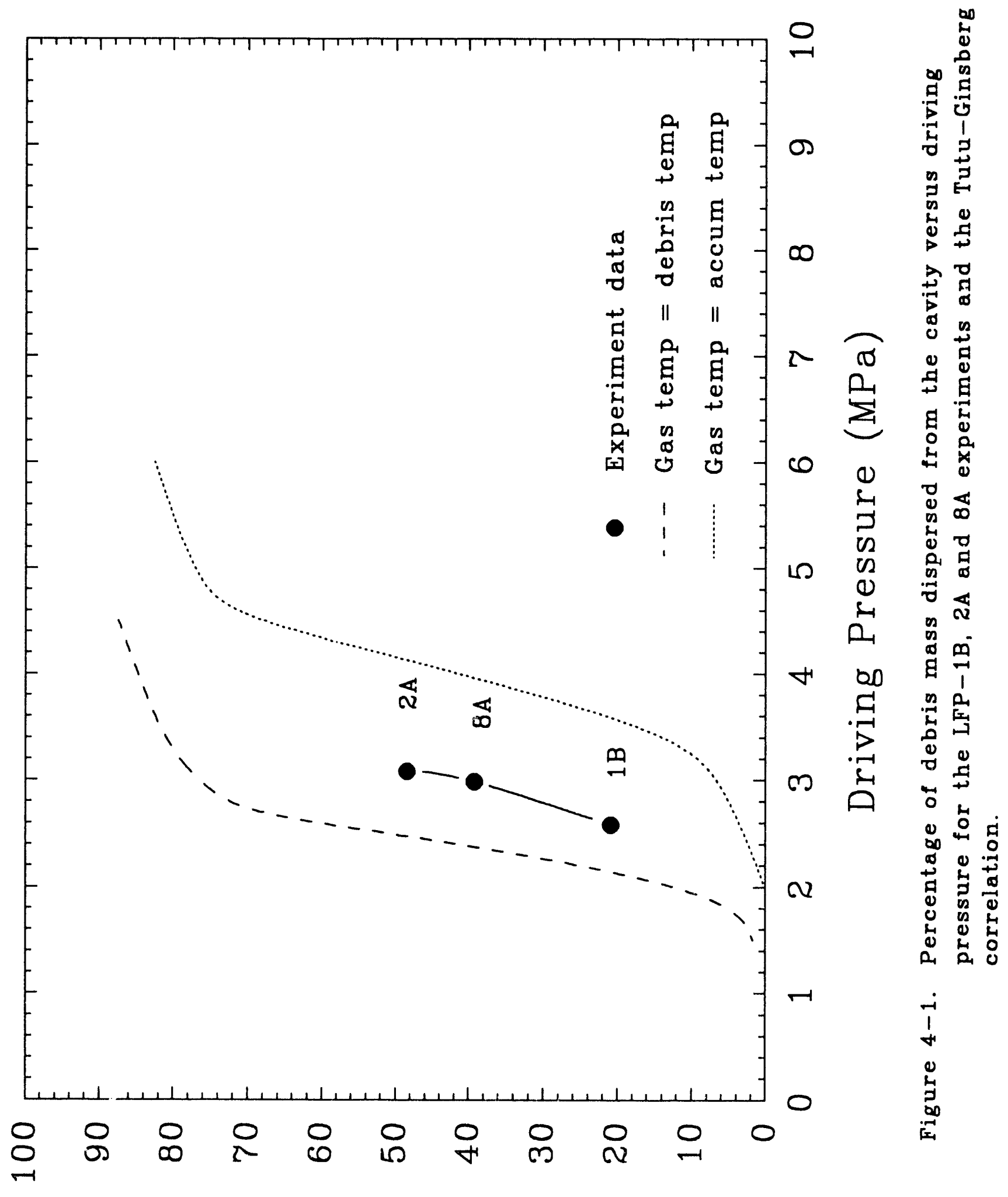

(\%) pəsıәdstด әฐеұนәวләd 


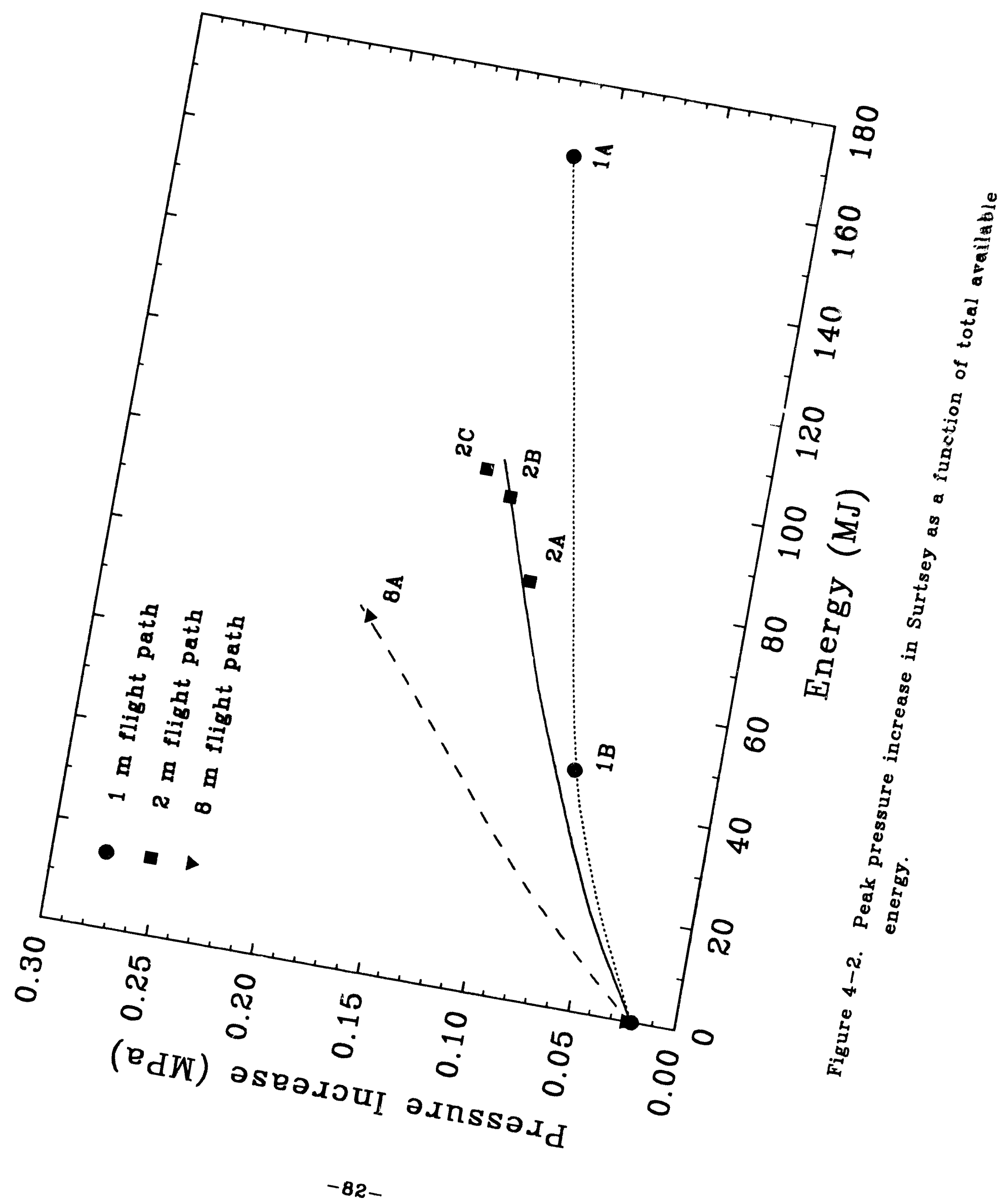




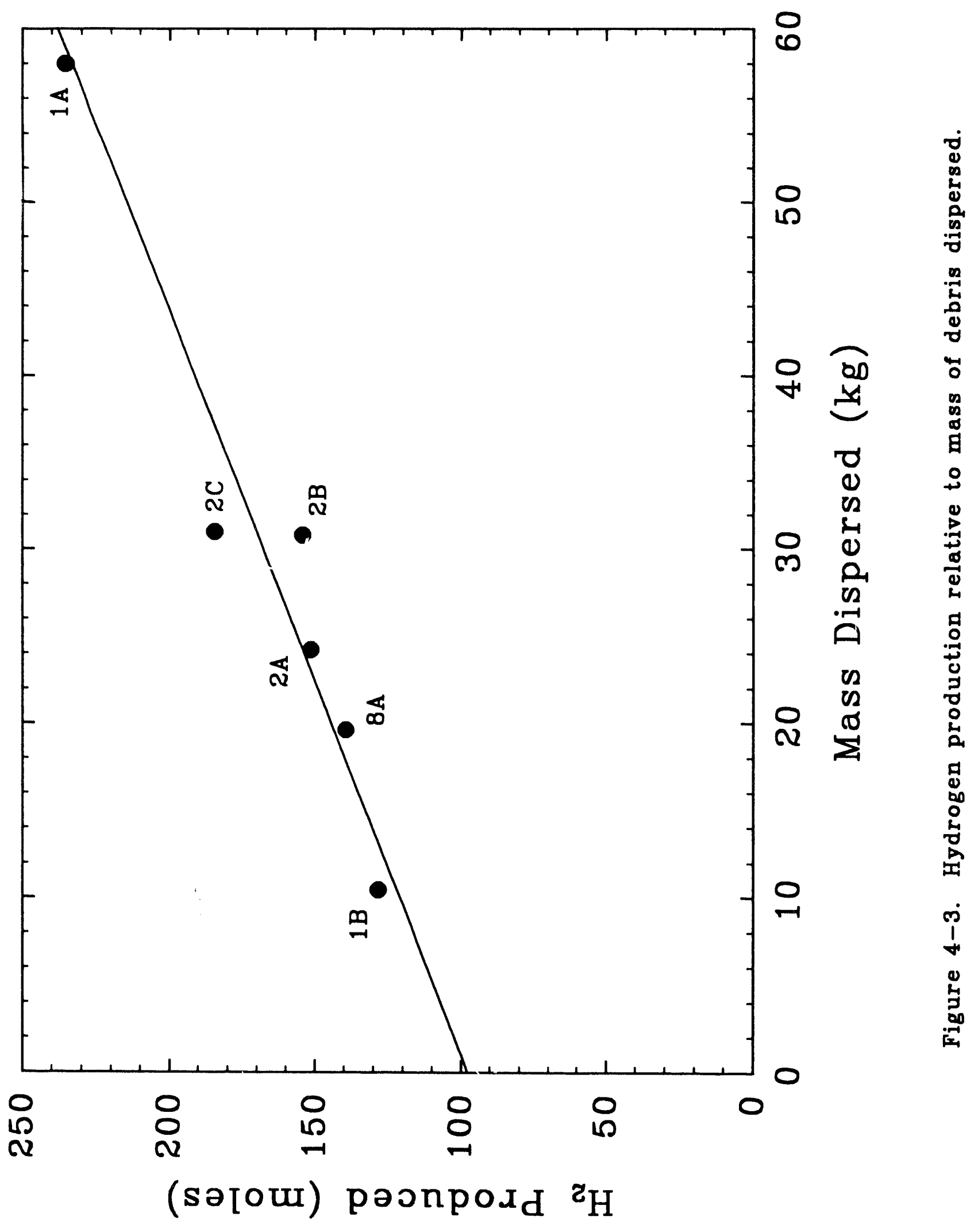




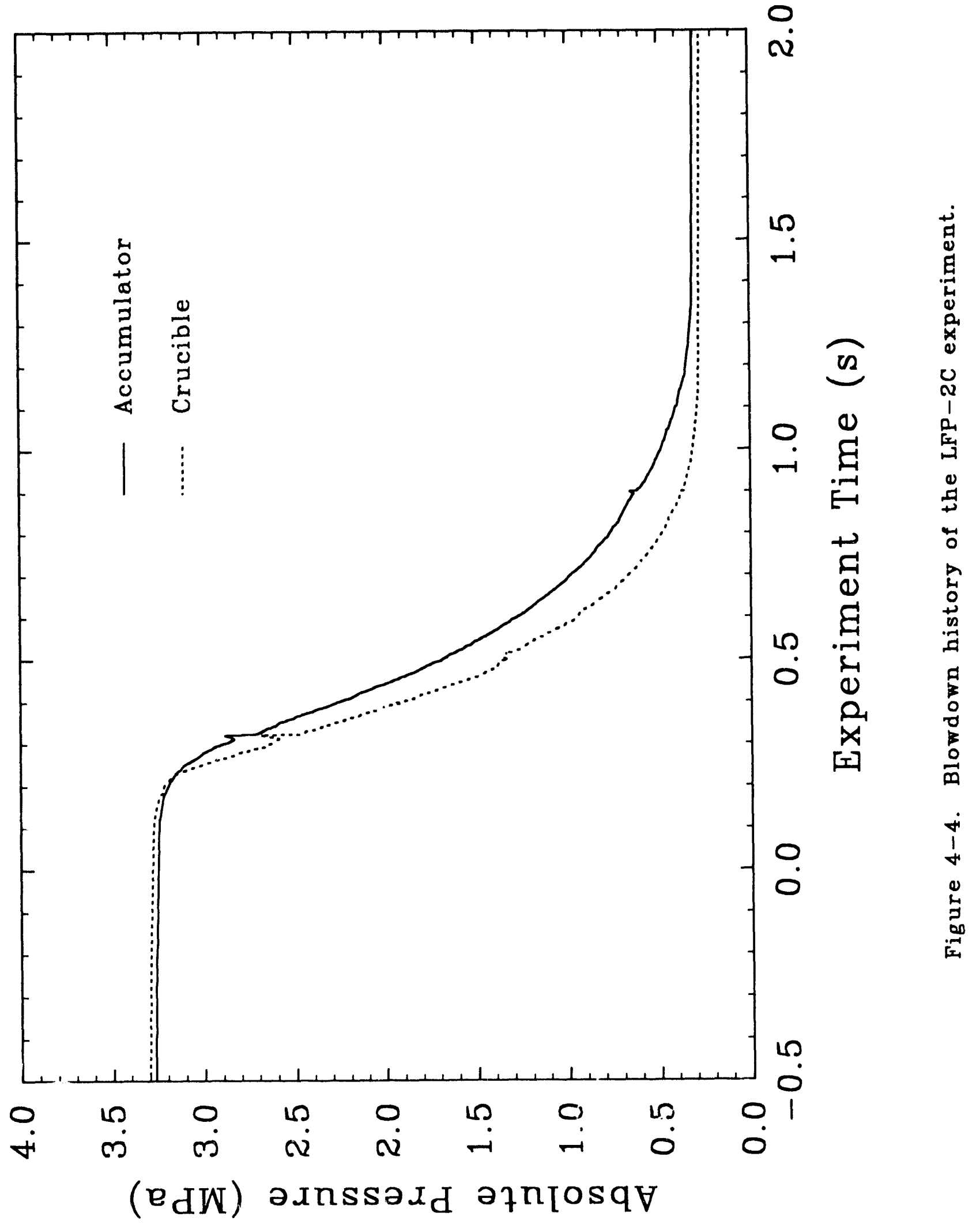




\section{SUMMARY}

The goal of the LFP test series was to investigate the effect of flight path length on direct containment heating. The LFP tests used a flight-path limiting concrete structure above the exit chute in the surtsey vessel. Debris in the IFP tests impacted the flight path-limiting structure and was deflected to the bottom head of the surtsey vessel. With flight paths of 1 or $2 \mathrm{~m}$ the debris that collected on the bottom head appeared to be a molten pool which later cooled and solidified. In the LFP-8A test the debris on the bottom head was lognormally distributed particles with a sieve mass median diameter of $1.1 \mathrm{~mm}$.

Debris dispersal initiation and the debris ej sction interval appeared to increase as the exit hole diameter decreased. The LFP-1B, LFP-2A, and LFP-8A tests had exit hole diameters of $3.5 \mathrm{~cm}$ with steam blowdown lasting $\simeq 3 \mathrm{~s}$. LFP-LA and LFP-2B had exit hole diameters of $\simeq 6 \mathrm{~cm}$ and blowdowns of $\simeq 2 \mathrm{~s}$. The LFP-2C test had an exit hole diameter of $\approx 9 \mathrm{~cm}$ and the steam blowdown lasted $\simeq 1 \mathrm{~s}$. The percentage of debris mass dispersed into the vessel was smaller for the experiments with $3.5-\mathrm{cm}$ diameter holes than for those with larger holes.

In experiments with flight paths of 1 or $2 \mathrm{~m}$, the temperatures measured at level 1 in the surtsey vessel were always substantially higher than the temperatures measured at levels 3 and 5. Levels 3 and 5 were abcve the flight-path limiting structure and only small amounts of aerosol were transported around the structure. This suggests that debris trapped in NPP subcompartments will not efficiently transfer heat to gas in the upper dome of a containment building.

High hydrogen concentrations were measured in the cavity during the high pressure melt ejection, indicating that the driving gas was a mixture of steam and hydrogen. Because of the large difference in molecular weights between steam ( $\mathrm{MW}=18 \mathrm{~g} / \mathrm{mole}$ ) and hydrogen ( $\mathrm{MW}=2 \mathrm{~g} / \mathrm{mole}$ ), the driving gas composition may affect the entrainment of debris from the cavity. 
Ginsberg, T. and N. K. Tutu, 1990, Comparison of BNI and SNL Debris Dispersal Results for the Surry Reactor Cavity, presentation, May 2, Severe Accident Research Program Partners Review Meeting, Brookhaven National Laboratory, Upton, NY.

Nichols, R. T. and W. W. Tarbell, 1988, Low Pressure Debris Dispersal from scaled Reactor Cavities, in ANS/ENS International Meeting, held in Washington, D.C., Oct. 31Nov. 4., SAND88-1702C, Sandia National Laboratories, Albuquerque, NM.

"arbell, w. W. et al., 1986, Pressurized Melt Ejection into Scaled Reactor Cavities, NUREG/CR-4512, SAND86-0153, Sandia National Laboratories, Albuquerque, NM.

Tarbell, W. W. et al., 1987, Results from the DCH-1 Experiment, NUREG/CR-4871, SAND86-2483, Sandia National Laboratories, Albuquerque, NM.

Tarbell, W. W. et al., 1988, DCH-2: Results from the second Experiment Performed in the Surtsey Direct Heating Test Facility, NUREG/CR-4917, SAND87-0976, Sandia National Laboratories, Albuquerque, NM.

Tarbell, W. W. et al., 1984, High-Pressure Melt streaming (HIPS) Program Plan, NUREG/CR-3025, SAND82-2477, Sandia National Laboratories, Albuquerque.

Tutu, N. K. et al., 1988, Debris Dispersal from Reactor Cavitics During High-pressure Melt Ejection Accident Scenarios, NUREj/CR-5146, Brookhaven National Laboratory, Upton, NY.

Tutu, N. K. et al., 1990, Melt Dispersal Characteristics of the Watts Bar Cavity, Tech. Rep. A-3024, 4/90, Brookhaven National Laboratory, Upton, NY. 
U. S. Nuclear Regulatory Commission (13)

office of Nuclear Regulatory Research

Attn: C. Tinkler, NLN-344 (6)

A. Reuben, NLN-344

M. Cunningham, NLS-372

F. Eltawila, NLN-344

G. Marino, NLS-007

J. Mitchell, NLS-314

B. Sheron, NLS-007

T. Walker, NLN-344

R. W. Wright, NLN-344

Washington, D.C. 20555

U. S. Nuclear Regulatory Commission (2)

office of Nuclear Reactor Regulation

Attn: R. Barrett, 10E4

W. Lyon, $8 \mathrm{E} 23$

Washington, D.C. 20555

U. S. Nuclear Rtgulatory Commission (7) NRC/RES

Attn: E. Beckjord, NLS-007

B. Hardin, NLS -169

T. Lee, NLN-353

R. Meyer, NLS-007

Z. Rosztoczy, NLS -007

C. Ryder, NLS-372

T. Speis, NLS-007

Washington, D.C. 20555

U. S. Department of Energy (1)

office of Nuclear Safety

NS -20

Attn: Patricia Worthington

Washington D.C. 20545

U. S. Department of Energy (2)

Albuquerque Operations office

Attn: C. E. Garcia, Director

For: C. B. Quinn

P. O. Box 5400

R. L. Holton

Albuquerque, NM 87185 
Electric Power Research Institute (4)

Attn: F. Rahn

R. Ritzman

W. Lowenstein

P. Sehgal

3412 Hillview Avenue

Palo Alto, CA 94303

Brookhaven National Laboratory (6)

Attn: R. A. Bari

T. Pratt

G. Greene

T. Ginsberg

M. Lee

130 BNL

N. Tutu

Upton, NY 11973

Professor R. Seale

Department of Nuclear Engineering

University of Arizona

Tucson, AZ 85721

Oak Ridge National Laboratory

Attn: T. Kress

P. O. BoX Y

Oak Ridge, TN 37830

Argonne National Laboratory (10)

Attn: A. Sharon

J. Binder

J. Rest

C. Johnson

L. Baker, Jr.

D. Cho

B. Spencer

$\mathrm{K}$. Leong

J. Fink

V. Novick

9700 S. Cass Avenue

Argonne, IL 60439

Cathy Anderson

Nuclear Safety Oversight Cominission 1133 15th Street, NW

Room 307

Washington, D.C. 20005 
Battelle Columbus Laboratory (4)

Attn: C. Alexander

P. Cybulskis

R. Denning

J. Gieseke

505 King Avenue

Columbus, OH 43201

U. S. Department of Energy

office of Nuclear Safety Coordination

Attn: R. W. Barber

Washington, D.C. 20545

Department of Energy

Scientific and Tech. Info. Center

P. O. Box 62

Oak Ridge, TN 37831

M. Fontana

Director, IDCOR Program

ENERGEX

575 Oak Ridge Turnpike

Oak Ridge, TN 37830

Fauske and Associates, Inc. (2)

Attn: R. Henry

M. Plys

16 W070 West 83rd street

Burr Ridge, IL 60952

R. Sherry

JAYCOR

P. O. Box 85154

San Diego, CA 92138

Los Alamos National Laboratories

Attn: M. Stevenson

P.O. Box 1663

Los Alamos, NM 87545

UCLA (2)

Nuclear Energy Laboratory

Attn: I. Catton

D. Okrent

$405 \mathrm{Hilgaard}$ Avenue

Los Angeles, CA 90024 
University of Wisconsin

Nuclear Engineering Department

Attn: M. L. Corradini

1500 Johnson Drive

Madison, WI 53706

EG\&G Idaho

Willow Creek Building, W-3

Attn: R. Hobbins

P. O. Box 1625

Idaho Falls, ID 83415

Battelle Pacific Northwest Laboratory

Attn: M. Freshley

I: O. Box 999

Richland, WA 99352

w. Stratton

2 Acoma Lane

Los Alamos, NM 87544

Dr. S. J. Niemczyk

154518 th Street, NW

\#112

Washington, D.C. 20036

Wang Lu

TVA

400 Commerce, W9C157-CK

Knoxville. TN 37902

Peter Bieniarz

Risk Management Associates

2309 Dietz Farm Road, NW

Albuquerque, NM 87107

J. E. Antill

Berkeley Nuclear Laboratory

Berkeley GL 139PB

Gloucestershire, England

UNITED KINGDOM 
W. G. Cunliffe

Bldg. 396

British Nuclear Fuels, Ltd.

Springfield Works

Salwick, Preston

Lancashire, England

UNITED KINGDOM

Professor Agustin Alonso

E.T.S. Ingenieros Industriales

Jost Gutierrez Abascal, 2

28006 Madrid

SPAIN

Dr. Alfonso Perez

Departmento de Seguridad Nuclear

Junta de Energia Nuclear

Avenida Complutense, 22

Madrid - 3

SPAIN

Gesellschaft fur Reaktorsicherheit (GRS)

Postfach 101650

Glockengrasse 2

5000 Koeln 1

FEDERAL REPUBLIC Of GERMANY

Kraftwerk Union

Attn: Dr. M. Peehs

Hammerbacher Strasse 1214

Postfach 3220

D-8520 Erlangen 2

FEDERAL REPUBLIC Of GERMANY

Technische Universitat Munchen Attn: Professor $H$. Karwat

8046 Garching, Forschungagelande

Munich

GERMANY 


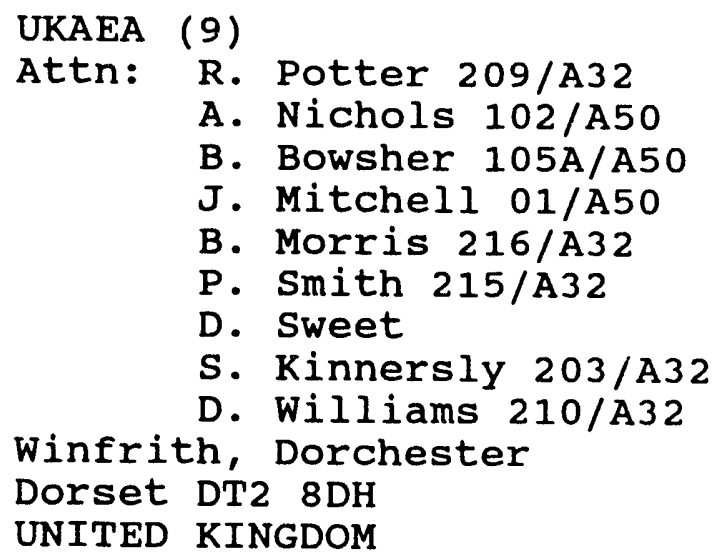

Dr. K. J. Brinkman

Reactor Centrum Nederland

1755 ZG Petten

THE NETHERLANDS

Kernforschungszentrum Karlsruhe (2)

Attn: H. Alsmeyer

H. Rininsland

Postfach 3640

75 Karlsruhe

FEDERAL REPUBLIC Of GERMANY

Mr. H. Bairiot, Chief

Department LWR Fuel

Belgonucleaire

Rue de Champde Mars. 25

B-1050 Brussels

BELGIUM

Japan Atomic Energy Research Institute

Attn: K. Sato

Fukoku Seimei Bldg.

2-2-2, Uchisaiwai-cho, Chiyoda-ku, Tokyo 100

JAPAN 
Japan Atomic Energy Research Institute

Tokai Research Establishment

Attn: Dr. S. Matsuura, Deputy Director General

Tokai-mura, Naka-gun, Ibaraki-ken

319-11

JAPAN

Japan Atomic Energy Research Institute

Department of Fuel Safety Resarch

Attn: Dr. M. Ichikawa, Director

Tokai-mura, Naka-gun, Ibaraki-ken

319-11

JAPAN

Japan Atomic Energy Research Institute Reactor Accident Laboratory

Attn: Dr. T. Fujishiro, Head

Tokai-mura, Naka-gun, Ibaraki-ken

319-11

JAPAN

Japan Atomic Energy Institute (20)

Severe Accident Research Laboratory

Attn: Dr. K. Soda, Head

Dr. N. Yamano

M. Kajimoto

Tokai-mura, Naka-gun, Ibaraki-ken

319-11

JAPAN

P. Fehrenback

Atomic Energy Canada, Ltd.

Chalk River, ontario

CANADA KOJ IJO

UKAEA (2)

Attn: A. Taig

M. Haynes

Safety and Reliability Directorate

Wigshaw Lane

Cuicheth

Warrington WA3 1NE

Chesire

UNITED KINGDOM 


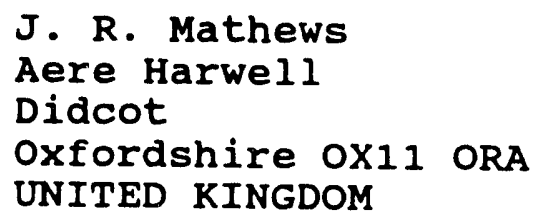

UKAEA Culham Laboratory (3)

Attn: N. J. Brealey E5.152

B. D. Turland E5.157

F. Briscoe

Abingdon

Oxfordshire OX14 3DB

UNITED KINGDOM

H. J. Teague (3)

UKAEA

Safety and Reliability Directorate Wigshaw Lane

Culcheth

Warrington, WA3 $4 \mathrm{NE}$

UNITED KINGDOM

M. Jankowski

IAEA

I.ivision of Nuclear Reactor Safety Wagranesrstrasse 5

P. O. Box 100

A/1400 Vienna

AUSTRIA

Statens Karnkraftinspektion (2)

Attn: L. Hammer

W. Frid

P. O. Box 27106

S-10252 stockholm

SWEDEN

Studvik Energiteknik $A B$

Attn: $K$. Johansson

s-611 82 Nykoping

SWEDEN 
Atomic Energy Canada Ltd. (2)

Attn: H. Rosinger

D. Wren

Pinawa, Manitoba

CANADA ROE 1LO

Korea Adv Energy Research Inst

Attn: H. R. Jun

P. O. Box 7

Daeduk-Danji

Choong-Nam

KOREA

Institute of Nuclear Energy Research

Attn: Sen-I Chang

P. O. Box 3

Lungtan

Taiwan 325

REPUBIIC OF CHINA

Juan Bagues

Consejo de Seguridad Nuckan

SOR Angela de la Cruz No 3

Madrid 28056

SPAIN

UKAEA

Reactor Development Division

Attn: T. Butland

Winfrith, Dorchester

Dorset DT2 8DH

UNITED KINGDOM

POSTECH

Department of Mechanical Engineering

Attn: Moo Hwan Kim

P.O. Box 125

Kyungbuk 790-600

KOREA

Japan Atomic Energy Research Institute

Reactivity Accident Laboratory

Attn: Toyoshi Fuketa

Tokai-Mura, Ibaraki-Ken

319-11

JAPAN 
Ms. C. Lecomte

CEN FAR

60-68 Av. du G. Leclerc - B.P.6

92265 Fontenay aux Roses cedex

France

Lr. A. Meyer-Heine

CEN Cadarache

13108 Saint Paul Lez Durance

France

Dr. A. Tattegrain

CEN Cadarache

13108 Saint Paul lez Durance

France

Dr. G. Hache

CEN Cadarache

13108 Saint Paul Lez Durance

France

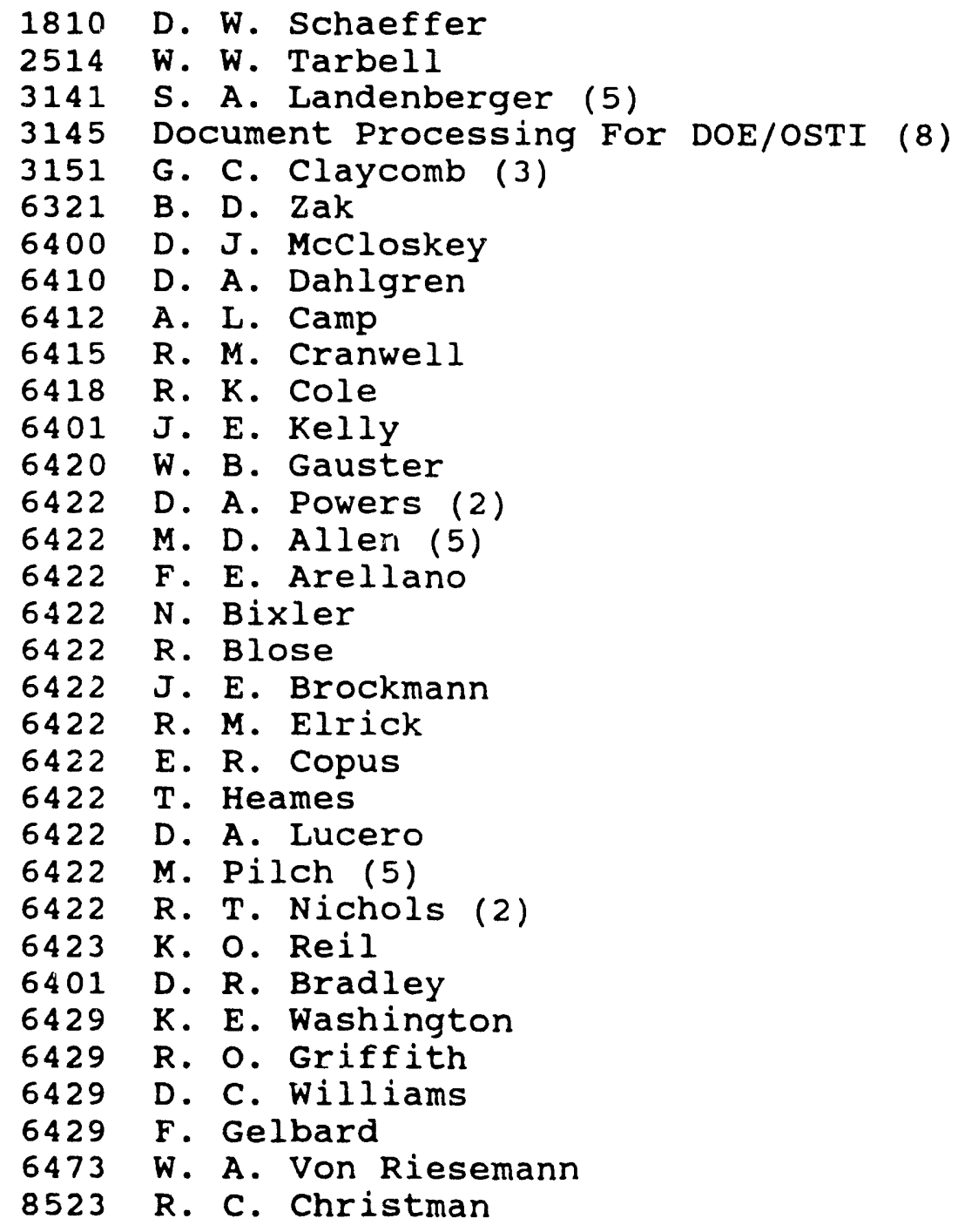




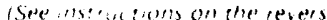

NUREG/CR-5728

SAND $91-1105$

Experiments to lnvestigate the Effect of Flight path on Direct Containment Heating (1)CH) in the surtsey Test Facility

The Limited Flight Path (LFP) Tests

AUTHORIS:

M. D. Allen, M. Pilch, R. T. Nichols, R. O. Griffith

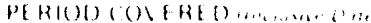

PERFORMING OHGANIZAIION

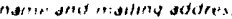

Sandia National laboratories

Albuquerque, NM 87185-5800

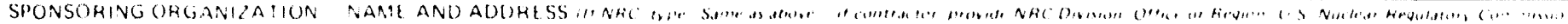

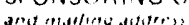

Division of Systems Research

Offlce of Nuclear Regulatory Research

Nuclear Regulatory Commission

Washington, DC 20555

SUPPLEMENAST NOTES

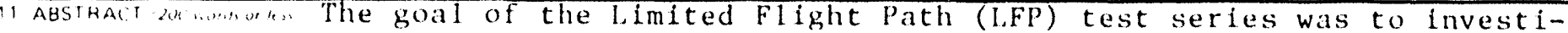
gate the effect of reactor subcompartment fight path length on direct containment heating (DCH). The test series consisted of eight experiments with nominal flight paths of 1,2 , or $8 \mathrm{~m}$. A thermitically generated mixture of iron, chromium, and alumina simulated the corium melt of a severe reactor acrident. After thermite ignition, superheated steam forcibly ejected the molten debris into a $1: 10$ linear scale model of a dry reactor cavity. The blowdown steam entrained the molten debris and dispersed $1 t$ into the Surtsey vessel. The vessel pressure, gas temperature, debris temperature, hydrogen produced by steam/metal reactions, debris velocity, mass dispersed into the Surtsey vessel, and debris particle size were measured to each experiment. The measured peak pressure for each experiment was normalized by the total amount of energy introduced into the Surtsey vessel; the normalized pressures increased with lengthened flight path. lhe debris temperature at the cavity exit was about $2320 \mathrm{~K}$. (jas grab samples indicated that steam in the cavity reacted rapldly to form hydrogen, so the driving gas was a mixture of steam and hydrogen. In these experiments approximately $70 \%$ of the steam driving gas was converted to hydrogen. The total amount of hydrogen produced was a weak function of the total debris mass dispersed into the Surtsey vessel, indicating that most of the steam/ metal reactions occurred in the reactor cavity.

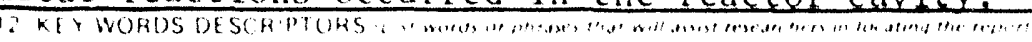

direct containment heating (DCH)

molten debris

Untimited

steam

hydrogen

Surtsey

Unclasslfied ,... mo.....,

Unclassit led

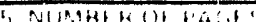



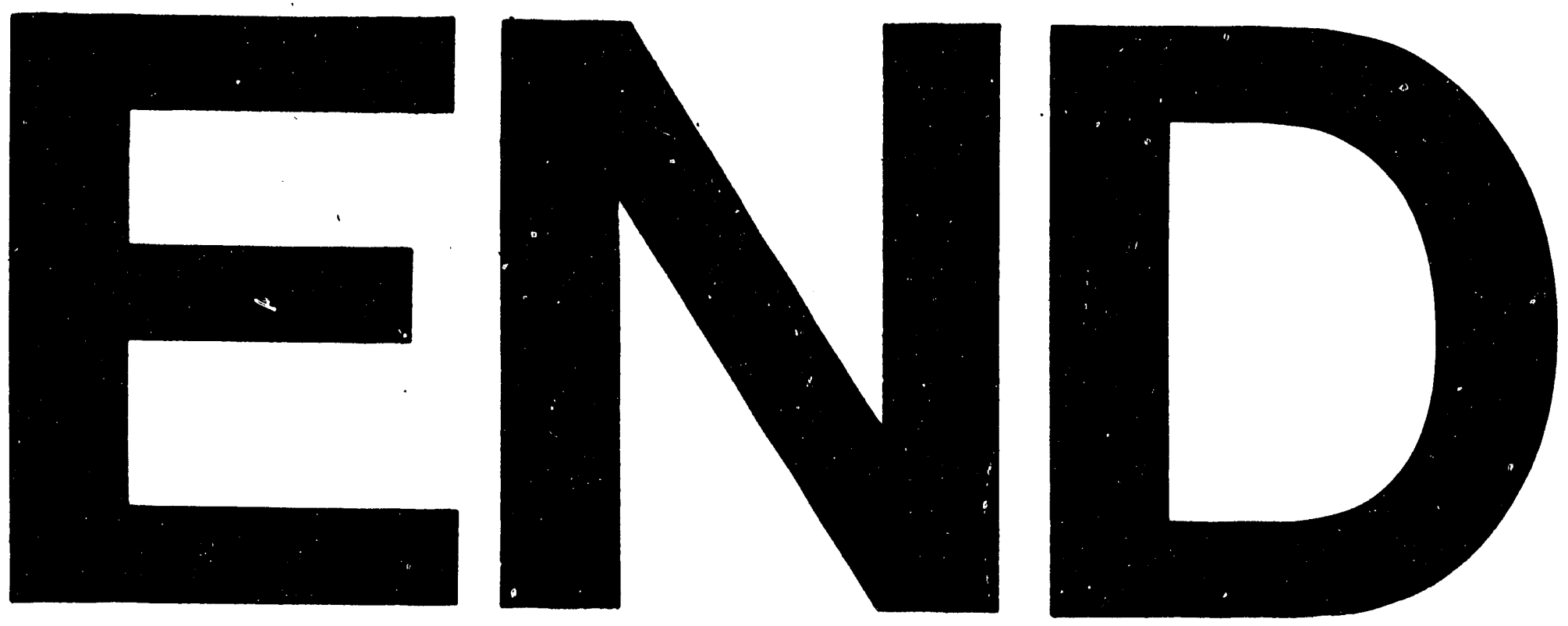

1
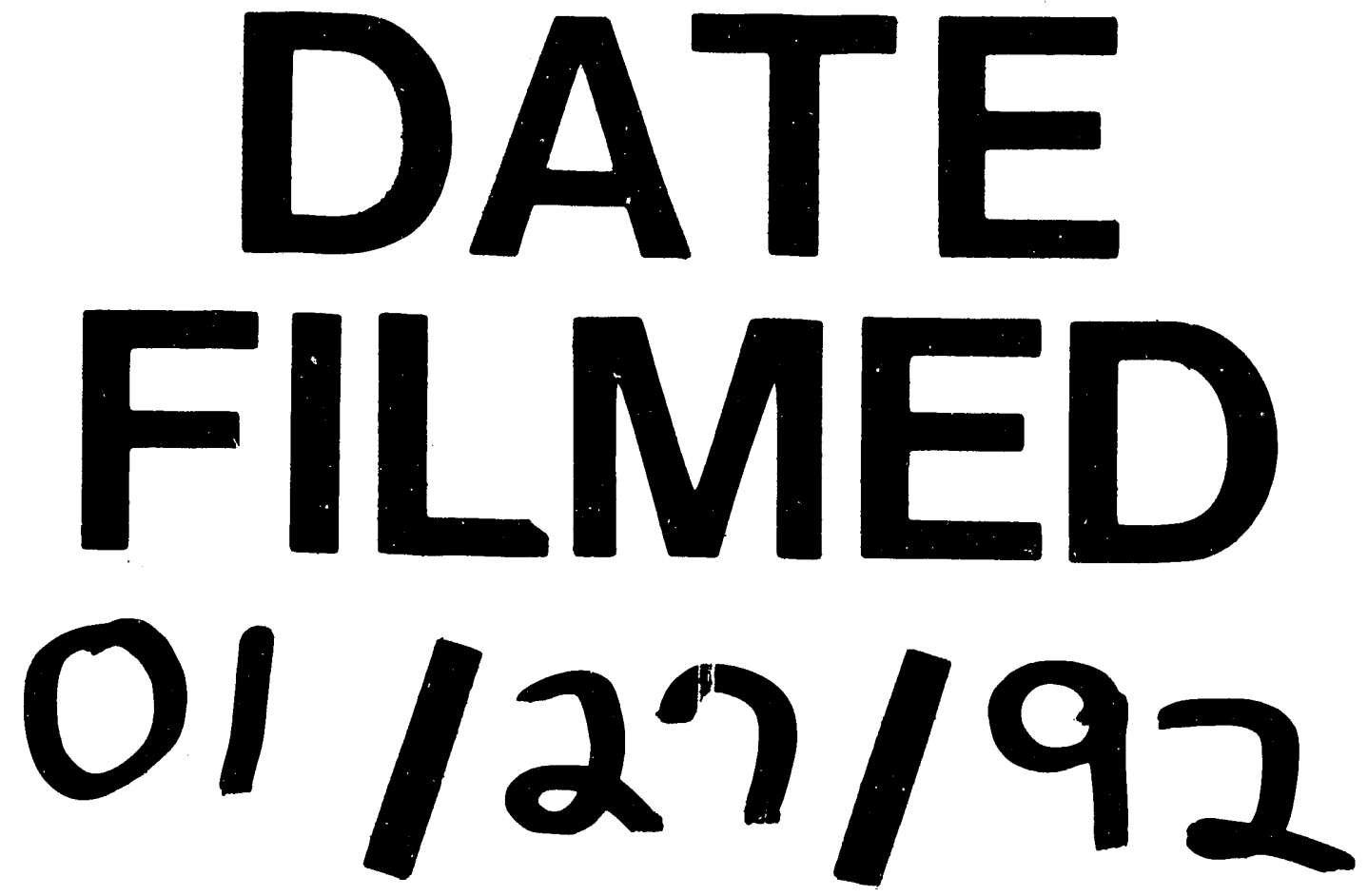
